UNIVERSIDADE DE SÃO PAULO

ESCOLA POLITÉCNICA

RAFAEL ORTEGA MARIN

OPEN INNOVATION INTEGRATION TO PRODUCT DEVELOPMENT PROCESS: AN INDUSTRY-LEVEL ANALYSIS WITHIN BRAZILIAN AUTOMOTIVE COMPANIES

SÃO PAULO 
RAFAEL ORTEGA MARIN

OPEN INNOVATION INTEGRATION TO PRODUCT DEVELOPMENT PROCESS: AN INDUSTRY-LEVEL ANALYSIS WITHIN BRAZILIAN AUTOMOTIVE COMPANIES

Revised Version

Dissertation presented to Escola Politécnica da Universidade de São Paulo to obtain the Master of Science (MSc) degree.

SÃo PAULO 


\title{
OPEN INNOVATION INTEGRATION TO PRODUCT DEVELOPMENT PROCESS: AN INDUSTRY-LEVEL ANALYSIS WITHIN BRAZILIAN AUTOMOTIVE COMPANIES
}

\author{
Revised Version
}

Dissertation presented to Escola Politécnica da Universidade de São Paulo to obtain the Master of Science (MSc) degree.

Concentration Area: Mechanical Engineering of Design and Manufacturing

Academic Advisor: Prof. Dr. Paulo Carlos Kaminski

\section{SÃO PAULO}


Autorizo a reprodução e divulgação total ou parcial deste trabalho, por qualquer meio convencional ou eletrônico, para fins de estudo e pesquisa, desde que citada a fonte.

Este exemplar foi revisado e corrigido em relação à versão original, sob responsabilidade única do autor e com a anuência de seu orientador.

São Paulo, de de

Assinatura do autor:

Assinatura do orientador:

\section{Catalogação-na-publicação}

\section{Marin, Rafael Ortega}

Open innovation integration to product development process: an industry level analysis within Brazilian automotive companies / R. O. Marin -- versão corr. -- São Paulo, 2020.

$$
107 \mathrm{p} \text {. }
$$

Dissertação (Mestrado) - Escola Politécnica da Universidade de São Paulo. Departamento de Engenharia Mecânica.

1.Desenvolvimento de produtos 2.Inovação aberta 3.Indústria automobilística 4.Gestão da inovação I.Universidade de São Paulo. Escola Politécnica. Departamento de Engenharia Mecânica II.t. 


\begin{abstract}
The automotive industry is no stranger to the concept of the so-called Open Innovation (OI), even decades before this expression started to be recognized among the scientific community. The purpose of the present study is to analyze how OI activities occur in Product Development Process (PDP) and design of new products. The focus of research is within Brazilian automakers and auto parts companies. The project is based in a survey and structured such that three main constructs are analyzed: the main characteristics of the PDP and how OI practice impact it, actors (and their characteristics) involved in the practice of OI, and risks and barriers to the implementation of new OI projects. The survey is applied to engineers and managers working in departments involving product development, with varying expertise. It intends to verify what the implications of open innovation regarding product development are, who are the main actors involved in those activities and what barriers and risks most hinder organizations from implementing them further. It also asks the question of how mature those organizations are regarding open innovation concepts and tools in their innovation process.
\end{abstract}

Keywords: product development, open innovation, innovation management, automotive industry, automakers. 


\section{RESUMO}

A indústria automotiva não é estranha ao conceito da inovação aberta (IA), mesmo décadas antes dessa expressão ser reconhecida na comunidade científica. O objetivo deste trabalho é analisar como atividades de IA ocorrem no Processo de Desenvolvimento de Produtos (PDP) e design de novos produtos. O foco da pesquisa é dentro da indústria automotiva brasileira, contemplando suas montadoras e seus sistemistas. O projeto é baseado em um questionário e estruturado de forma que três construtos sejam analisados: as principais características do PDP e como a atividade de IA as impactam, os atores (e suas características) envolvidos na prática de IA, e os riscos e barreiras encontrados na implantação de novos projetos de IA. O questionário é aplicado a engenheiros e gerentes pertencentes a departamentos de desenvolvimento de produtos, com expertise variada. A pesquisa tem como objetivo verificar quais são as implicações da IA no que tange ao desenvolvimento de produtos, quem são os principais atores envolvidos nessas atividades e quais são as barreiras e riscos que mais impedem que organizações implementem esses projetos. A pesquisa ainda levanta a questão de quão maduras são essas organizações com os conceitos de IA e as ferramentas disponíveis para seus processos de inovação.

Palavras-chave: desenvolvimento de produto, inovação aberta, gestão da inovação, indústria automotiva, montadoras 


\section{LIST OF FIGURES}

Figure 1.1 - Number of publications on the subject of Open Innovation, per year 16

Figure 1.2 - Relevance of the topic Open Innovation on Google Trends

Figure 1.3 - Number of publications on the subject of PDP, over time

Figure 2.1 - Timing and ability to influence outcome throughout the development process ..23

Figure 2.2 - Evans' Design Spiral

Figure 2.3 - Product Development Funnel

Figure 2.4 - Cooper's Stage-gates model

Figure 2.5 - The closed innovation model

Figure 2.6 - The open innovation model.

Figure 2.7 - The open innovation journey

Figure 2.8 - Open product development process framework

Figure 3.1 - Research Constructs

Figure 3.2 - Conceptual model for the constructs' hypotheses

Figure 4.1 - Histogram of respondents' year of experience in the automotive industry 45

Figure 4.2 - Open innovation inbound activities (global mean values)

Figure 4.3 - Open innovation outbound activities (global mean values)

Figure 4.4 - Perceived value of open innovation 48

Figure 4.5 - Most important partnerships in open innovation (as a \% of total) 48

Figure 4.6 - Barriers and risks in OI engagements 49 


\section{LIST OF TABLES}

Table 2.1 - PDP approaches 26

Table 2.2 - Issues associated with each type of openness and core process in OI 33

Table 2.3 - Associated issues correlated with each open innovation perspective 34

Table 3.1 - List of variables related to each construct 40

Table 3.2 - Hypotheses for the regression model 41

Table 3.3 - Survey questions divided by variable groups and constructs 42

Table 3.4 - Survey questions grouped by variable 43

Table 3.5 - Control variables 44

Table 4.1 - Importance of partnerships in OI factor analysis 52

Table 4.2 - Open innovation inbound practices factor analysis 53

Table 4.3 - Open innovation outbound practices factor analysis 54

Table 4.4 - Perceived importance of OI engagements factor analysis 54

Table 4.5 - Organizational culture in OI factor analysis 55

Table 4.6 - Degree of innovation performed in their company factor analysis 56

Table 4.7 - Adoption to newer PDP methods and tools factor analysis 56

Table 4.8 - Perceived barriers and risks in OI engagements. 57

Table 4.9 - Summary of variables 58

Table 4.10 - Correlation matrix for variables used in regression model 59

Table 4.11 - OLS regressions correlations summary for hypothesis 1: OI Organizational Culture versus PDP Aspects (model 3) 59 
Table 4.12 - OLS regressions correlations summary for hypothesis 2: PDP Aspects versus Barriers and Risks (model 3) 60

Table 4.13 - OLS regressions correlations summary for hypothesis 3: OI Organizational Culture versus Barriers and Risks (model 3) 60

Table 4.14 - Test of hypotheses 61

Table 5.1 - Correlation matrix for variables used in regression model for auto parts respondents 63

Table 5.2 - OLS regressions correlations summary for hypothesis 1: OI Organizational Culture versus PDP Aspects (model 2) for auto parts respondents 64

Table 5.3 - OLS regressions correlations summary for hypothesis 2: PDP Aspects versus Barriers and Risks (model 2) for auto parts respondents 64

Table 5.4 - OLS regressions correlations summary for hypothesis 3: OI Organizational Culture versus Barriers and Risks (model 2) for auto parts respondents

Table 5.5 - Test of hypotheses for auto parts respondents 65

Table 5.6 - Correlation matrix for variables used in regression model, with the complete dataset 66

Table 5.7 - OLS regressions correlations summary for hypothesis 1: OI Organizational Culture versus PDP Aspects (model 2) for the complete dataset

Table 5.8 - OLS regressions correlations summary for hypothesis 2: PDP Aspects versus Barriers and risks (model 2) for the complete dataset.

Table 5.9 - OLS regressions correlations summary for hypothesis 3: OI Organizational Culture versus Barriers and risks (model 2) for the complete dataset.

Table 5.10 - Test of hypotheses for the complete dataset

Table 5.11 - Comparison between the hypothesis test between each set of data 68 
Table B.1 - OLS regressions for Reasons for partnership measure versus PDP aspects measure (statistically significant $\mathrm{p}$ values in bold)

Table B.2 - OLS regressions for Reasons for partnership measure versus Barriers and risks (statistically significant $\mathrm{p}$ values in bold)

Table B.3 - OLS regressions for PDP aspects measure versus Barriers and risks (statistically significant $\mathrm{p}$ values in bold) 95

Table B.4 - OLS regressions for Partners measure versus Barriers and risks (statistically significant $\mathrm{p}$ values in bold) 96

Table B.5 - OLS regressions for Partners measure versus PDP Aspects (statistically significant $\mathrm{p}$ values in bold) 97

Table B.6 - OLS regressions for Cultural aspects measure versus Barriers and risks measure (statistically significant $\mathrm{p}$ values in bold) 98

Table B.7 - OLS regressions for Cultural aspects measure versus PDP Aspects ..... .99

Table C.1 - OLS regressions for Reasons for partnership measure versus PDP aspects measure (statistically significant $\mathrm{p}$ values in bold)

Table C.2 - OLS regressions for Reasons for partnership measure versus Barriers and risks (statistically significant $\mathrm{p}$ values in bold)

Table C.3 - OLS regressions for PDP aspects measure versus Barriers and risks (statistically significant $\mathrm{p}$ values in bold). 101

Table C.4 - OLS regressions for Partners measure versus Barriers and risks (statistically significant $\mathrm{p}$ values in bold) 101

Table C.5 - OLS regressions for Partners measure versus PDP Aspects (statistically significant $\mathrm{p}$ values in bold) 102

Table C.6 - OLS regressions for Cultural aspects measure versus Barriers and risks measure (statistically significant $\mathrm{p}$ values in bold) 102

Table C.7 - OLS regressions for Cultural aspects measure versus PDP Aspects 103 
Table D.1 - OLS regressions for Reasons for partnership measure versus PDP aspects measure (statistically significant $\mathrm{p}$ values in bold) 104

Table D.2 - OLS regressions for Reasons for partnership measure versus Barriers and risks (statistically significant $\mathrm{p}$ values in bold) 104

Table D.3 - OLS regressions for PDP aspects measure versus Barriers and risks (statistically significant $\mathrm{p}$ values in bold) 105

Table D.4 - OLS regressions for Partners measure versus Barriers and risks (statistically significant $\mathrm{p}$ values in bold) 105

Table D.5 - OLS regressions for Partners measure versus PDP Aspects (statistically significant $\mathrm{p}$ values in bold) 106

Table D.6 - OLS regressions for Cultural aspects measure versus Barriers and risks measure (statistically significant $\mathrm{p}$ values in bold) 106

Table D.7 - OLS regressions for Cultural aspects measure versus PDP Aspects. 107 


\section{LIST OF SYMBOLS AND ACRONYMS}

$\begin{array}{ll}\text { R\&D } & \text { Research and Development } \\ \text { PDP } & \text { Product Development Process } \\ \text { OI } & \text { Open Innovation } \\ \text { GDP } & \text { Gross Domestic Product } \\ \text { NPD } & \text { New Product Development } \\ \text { PCF } & \text { Principal Components Factor } \\ \text { KMO } & \text { Kaiser-Meyer-Olkin } \\ \text { OLS } & \text { Ordinary Least Squares }\end{array}$




\section{CONTENTS}

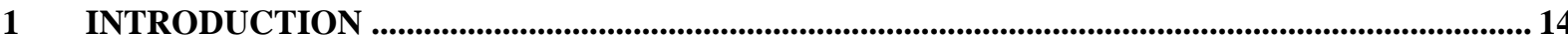

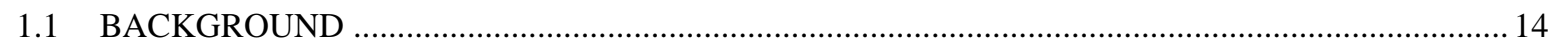

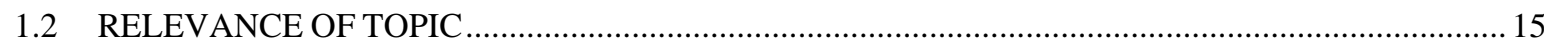

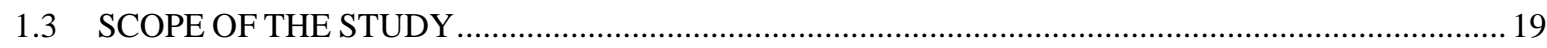

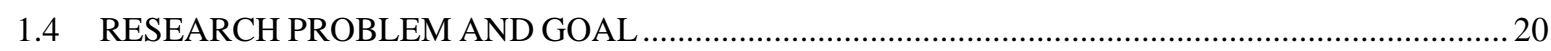

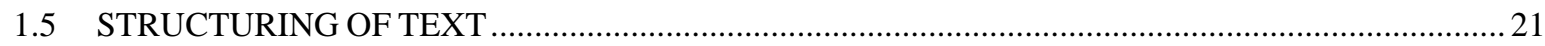

2 LITERATURE REVIEW AND THEORETICAL FOUNDATIONS ................................................. 22

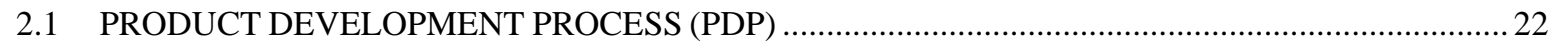

2.1.1 Scope and structure of PDP adopted in the current study ........................................................ 27

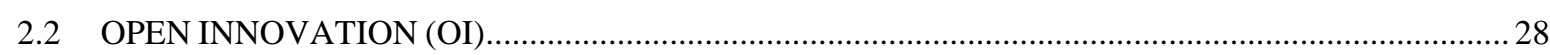

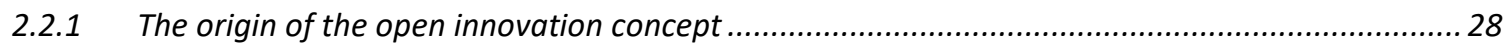

2.2.2 Open Innovation characteristics and definitions ................................................................... 31

2.3 PRODUCT DEVELOPMENT FRAMEWORK FOR OPEN INNOVATION ............................................. 36

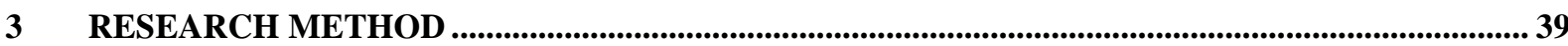

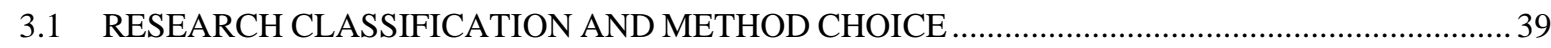

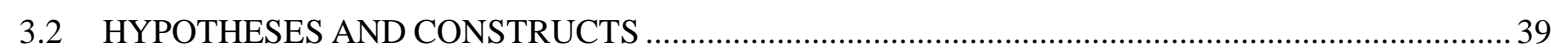

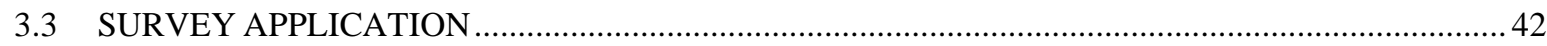

4 RESULTS AND ANALYSES: AUTOMAKER COMPANIES .............................................................. 45

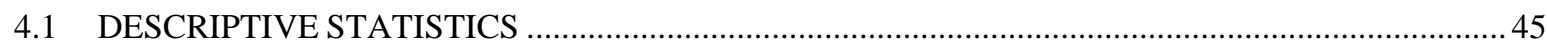

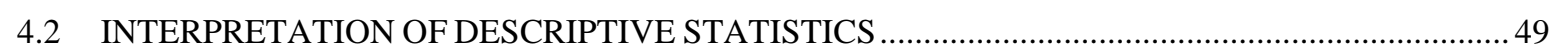

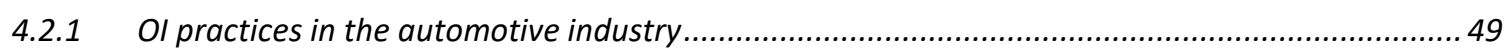

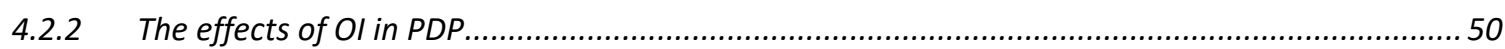

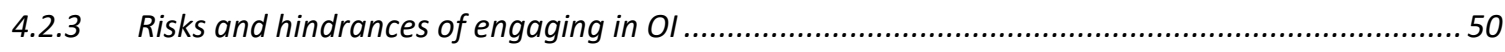

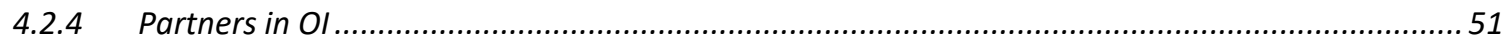

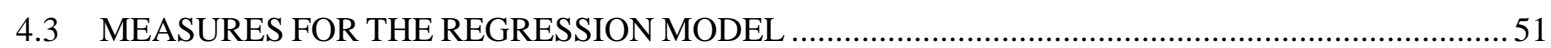

4.3.1 Ol Organizational Culture: Most important partnerships in open innovation ...............................52

4.3.2 Ol Organizational Culture: Open innovation perceived value and practices (reasons for partnership) 53

4.3.3 Ol Organizational Culture: Organizational culture of open innovation (cultural aspects) .............55

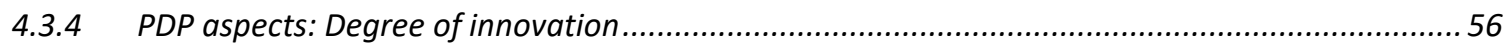

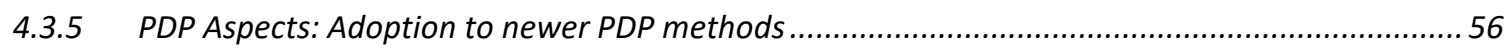

4.3.6 Perceived barriers and risks in Ol engagements.......................................................................5

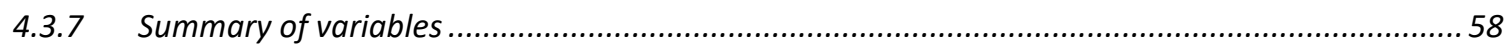

4.4 REGRESSION MODEL AND INTERPRETATION OF RESULTS …….............................................58

5 RESULTS AND ANALYSES: AUTO PARTS MANUFACTURERS ...................................................... 63 
5.1 AUTO PARTS MANUFACTURERS

5.2 ANALYSIS USING DATA FROM BOTH AUTOMAKERS AND AUTO PARTS MANUFACTURERS 65

5.3 DISCUSSION ON THE RESULTS OF THE REGRESSIONS 68

6 CONCLUSIONS ............................................................................................................................................... 70

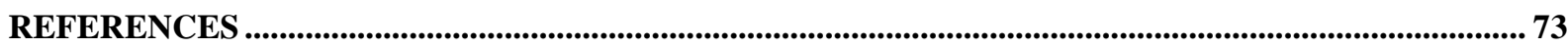

APPENDIX A: QUESTIONNAIRE ..................................................................................................... 79

APPENDIX B: OLS REGRESSION TABLES - AUTOMAKERS DATA...................................................93

APPENDIX C: OLS REGRESSION TABLES - AUTO PARTS MANUFACTURERS DATA ................ 100 APPENDIX D: OLS REGRESSION TABLES - COMPLETE DATASET .................................................... 104 


\section{INTRODUCTION}

\subsection{BACKGROUND}

The automotive industry has continuously proven to be a cornerstone to the development of many countries, being of great importance to economic and social growth, both in the short and long term (Mello, Marx, \& Motta, 2016).

According to the Brazilian Automotive Industry Association (ANFAVEA, 2019), the Brazilian automotive sector, hereby meaning the auto parts, auto makers and their respective suppliers, represents $22 \%$ of the country's industrial GDP (4\% of the national GDP). Furthermore, the industry has an installed capacity to manufacture over 5 million vehicles per year, by the 26 automakers present in the country. The automotive value chain employs, directly and indirectly, over 1.3 million people, reporting over U\$14bi in taxes to the government. It is clear the economic and social impact that this industry represents to the country and keeping this industry competitive at the global level is a matter of the utmost importance, with governments acknowledging that an important driver for that is innovation.

Innovation is recognized as a fundamental source of competitive advantage to companies, and governments around the world try to encourage companies to leverage their innovation capabilities in order to keep the whole nation competitive on a global scale. Innovation management capabilities, in turn, are requiring more and more resources that are external to the organization in order to maximize the potential competitive advantage. That paradigm shift went from innovation originating mostly from stand-alone R\&D labs, to being internalized as much as possible within the company in the form of corporate R\&D labs, into what is called an innovation network, balancing both in-house and external innovation capabilities (Armellini, 2013). Consequently, strategies to combine technologies and market opportunities into a feasible and commercial product or service (the definition of innovation) change and evolve to better adapt to market demands and competitive forces (Oliveira \& Kaminski, 2012).

The branch of innovation theory that deals with how products or services are developed and how this development process is structured, managed and optimized is generally into the context of Product Development Process (PDP) (Brown \& Eisenhardt, 1995). The PDP is an organizational process that can be defined as "the collective of activities, involving almost all the departments of a company, that have the purpose of transforming market needs into economically viable products or services" (Kaminski, 2000). As an organizational process, it 
can be divided into a series of activities that can be formalized, measured and optimized. As such, it has been evolving since their first formalization and conception, which began as an engineering design framework during the early 60's (Evans, 1959), and then evolved into the study of the whole development process, not "just" the design phase. Later PDP models propose that knowledge and technology management should be combined with traditional R\&D processes (Liyanage et al., 1999, p.376). Current PDP literature is extensive, with reviews differentiating between the myriad of approaches created by adapting new technologies to traditional processes (Canuto da Silva \& Kaminski, 2017).

Therefore, innovation management taps not only into the internal resources of a company but also external knowledge sources, managing globalized research networks collaborations and strategic alliances to ultimately unify research, technology and innovation management (Armellini, 2013).

This shift in innovation is regarded as Open Innovation (OI). Open Innovation is defined as "the purposive use of inflows and outflows of knowledge to accelerate innovation in one's own market, and expand the use of internal knowledge in external markets, respectively" (Chesbrough, Vanhaverbeke, \& West, 2006). This concept assumes that companies can and should use external information, knowledge, and technology into their innovation processes. The concept also touches on the notion that companies should do the inverse - leverage their own knowledge and technologies to the market - the outbound open innovation, so to speak. Recent research has shown evidences that collaborative innovations are more probable of having more technical significance and commercialization capacity (Walsh, Lee, \& Nagaoka, 2016).

It is evident that the level of adoption to OI is different from company to company and industry to industry, depending on variables like technology intensity of the offered products and services and their position in the value chain. Level of adoption to OI has also been studied, and different ways to categorize it and place companies within the so called "open innovation journey" have been discussed (Chiaroni, Chiesa, \& Frattini, 2011).

\subsection{RELEVANCE OF TOPIC}

Although the subject itself spans over a decade and a half, Open Innovation has never been more popular in both academy and industry. There is an evident increase in the number of publications related to the subject of OI. Figure 1.1 portrays this increase showing results from 
scientific publications (all document types), containing the phrase "Open Innovation" either in the topic or title, indexed in the ISI Web of Knowledge, Web of Science Core Collection database, grouped by year.

Figure 1.1 - Number of publications on the subject of Open Innovation, per year

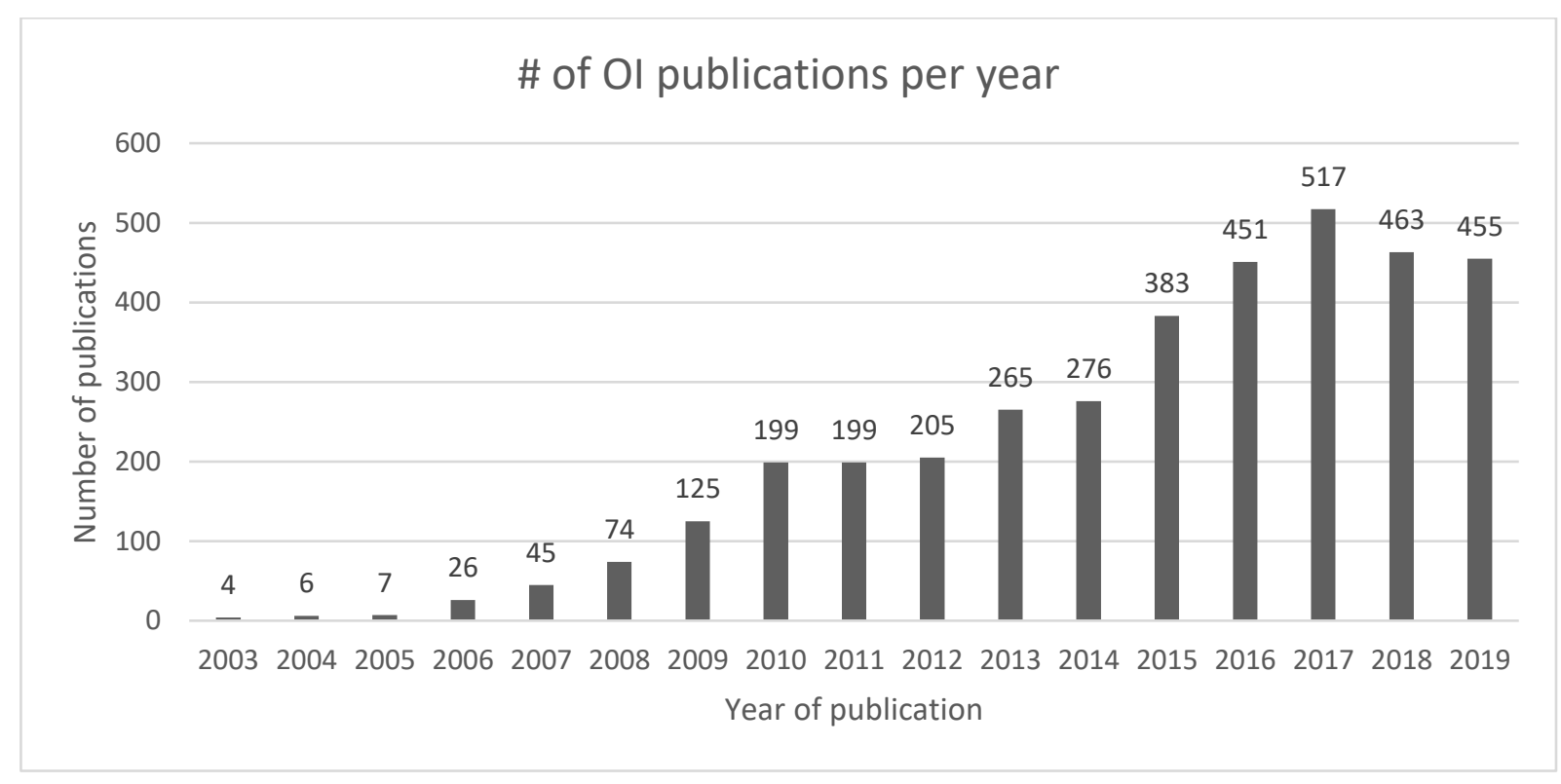

Source: ISI Web of Knowledge database, chart created by the author. Search performed in jan 7, 2020.

The interest is not restricted to the academic community. There is also a growing interest in the subject of Open Innovation in the industry. One way to show that is using the Google Trends tool, providing an unbiased sample of Google search data. The popularity of the term "Open Innovation", plotted over time up to the second half of 2019, is shown in Figure 1.2. 
Figure 1.2 - Relevance of the topic Open Innovation on Google Trends

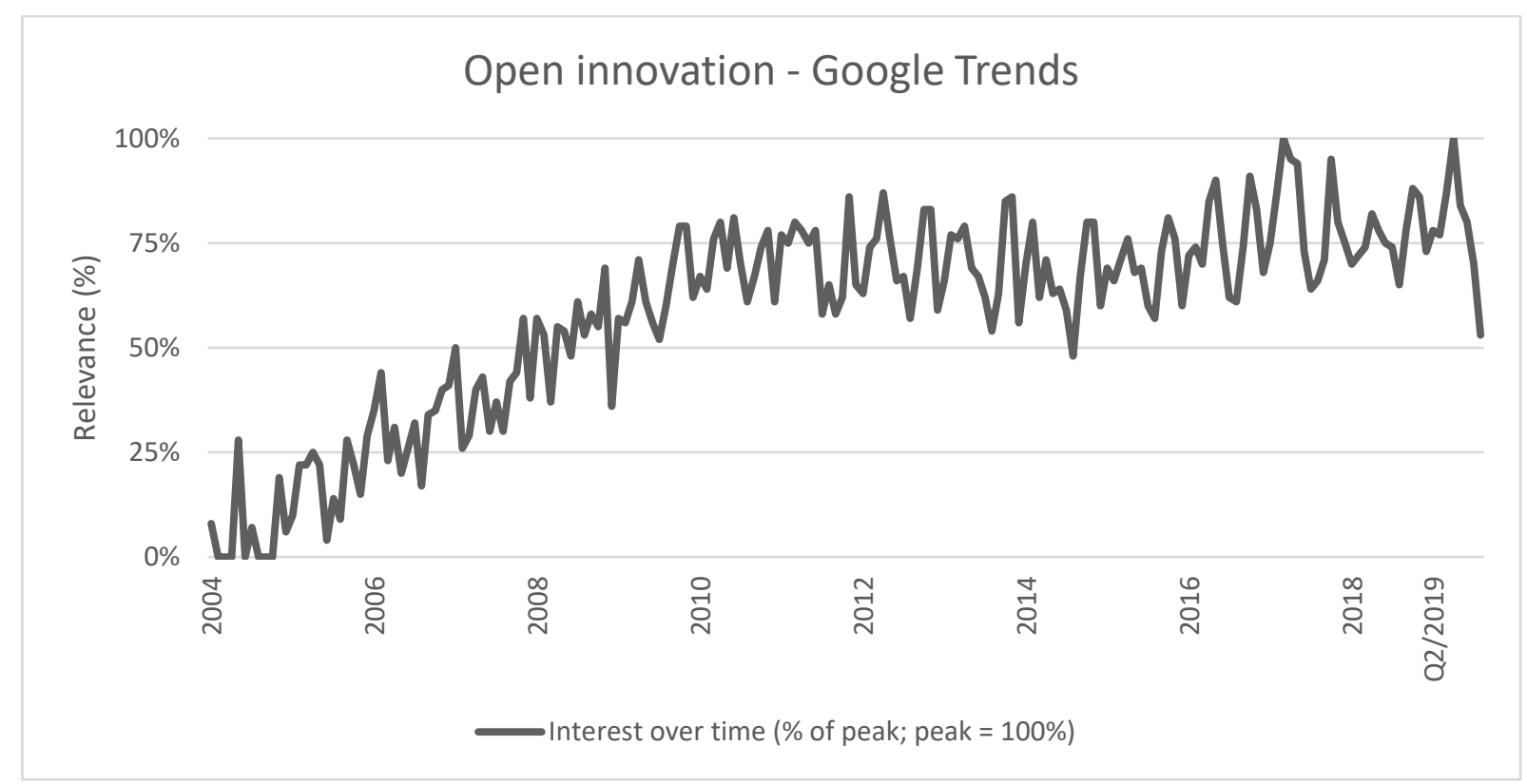

Source: Google Trends, chart created by the author. Search performed in nov 5, 2019.

These two charts serve the purpose of showing the growing relevance of the subject of OI. The subject of PDP also shares similar trends, as can be evidenced by Figure 1.3, which shows the results of the number of publications (all document types) indexed with the topic or title containing the phrase "Product Development Process", within the ISI Web of Knowledge, Web of Science Core Collection database, plotted over time. 
Figure 1.3 - Number of publications on the subject of PDP, over time

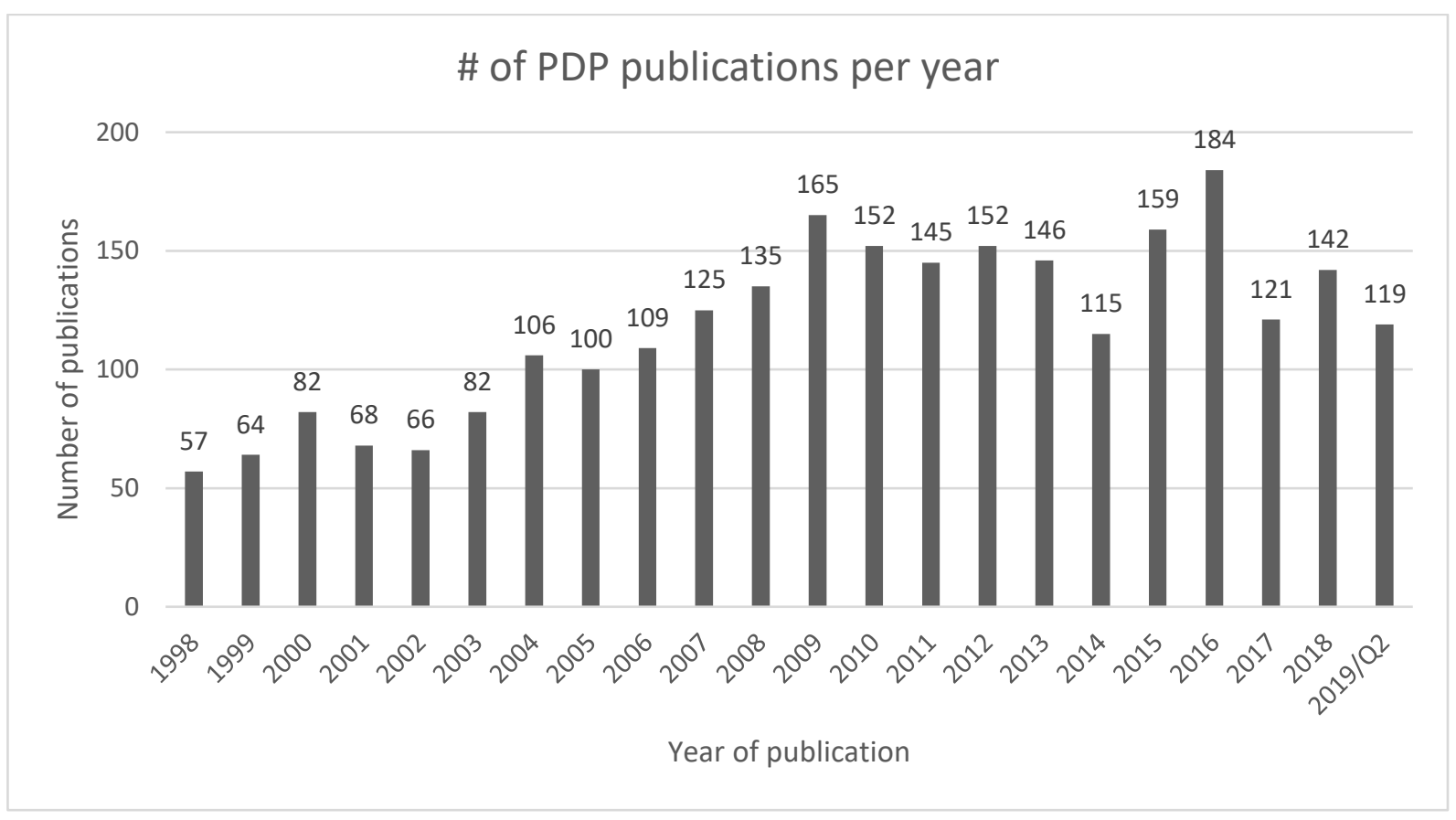

Source: ISI Web of Knowledge, chart created by the author. Search performed in nov 5, 2019.

The motivation behind choosing the automotive sector as a subject of study stems from two main points. Firstly, there is a current lack of publications addressing the matter of open innovation in this sector. Open innovation is greatly researched in the chemical and pharmaceutical (Gassmann, Enkel, \& Chesbrough, 2010), as well as in segments appropriately named "open-dominated industries", such as open source software $(H$. W. Chesbrough \& Appleyard, 2007). The role of open innovation in SMEs has also been the subject of discussion (Vrande, Jong, Vanhaverbeke, \& de Rochemont, 2009). Traditional manufacturing (and low tech) industries, on the other hand, have limited studies (Armellini, Beaudry, \& Kaminski, 2016). Even though there are, in fact, studies on the automotive industry (Ili, Albers, \& Miller, 2010; Massis, Lazzarotti, Pizzurno, \& Salzillo, 2012), they are restricted to specific case studies and don't deal with inter organizational relationships or with a larger sample size.

Secondly, the automotive industry is coming to an inflection point with regards to its $R \& D$ paradigm, with the industry as a whole being about to experience a revolutionary discontinuity in generating innovations, especially regarding electrifrication and digitalization as vectors for this change (Ili et al., 2010; Theoto \& Kaminski, 2019; Wittmann, 2017). For decades, the industry has engaged in what would now be called open innovation strategies, including an intricate supplier network acting in multiple stages of research and product development (Parente \& Geleilate, 2016) as well as being an industry with an extensive knowledge base for 
product development processes (Canuto da Silva \& Kaminski, 2017) (though not all that is considered open innovation now had already been practice in the automotive industry). This makes the automotive industry an especially interesting subject of study.

Research of open innovation is majorly restricted in its majority to developed countries (Armellini, Kaminski, \& Beaudry, 2014), especially North American, Asian and European companies (Blankesteijn, De Jong, \& Bossink, 2019; Karlsson \& Sköld, 2013; MacNeill \& Bailey, 2010), leaving a lack of research done in South America. The Brazilian case is interesting not only because the country invests a higher percentage of its GDP in R\&D than its neighboring countries, but also because the most important innovation strategy in Brazilian firms is technology acquisition (Jugend et al., 2018), which furthers its importance as a locus of research. Other researches have also addressed the subject of open innovation in the Brazilian automotive industry (Balcet \& Consoni, 2007; Gondim, Borini, \& Carneiro-Da-Cunha, 2017; Ibusuki, Bernardes, \& Consoni, 2015; Martins \& Kaminski, 2019).

The present study is also a continuation of other published research, both concerning case studies within the Brazilian automotive industry (Marin \& Kaminski, 2018) as well as comparisons of the Brazilian case with the French case (Marin, Kaminski, \& Armellini, 2018).

The importance is not restricted to studies on whether and how an industry adopts OI, but also to understand to which degree they do it - or how far along their "open innovation journey" they are (Chiaroni et al., 2011).

In summary, this subchapter stresses that the two subjects of study in this paper - Open Innovation and Product Development Process, are relevant both in the academic community and in the industry. The literature review (Section 2) of this text delves deeper into the origins and current state of the art of each subject, however one should also emphasize the importance of those subjects beforehand.

\subsection{SCOPE OF THE STUDY}

Delving into the world of subjects as vast as innovation is, without properly demarcating boundaries, would dilute the research into an over generalized work. Therefore, it is important to set the limits of what constitutes the scope of this study. 
Thus, the present work limits to analyze OI activities specifically within Product Development Processes. That limitation comprises innovations regarding both product and services developed in those companies but also innovations regarding the development process itself.

Another limitation of scope is the industry focus of research, which is in one specific regional context: the Brazilian automotive industry, an industry of vital importance to Brazil's economic and social development. Automakers here comprehend companies which partake in the manufacturing of cars, light commercial vehicles, trucks and buses. It excludes manufacturers of agricultural and highway construction machinery.

Even though there are multiple layers of companies among the entire automotive value chain, going from the iron ore to the actual vehicle, the study focuses the analysis on two specific segments: the automaker companies, as well as their first-tier suppliers, the auto parts manufacturers (or systemists). The reason for restricting the research to only automakers and their systemists, as opposed to the entirety of the automotive industry, is due to an effort in keeping the results restricted to the automotive industry. Other suppliers, for instance, rubber and glass suppliers, which even though usually work directly with the automaker (Dias, Galina, $\&$ Silva, 1999), only benefit partially from the automotive industry, and most of their revenue comes from other industries. It would be expected, therefore, that including these companies in the study might muddle the results when talking about the automotive industry by itself. By studying the automaker companies specifically, one can focus on grouping companies that devote all (or at least the majority of) their resources into innovation for the automotive industry. Therefore, an analysis made on this group should somewhat also represent the Brazilian automotive industry.

\subsection{RESEARCH PROBLEM AND GOAL}

The purpose of the present study is to analyze how different OI activities occur in the Product Development Process (PDP) from Brazilian automaker and auto parts companies, aiming to identify the main actors involved in OI, the main barriers that are present in the implementation of OI projects, as well as the maturity those companies have with OI and how all of this affects their new product design processes. This paper explores several research questions, listed below.

- What is the relationship between engaging in more open innovation activities and how likely a company is in engaging in more radical innovation, as well as adopting newer 
PDP models and development methods? Who are their main actors involved in open innovation? What is the relationship between those actors on a given company and the most commonly performed and/or valued open innovation activities?

- What are the barriers and risks that most hinder the implementation of OI projects within the organization? How do they relate to the innovation performed within the company with respect to its degree of innovation?

- How the maturity those companies have regarding open innovation concepts, tools and practices relate to their innovation processes?

- How dependent are the answers to these questions on where in the automotive value chain the company is? In other words, how much do auto maker companies perform open innovation differently from their suppliers?

\subsection{STRUCTURING OF TEXT}

The present text has the following structure: Chapter 2 provides a literature review concerning the topics of product development processes, open innovation, and a reference framework unifying both. Chapter 3 presents the research method chosen, as well as details of the analytical model considered, and the hypotheses formulated. It also describes in detail the processes of survey application, data gathering and data modelling. Appendix A contains the complete questionnaire used (including questions outside of the scope of this work).

Chapters 4 and 5 presents the results obtained and a detailed analysis concerning the research questions, firstly in a qualitative perspective and then in a more quantitative approach. They are divided as follows: Chapter 4 analyses responses from respondents that come from automaker companies, which is a subset of roughly half of the sample size taken; Chapter 5 brings the other half of responses, which come from respondents from auto parts manufacturing companies. Then, it also brings an analysis which combine the entirety of the data obtained in the survey, using the respondents' origin as a control variable. Results are complemented by Appendices B, C and D of this text, which bring all the data tables from the quantitative analyses.

Finally, Chapter 6 concludes the work and comments on the limitations of the study, as well as how they could be addressed in future research. 


\section{LITERATURE REVIEW AND THEORETICAL FOUNDATIONS}

The literature review conducted in this chapter is divided into three main topics: (1) product development processes (or PDP), (2) open innovation, its history and its contribution to innovation management, and (3) a brief review on an open innovation framework integrated to product development process.

Reference material used in this section comes from extensive research on the most relevant authors in academia, whose research have echoed throughout even the most recent scientific papers, for more than half a century. As will be shown in the following sections, there are a myriad of different frameworks and models to a subject as vast as innovation. Even then, much of the recent (and relevant) academic content stems directly from those very authors.

\subsection{PRODUCT DEVELOPMENT PROCESS (PDP)}

Expanding on the definition provided in the introduction of this text, PDP (also sometimes regarded as New Product Development, or NPD) is:

"(...) a set of activities through which one seeks, from the market needs and technological possibilities and constraints, and considering the competitive and product strategies of the company, to reach technical specifications for the design of a product and its production process, so that manufacturing is able to produce it." (Freely translated from Rozenfeld et al., 2006).

Other definitions (Krishnan \& Ulrich, 2001) give PDP a more strict meaning in terms of scope, not involving the process of research and development of the technology itself - also known as technology development processes - into the product development process. For those authors, PDP is composed of two categories: one dealing with decisions concerning an individual project, and another focusing on decisions concerning the entire organization and its planning towards new products and services development. That latter category is the one that most PDP approaches refer to, also sometimes regarded as portfolio management (Cooper, Edgett, \& Kleinschmidt, 2001), while the former comprehends activities typical of traditional R\&D groups, project management and product design.

According to Rozenfeld et al. (2006), the characteristics of PDP that differ it in relation to other organizational processes stem from the fact that decisions in PDP are taken when uncertainty, as well as the ability to change initial decisions, are the greatest. The process follows an iterative 
cycle with inputs coming from diverse sources within the company, and as uncertainty lowers, so does the ability to change initial decisions. Clark and Wheelwright (1993) comment on the apparent paradox that surges from this (Figure 2.1): even though traditional management tends to focus attention and activities during the later stages of development, most of the important decisions have already been taken, and the ability to influence the overall outcome is heavily hindered. That argument stresses the importance of a structured and manageable product development process.

Figure 2.1 - Timing and ability to influence outcome throughout the development process

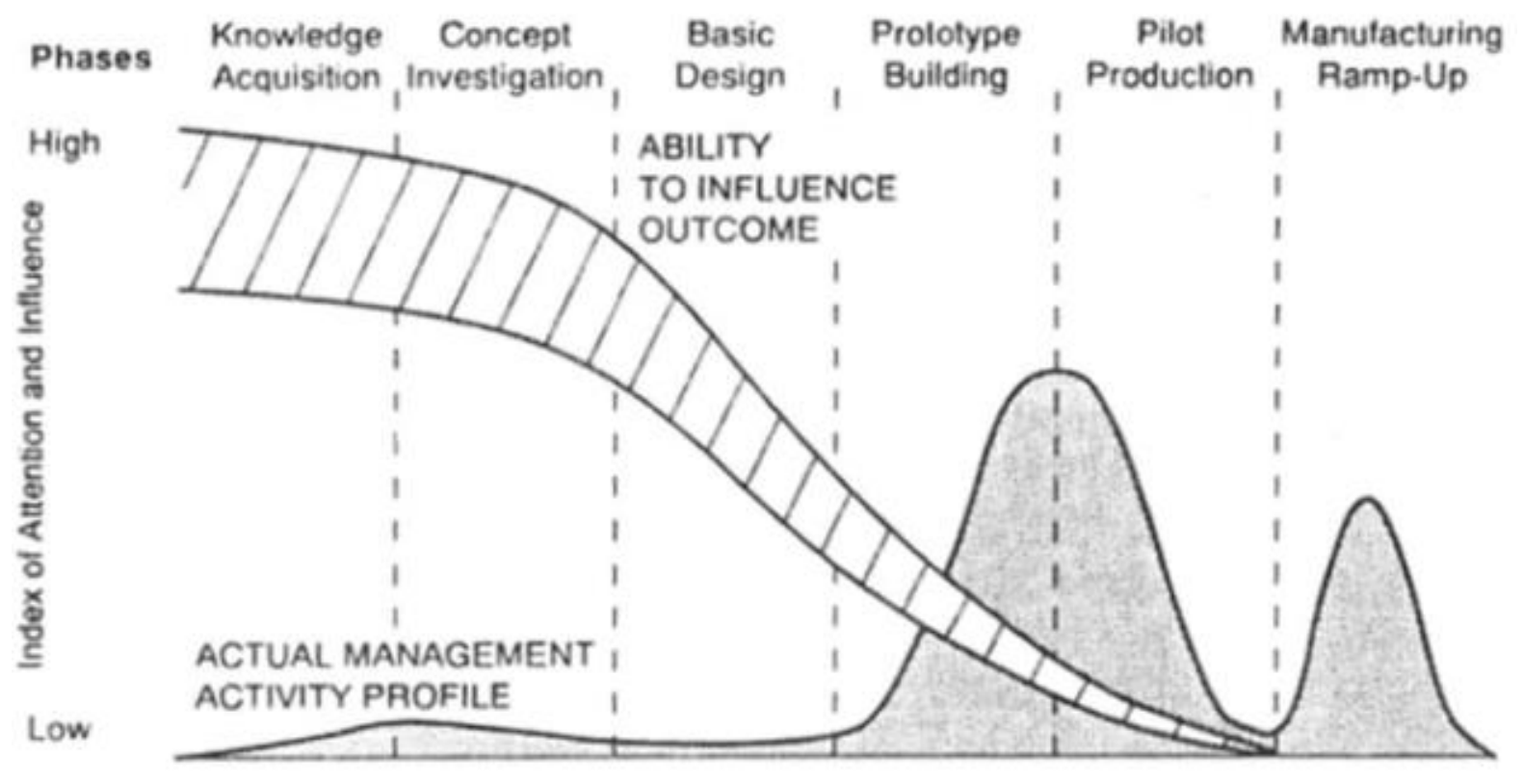

Source: (Clark \& Wheelwright, 1993).

Two very important concepts from the early 60's heavily influenced recent PDP literature: the design spiral (Evans, 1959) and Asimow's design process, also known as the production and consumption cycle (Asimow, 1962). The design spiral (Figure 2.2), albeit a product design methodology, regards the iterative nature of product development as one of its core attributes points, illustrated by how the uncertainty during development decreases over time (the spiral “closing in"). Asimow's design process is a truly visionary concept, going from the identification of market needs and demands to the design phases and then the production and consumption (not unlike a lifecycle analysis) cycles. Those two authors set the stepping-stones to modern PDP literature and their contributions echo across practically all the other models referenced in this chapter. 
Figure 2.2 - Evans' Design Spiral

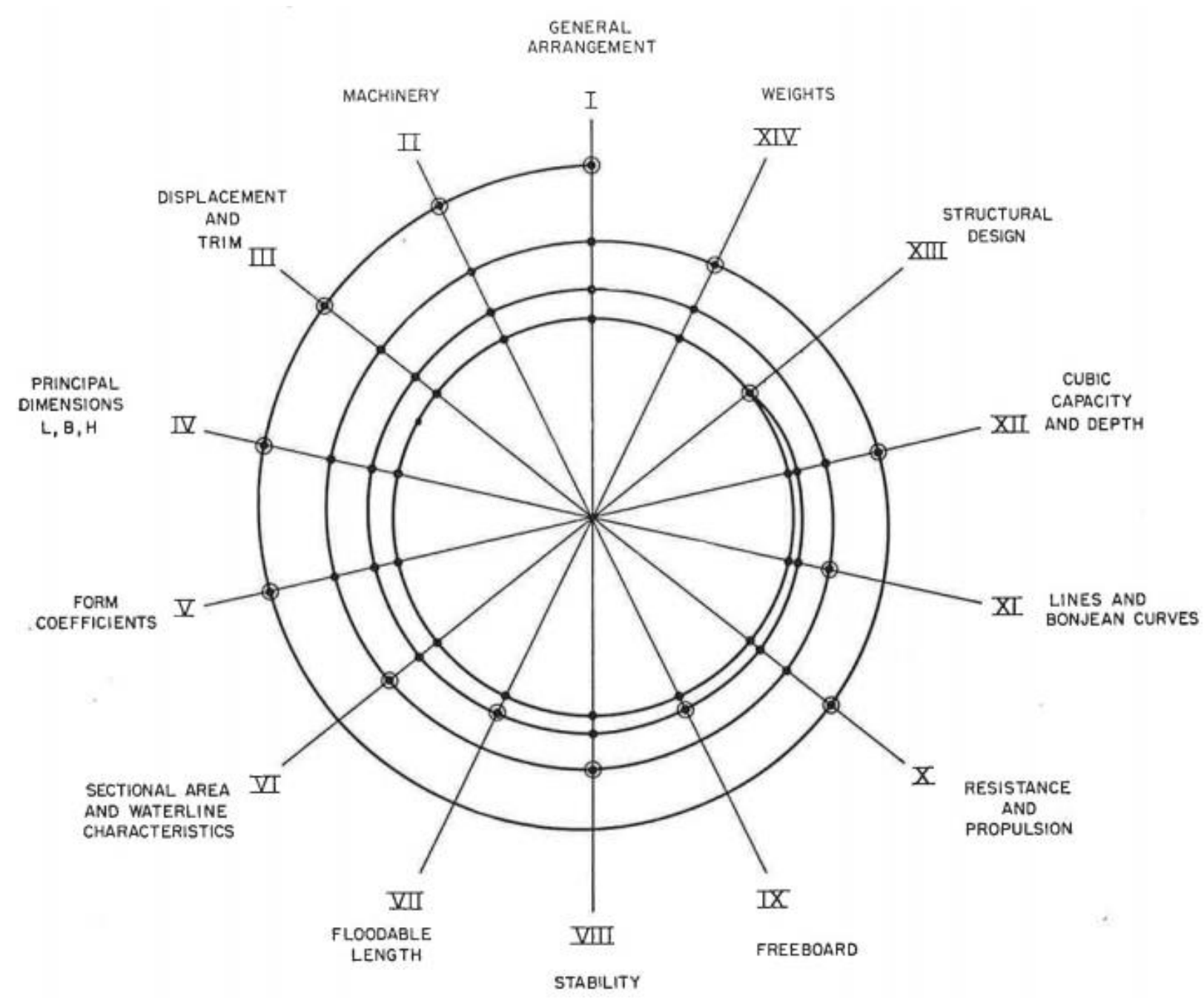

Source: (Evans, 1959).

Another main contribution to the literature is the development funnel concept, proposed by Clark and Wheelwright (1993), and illustrated in Figure 2.3. The authors proposed a linear process, characterized by the geometric shape of a funnel, with the number of inputs being larger than outputs, giving the idea that the process of product development should filter the good ideas and recombining them until a final product is ready for the market. The implication here is that during the development process, there should be steps and activities to review current progress, status or feasibility of a project (or multiple projects) and, if deemed necessary, stop development, or discard the project altogether.

An observation derived from the concept of the development funnel in comparison to other models (such as Rozenfeld et al., 2006) is that all the filtering and recombining of ideas is done 
up to the development stage, and once that has begun, there is no such criteria anymore (Armellini, 2013).

Figure 2.3 - Product Development Funnel

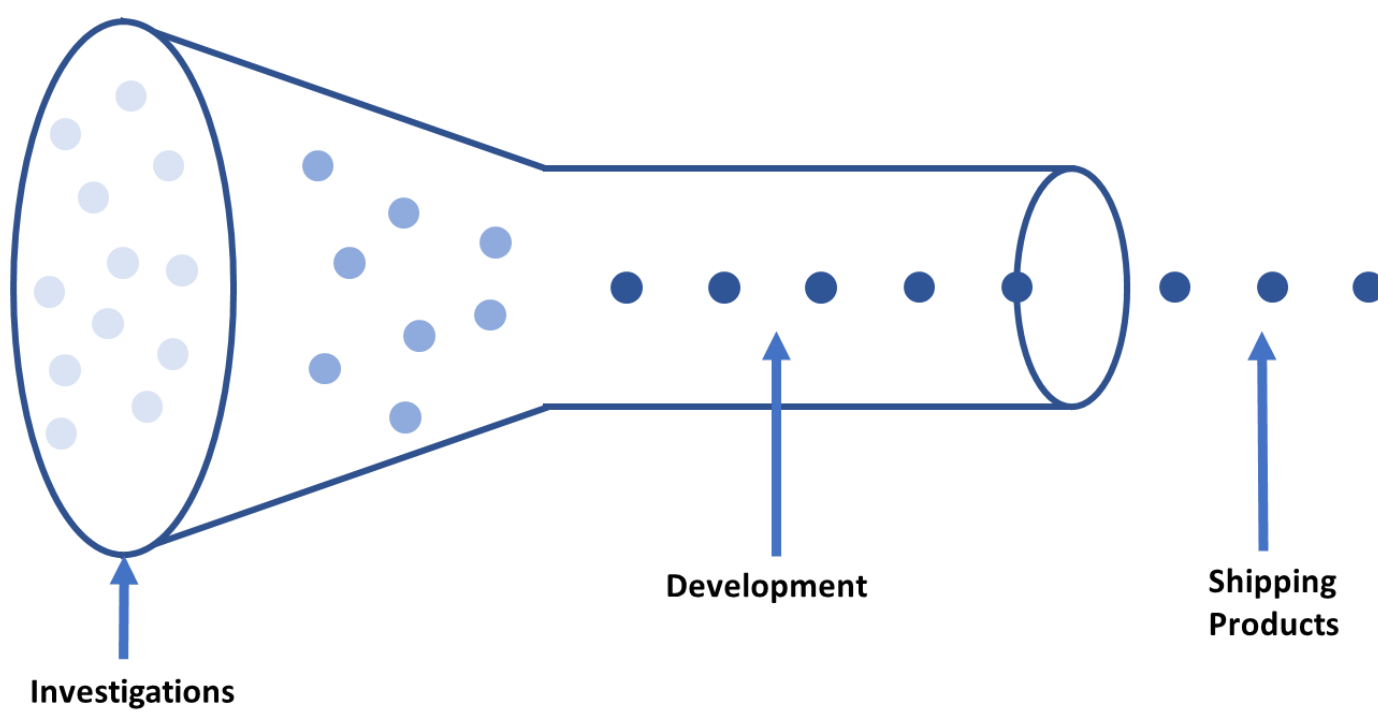

Source: (Clark \& Wheelwright, 1993).

Similarly, Cooper (1990) developed the stage-gates concept (Figure 2.4), another linear model grouping activities into two kinds: stages, and gates. Gates serve as points for systematic and structured decision making so that the project can advance to the next development step (the stage), according to a company's strategic planning.

Figure 2.4 - Cooper's Stage-gates model

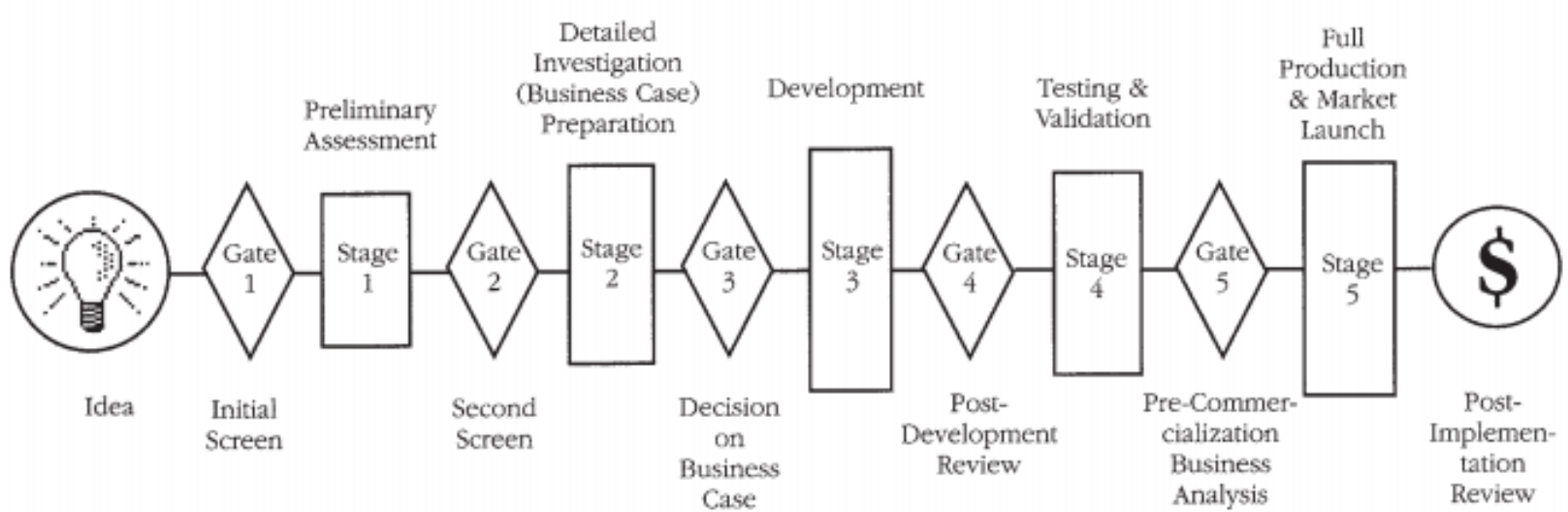

Source: (Cooper, 1990).

Several different approaches and reference models have been proposed to PDP, and numerous literature reviews have been made on the subject. It is not the purpose of this study to provide such an extensive review on PDP - that could have been a dissertation by itself, and therefore 
it is useful to rely on past reviews. Table 2.1 presents an adaptation of Canuto da Silva and Kaminski (2017), a chronologically ordered compilation of the main contribution to PDP literature, with a special focus on PDP in the automotive industry or, more generally, in the manufacturing industry, over the decades, and their main contributions.

Table 2.1 - PDP approaches

\begin{tabular}{|c|c|c|}
\hline Author & Title & PDP Approach \\
\hline (Evans, 1959) & Basic design concepts & $\begin{array}{l}\text { Product design } \\
\text { spiral }\end{array}$ \\
\hline (Asimow, 1962) & Introduction to design & $\begin{array}{l}\text { Production and } \\
\text { consumption } \\
\text { cycle }\end{array}$ \\
\hline (Cooper, 1990) & $\begin{array}{l}\text { Stage-gate systems: A new tool for managing new } \\
\text { products }\end{array}$ & $\begin{array}{l}\text { Stage-gate } \\
\text { concept }\end{array}$ \\
\hline $\begin{array}{l}\text { (Womack, Jones, } \\
\text { \& Roos, 1990) }\end{array}$ & $\begin{array}{l}\text { The machine that changed the world: the story of } \\
\text { lean production }\end{array}$ & $\begin{array}{l}\text { Lean product } \\
\text { development }\end{array}$ \\
\hline $\begin{array}{c}\text { (Clark \& } \\
\text { Fujimoto, 1991) }\end{array}$ & $\begin{array}{l}\text { Product development performance: strategy, } \\
\text { organization and management in the auto industry }\end{array}$ & $\begin{array}{l}\text { Development } \\
\text { funnel concept }\end{array}$ \\
\hline $\begin{array}{c}\text { (Clark \& } \\
\text { Wheelwright, } \\
\text { 1993) }\end{array}$ & Managing new product and process development & $\begin{array}{l}\text { Development } \\
\text { funnel concept }\end{array}$ \\
\hline $\begin{array}{l}\text { (Krishnan \& } \\
\text { Ulrich, 2001) }\end{array}$ & $\begin{array}{l}\text { Product development decisions: a review of the } \\
\text { literature }\end{array}$ & $\begin{array}{c}\text { PDP } \\
\text { perspectives }\end{array}$ \\
\hline (Suh, 2001) & Axiomatic Design & $\begin{array}{l}\text { Axiomatic } \\
\text { design }\end{array}$ \\
\hline $\begin{array}{l}\text { (Rozenfeld et al., } \\
\text { 2006) }\end{array}$ & Product development process management & $\begin{array}{c}\text { Product } \\
\text { lifecycle } \\
\text { Management }\end{array}$ \\
\hline $\begin{array}{c}\text { (Dieter \& } \\
\text { Schmidt, 2009) }\end{array}$ & Engineering design & $\begin{array}{c}\text { Technical and } \\
\text { managerial } \\
\text { gates }\end{array}$ \\
\hline (Weber, 2009) & Automotive development processes & $\begin{array}{l}\text { Customer } \\
\text { oriented }\end{array}$ \\
\hline
\end{tabular}




\begin{tabular}{|c|c|c|}
\hline (Omar, 2011) & $\begin{array}{c}\text { The automotive car body manufacturing systems } \\
\text { and processes }\end{array}$ & $\begin{array}{l}\text { Automotive } \\
\text { manufacturing } \\
\text { design }\end{array}$ \\
\hline $\begin{array}{l}\text { (Canuto da Silva } \\
\text { \& Kaminski, } \\
\text { 2016) }\end{array}$ & $\begin{array}{l}\text { Selection of virtual and physical prototypes in } \\
\text { the product development process }\end{array}$ & $\begin{array}{c}\text { Virtual and } \\
\text { physical prototypes } \\
\text { selection }\end{array}$ \\
\hline $\begin{array}{l}\text { (Canuto da Silva } \\
\text { \& Kaminski, } \\
\text { 2017) }\end{array}$ & $\begin{array}{l}\text { Proposal of framework to managing the } \\
\text { automotive product development process }\end{array}$ & $\begin{array}{l}\text { Automotive PDP } \\
\text { framework }\end{array}$ \\
\hline $\begin{array}{c}\text { (Wynn \& } \\
\text { Clarkson, 2018) }\end{array}$ & Process models in design and development & $\begin{array}{l}\text { PDP models } \\
\text { framework }\end{array}$ \\
\hline $\begin{array}{c}\text { (Baraldi \& } \\
\text { Kaminski, 2018) }\end{array}$ & $\begin{array}{l}\text { Reference model for the implementation of new } \\
\text { assembly processes in the automotive sector }\end{array}$ & $\begin{array}{c}\text { Automotive } \\
\text { assembly } \\
\text { processes design }\end{array}$ \\
\hline $\begin{array}{l}\text { (Blankesteijn et } \\
\text { al., 2019) }\end{array}$ & $\begin{array}{c}\text { Closed-open innovation strategy for autonomous } \\
\text { vehicle development }\end{array}$ & $\begin{array}{c}\text { Closed-open } \\
\text { innovation } \\
\text { strategy in R\&D }\end{array}$ \\
\hline
\end{tabular}

Source: adapted from (Canuto da Silva \& Kaminski, 2017).

\subsubsection{Scope and structure of PDP adopted in the current study}

For the scope of this study, the PDP definition adopted is a more generic (and general) one, such as stated by Rozenfeld et al. (2006) earlier in this chapter. Such definition encompasses both R\&D activities and technical aspects of the PDP, as well as activities related to business development and management of product portfolio and development projects. In his work, Armellini (2013) made the same choices regarding his approach to PDP. According to him, technology development is a preliminary phase of the PDP:

"[...] this work adopts the broader concept of the PDP, by considering both technology and product development as parts of the PDP. [...] although the technology development may be distinguishable to product development itself, it is nothing but a preliminary phase of the PDP. " (Armellini, 2013)

The current study also groups R\&D activities with portfolio and project management. Companies usually divide those activities into different departments: the former usually called R\&D, Product Development or Development, while the latter usually called Project 
Management Office or Business Development. However, for the purposes of looking at the whole of innovative product development process - from idea to market - it makes sense to from a logical and practical standpoint to view them together.

In terms of a structure or model considered as the basis of analysis, the present study considers the development funnel model, proposed by Clark and Wheelwright (1993). Such decision is justified by two main factors. Firstly, in Sections and 2.2 and 2.3, the frame of reference used for Open Innovation, from Chesbrough, also adopts the development funnel concept as a basis for his analysis, and therefore there is a practical advantage in using it in this study also.

Secondly, when comparing between the models and approaches mentioned in Table 2.1, the author considers that different approaches usually stem mainly from variations and improvements of the same funnel concept. That is, the processes at least in some form, have the relatively same characteristic of the following main phases (the nomenclature used here stems from Rozenfeld et al., 2006):

- A pre-development phase, consisting of idea generation or investigations (as called by Clark and Wheelwright), establishing connections between market needs, strategic goals within the company and current resources. These activities can appear under the guise of product portfolio management, as previously discussed.

- A development phase, in which more pragmatic approaches, such as Evans' Design Spiral and Asimow's production and consumption cycle, usually focus on. This phase starts from an idea, strategy or concept and builds upon it, iterating until a final product is ready for the market.

- A post-development phase, which has the main goal of feeding back the predevelopment phases with data, both internal and external, from the product developed and introduced to the market.

\subsection{OPEN INNOVATION (OI)}

\subsubsection{The origin of the open innovation concept}

It is useful to begin the literature review on Open Innovation (OI) by first discussing the "closed" model. Chesbrough (2003), using the development funnel, argued that the closed model can be represented in such a way that the funnel represents the boundaries of a firm 
(Figure 2.5). Those boundaries are determined by the company's business model and strategic approach, and any product development that does not fit inside the scope of the funnel should be eliminated, by definition, from the process. Information, knowledge and technologies are not exchanged between different funnels (different companies) and spillovers are considered inefficiencies to be dealt with, not something to look for.

Figure 2.5 - The closed innovation model

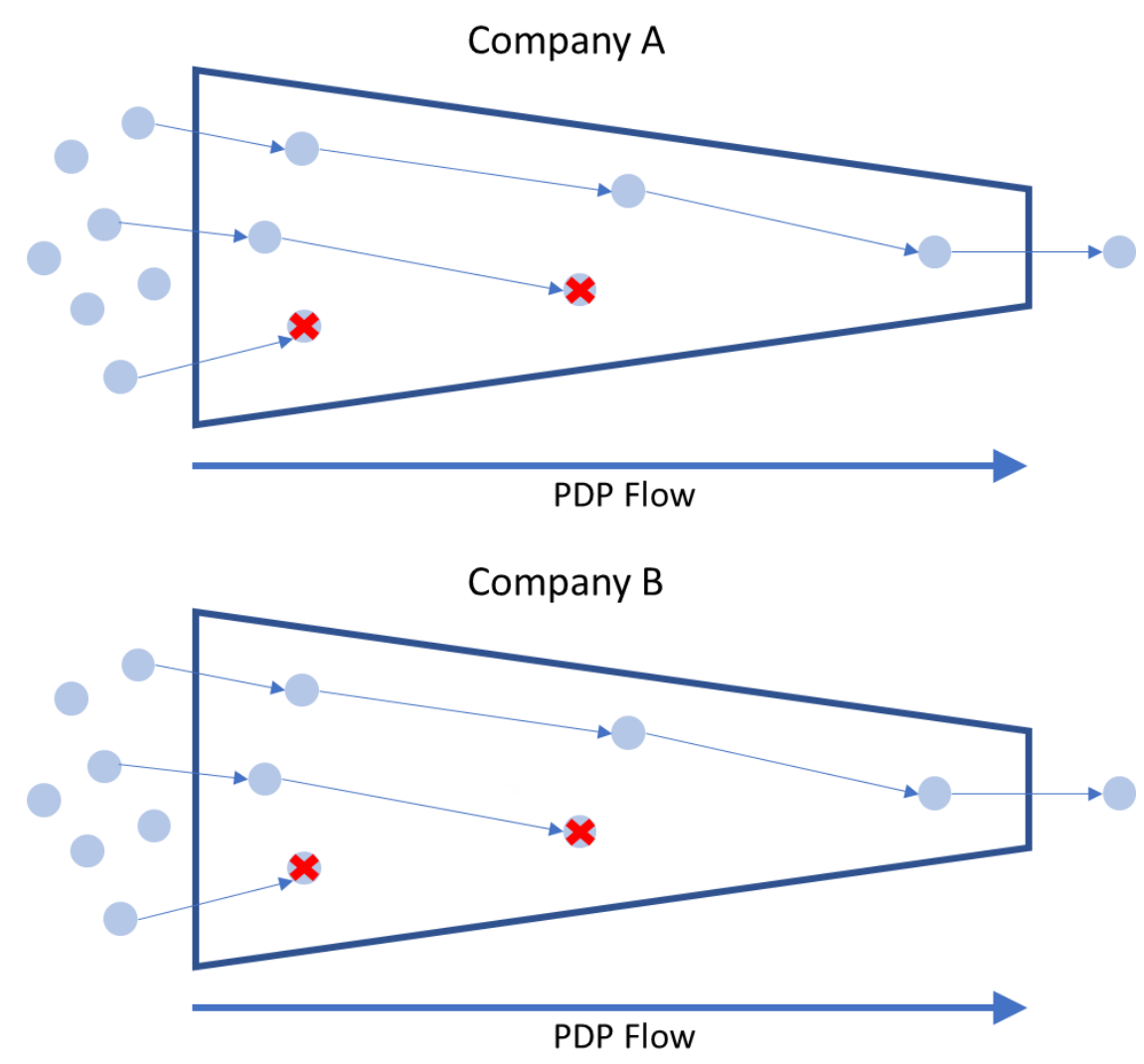

Source: (H. W. Chesbrough, 2003)

However, many factors have influenced this mindset:

- An increase in mobility of skilled workers - more frequent job changes among specialized fields;

- Higher quality research being performed outside traditional R\&D labs (especially with more funding going to universities);

- More small companies performing the majority of R\&D expenditures;

- Venture Capital market giving key engineers of a company the ability to spin-out emerging technology from a company (that would not use it otherwise - because of the boundaries of the funnel) in the form of startups; 
- Increased costs in R\&D associated with increased complexity and lower return on investment (especially because of shorter product lifecycles), discouraging more investments from the bigger companies.

A small caveat is that the historical context of the time that Chesbrough wrote his work does matter. Chesbrough (and his co-authors) published his works on Open Innovation in the early 2000's and therefore such time-sensitive data should be considered. However, for the purposes of this review, and considering the growth and relevance of the subject of Open Innovation, it can be assumed that the trend related to the factors mentioned above continued for the following years also. Therefore, this mindset of the closed model, due to the aforementioned factors, gave way to a new - "open" - innovation model.

This mindset shift began what Chesbrough defined as Open Innovation. Therefore, according to him:

\begin{abstract}
"Open innovation is the use of purposive inflows and outflows of knowledge to accelerate internal innovation, and expand the markets for external use of innovation, respectively." (Chesbrough et al., 2006, p.1)
\end{abstract}

Also:

\begin{abstract}
"Open innovation means that companies should make much greater use of external ideas and technologies in their own business, while letting their unused ideas be used by other companies. This requires each company to open up its business model to let more external ideas and technologies flow from the outside and let more internal knowledge flow to the outside." (Chesbrough et al., 2006, preface, $p$. xiii)
\end{abstract}

In his definitions, he first would use the term "paradigm shift" to characterize the depth of the change that the new model would incur - later, that would change into milder terms.

The contrast between the closed model (shown in Figure 2.5) and the open model is shown in Figure 2.6, illustrating a few open innovation activities: the spin-out, where a knowledge or technology that does not quite fit inside the boundaries of the firm, is taken into external paths to the market (the knowledge or technology is first developed into a product), and the spin-in, where a strategic knowledge or technology is taken from outside the organizational into it and 
then developed into a product. It also portrays the acquisition, another activity related to open innovation. In this case, the flow of knowledge or technology happens later during development, and the organizational purchases the rights to the technology or infrastructure almost ready for the market.

Figure 2.6 - The open innovation model

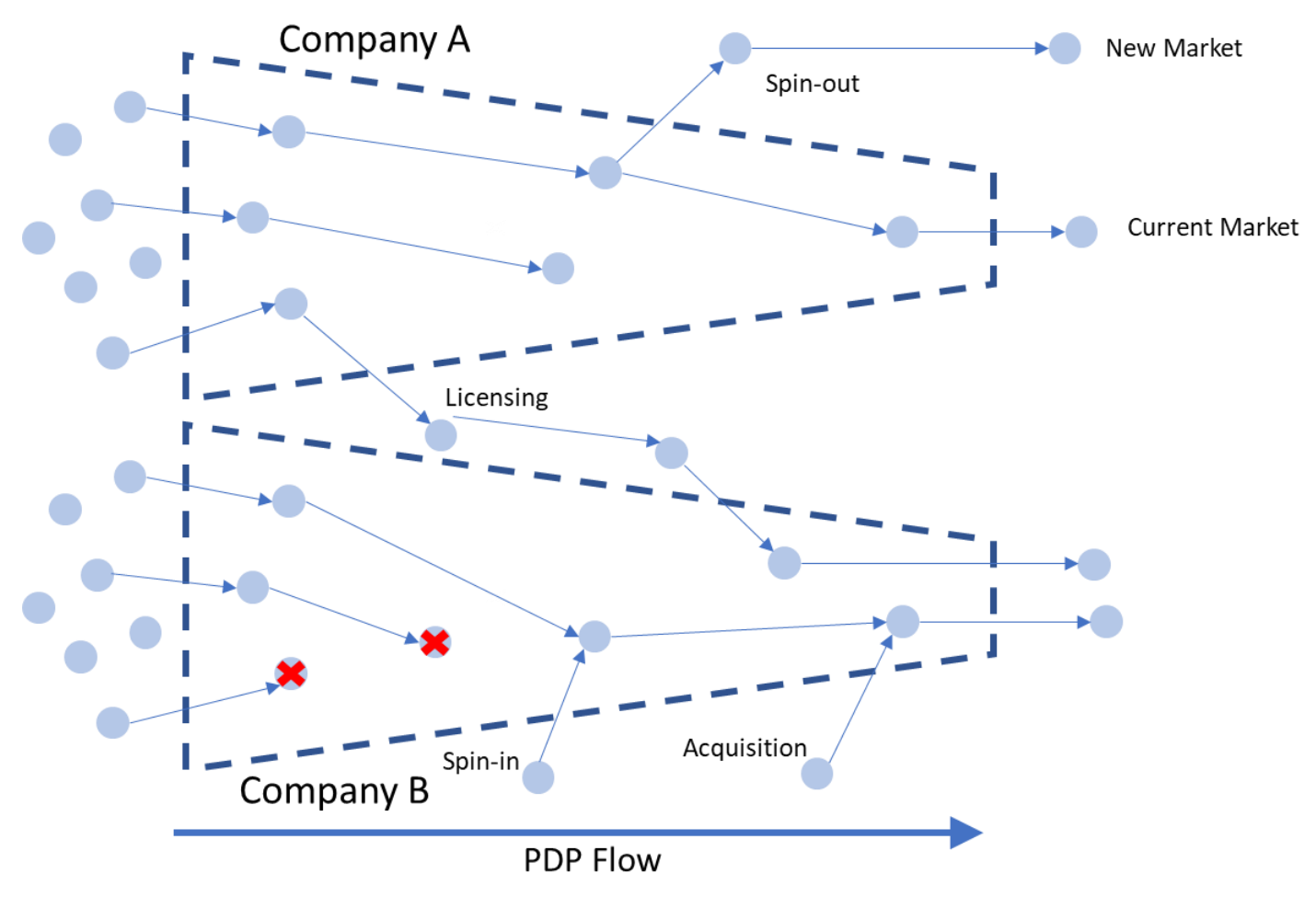

Source: (H. W. Chesbrough, 2003)

\subsubsection{Open Innovation characteristics and definitions}

Not unlike PDP, Open Innovation (OI) is a concept that, although with a much shorter lifespan, has evolved into many definitions, models and categorizations. Since its conception (and first formalization) in the early 2000 's, several definitions for OI have been proposed. A report from the Organization for Economic Co-creation and Development (OECD, 2008) presents nine different definitions for OI, and still newer definitions have been made to understand what actually is open innovation (Bogers, Chesbrough, \& Moedas, 2018; West \& Bogers, 2014). Regardless of their differences, all those definitions deal with aspects of external agents interacting with ideas, knowledge or technologies (both from the outside to the inside of an organization and vice-versa) in order to develop a new product, service or process that is marketable and generate values to an organization. 
The following definition for OI, made almost a decade after the first definition by Chesbrough, considers:

"[...] Following the original and more recent conceptualizations [...], we define open innovation as a distributed innovation process based on purposively managed knowledge flows across organizational boundaries, using pecuniary and non-pecuniary mechanisms in line with the organization's business model. These flows of knowledge may involve knowledge inflows to the focal organization (leveraging external knowledge sources through internal processes), knowledge outflows from a focal organization (leveraging internal knowledge through external commercialization processes) or both (coupling external knowledge sources and commercialization activities) [...]" ( $\mathrm{H}$. Chesbrough \& Bogers, 2014).

For the scope of this study, the definitions and framework proposed by Chesbrough and Bogers (2014) are adopted as the foundations of analysis, because of both their relevance to OI research and its pertinence to the PDP literature, by using Clark and Wheelwright's development funnel concept as a foundation.

According to the definition, there are two different classifications for OI activities. The first is related to whether there are pecuniary mechanisms involved, being either pecuniary or nonpecuniary. The second is with respect to the direction of knowledge inflow, which can be:

- From the outside-in, with the organization leveraging external sources of knowledge or technology into the organization;

- From the inside-out, with the organization leveraging their own internal knowledge and technology into external access to the market;

- One combining both directions, coupling external and internal knowledge and technology sources to external (and internal) paths to the market.

Another classification of OI activities (Dahlander \& Gann, 2010) groups them into four types of openness: sourcing, acquiring, revealing, and selling. Armellini et al. (2016) presented a useful combination of those two different classifications, as well as issues associated with each combination (of core process and type of openness), as shown in Table 2. 
Table 2.2 - Issues associated with each type of openness and core process in OI

\begin{tabular}{|c|c|c|}
\hline Core process & Type of openness & Associated issues \\
\hline \multirow{5}{*}{$\begin{array}{l}\text { Outside-in } \\
\text { (inbound) }\end{array}$} & \multirow{3}{*}{ Sourcing } & External sources of knowledge/technologies \\
\hline & & Client and/or user integration into the innovation process \\
\hline & & Supplier integration into the innovation process \\
\hline & \multirow{2}{*}{ Acquiring } & Licensing-in \\
\hline & & Spin-ins, mergers and acquisitions (M\&A) \\
\hline \multirow{5}{*}{$\begin{array}{l}\text { Inside-out } \\
\text { (outbound) }\end{array}$} & Revealing & Intellectual Property (IPs) portfolio activities \\
\hline & \multirow{4}{*}{ Selling } & Licensing-out \\
\hline & & Spin-offs \\
\hline & & Spinouts and disinvestments \\
\hline & & Research and development (R\&D) outsourcing \\
\hline \multirow{3}{*}{ Coupled } & Sourcing/Revealing & Co-development and co-design with other companies \\
\hline & Acquiring & Collaboration with universities and other research centers \\
\hline & Selling & Venture Capital \\
\hline
\end{tabular}

Source: adapted from (Armellini et al., 2016).

Gassmann et al. (2010) identified in their work nine different perspectives or dimensions by which open innovation can be analyzed: (1) spatial, (2) structural, (3) user, (4) supplier, (5) leveraging, (6) process, (7) tool, (8) institutional and (9) cultural. Those dimensions, when combined with the issues and core processes described in Table 2.2, were correlated by Armellini (2013) to find which issues are applicable to each perspective, as can be seen in Table 2.3. 
Table 2.3 - Associated issues correlated with each open innovation perspective

\begin{tabular}{|c|c|c|c|c|c|c|c|c|c|c|}
\hline \multirow[b]{2}{*}{$\begin{array}{c}\text { Core } \\
\text { process }\end{array}$} & \multirow[b]{2}{*}{ Associated Issues } & \multicolumn{9}{|c|}{ Perspectives } \\
\hline & & 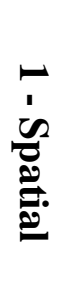 & 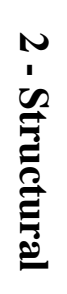 & 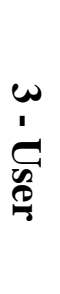 & 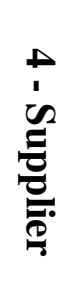 & 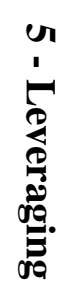 & $\begin{array}{l}9 \\
\dot{0} \\
0 \\
0 \\
0 \\
0 \\
0\end{array}$ & 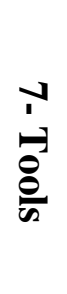 & 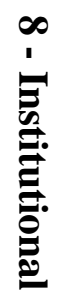 & 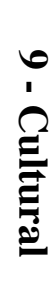 \\
\hline \multirow{5}{*}{ Outside-in } & $\begin{array}{c}\text { External sources of } \\
\text { knowledge/technologies }\end{array}$ & $\mathrm{x}$ & $\mathrm{x}$ & & & & $\mathrm{x}$ & $\mathrm{x}$ & & $\mathrm{x}$ \\
\hline & $\begin{array}{l}\text { Client and/or user integration } \\
\text { into the innovation process }\end{array}$ & & & $\mathrm{x}$ & & & $\mathrm{x}$ & $\mathrm{x}$ & & $\mathrm{x}$ \\
\hline & $\begin{array}{l}\text { Supplier integration into the } \\
\text { innovation process }\end{array}$ & & & & $\mathrm{x}$ & & $\mathrm{x}$ & $\mathrm{x}$ & & $\mathrm{x}$ \\
\hline & Licensing-in & $\mathrm{X}$ & $\mathrm{X}$ & $\mathrm{x}$ & $\mathrm{x}$ & & $\mathrm{x}$ & $\mathrm{X}$ & $\mathrm{x}$ & $\mathrm{x}$ \\
\hline & $\begin{array}{l}\text { Spin-ins, mergers and } \\
\text { acquisitions (M\&A) }\end{array}$ & & & & & & $\mathrm{x}$ & $\mathrm{x}$ & $\mathrm{x}$ & $\mathrm{x}$ \\
\hline \multirow{5}{*}{ Inside-out } & $\begin{array}{l}\text { Intellectual Property (IPs) } \\
\text { portfolio activities }\end{array}$ & & & & & $\mathrm{x}$ & $\mathrm{x}$ & $\mathrm{x}$ & & $\mathrm{x}$ \\
\hline & Licensing-out & $\mathrm{x}$ & $\mathrm{x}$ & $\mathrm{x}$ & $\mathrm{x}$ & $\mathrm{x}$ & $\mathrm{x}$ & $\mathrm{x}$ & $\mathrm{x}$ & $\mathrm{x}$ \\
\hline & Spin-offs & & & & & $\mathrm{X}$ & $\mathrm{X}$ & & $\mathrm{X}$ & $\mathrm{x}$ \\
\hline & Spin-outs and disinvestments & & & & & $\mathrm{x}$ & $\mathrm{X}$ & & $\mathrm{X}$ & $\mathrm{x}$ \\
\hline & $\begin{array}{l}\text { Research and development } \\
\text { (R\&D) outsourcing }\end{array}$ & $\mathrm{X}$ & $\mathrm{X}$ & & & $\mathrm{x}$ & $\mathrm{x}$ & & & $\mathrm{x}$ \\
\hline \multirow{3}{*}{ Coupled } & $\begin{array}{l}\text { Co-development and co-design } \\
\text { with other companies }\end{array}$ & $\mathrm{x}$ & $\mathrm{x}$ & $\mathrm{x}$ & $\mathrm{x}$ & $\mathrm{x}$ & $\mathrm{x}$ & $\mathrm{x}$ & $\mathrm{x}$ & $\mathrm{X}$ \\
\hline & $\begin{array}{l}\text { Collaboration with universities } \\
\text { and other research centers }\end{array}$ & $\mathrm{x}$ & $\mathrm{X}$ & & & & $\mathrm{x}$ & & $\mathrm{x}$ & $\mathrm{x}$ \\
\hline & Venture Capital & & $\mathrm{X}$ & & & $\mathrm{x}$ & $\mathrm{x}$ & $\mathrm{x}$ & $\mathrm{x}$ & $\mathrm{x}$ \\
\hline
\end{tabular}

Source: (Armellini, 2013).

Although Chesbrough considered the concept of OI a paradigm-shift, many of the issues and processes associated with open innovation that affect the PDP are not necessarily new to many industries. It is possible to observe many of those individual practices and activities happening, even when the company does not have a formal structure for it, as observed by Chiaroni et al. (2011). The automotive industry, in particular, has been working for decades with an intricate value chain, connecting auto parts manufacturers with automakers in complex partnerships, and the activities mentioned happen in the PDP of those companies (Dias et al., 1999).

The challenge that organizations face, therefore, is in going from the occasional and nonstructured open innovation to the formalization within the organization in the form of structured open innovation processes - such as in PDP - and in the organizational culture (Chiaroni et al., 
2011). Chiaroni et al. (2011) also argued that there is a path - or a "journey", as the authors call it - by which companies willing to incorporate open innovation into their strategy follow, comprised of three aspects: dimensions of open innovation, managerial levers for open innovation and process of adoption of open innovation (Figure 2.7).

Figure 2.7 - The open innovation journey

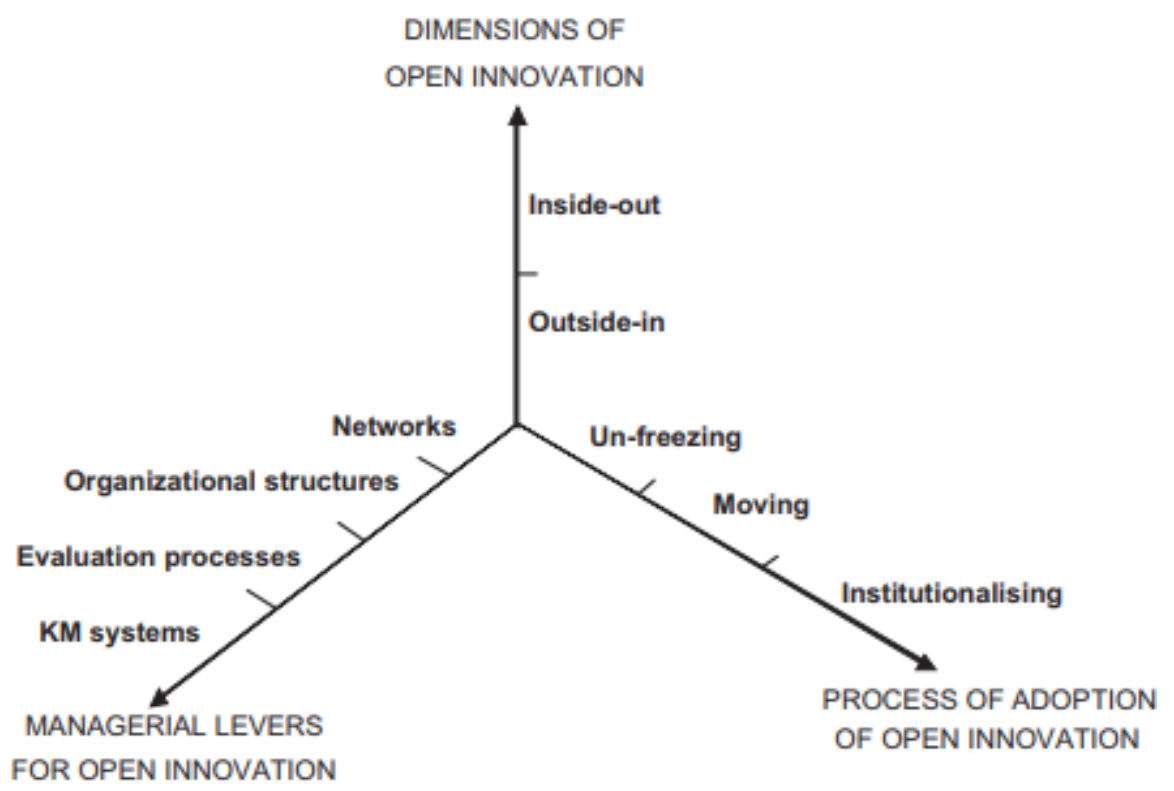

Source: (Chiaroni et al., 2011)

One of the most important aspects that can be taken from Chiaroni et al. (2011) model, is that the open innovation journey begins with the outside-in processes, and only then moves on to the inside-out activities. That conjecture not only makes sense but has been corroborated by other authors too (Armellini et al., 2014). By and large, most open innovation efforts first begin by companies utilizing external sources of information, knowledge and technologies into their own innovation processes, and the opposite is rarer to observe (Chiaroni et al., 2011).

The process of adoption of open innovation processes is also discussed in that framework. According to Chiaroni et al. (2011), although the concept of OI may sound like something new, it has also been observed that many of the activities listed are common among many industries, including the automotive industry. The challenge is, therefore, in a company move from the occasional use to the institutionalized formalization of open innovation processes in its innovation management structure. Chiaroni et al. (2011) divided this process in three steps: unfreezing, moving and institutionalizing. 
Unfreezing stands for the process of the firm's top management making clear its intent and commitment towards open innovation. The authors have found that unfreezing is a prerequisite for the implementation of open innovation. At this stage, the role played by the firm's network is basically irrelevant, and the firm has the responsibility of introducing a new management style that favors and incentivizes open innovation. The authors classify this change in two principles:

"[the firm's top management] make the change immediately visible to every one within the firm, i.e. they are strong signs that the status quo has been unfrozen to enable change; and they do not interfere with the basic processes and routines of the firm, they do not conflict directly with the status quo." (Chiaroni et al., 2011)

Moving happens once a firm is made aware of the need for a new approach to OI. As such, this step consists in introducing OI to an experimental field, to identify which OI solutions best fit the firm. This field can be a new project or development process, the establishing of an innovation office or a new organizational structure within the firm. Institutionalizing corresponds to the last stage, where the changes made with the experimental field are then taken to the rest of the firm's organizational structure. Deep changes are made to processes and evaluation metrics, both for employees' performance and the firms'.

\subsection{PRODUCT DEVELOPMENT FRAMEWORK FOR OPEN INNOVATION}

Armellini et al. (2014) proposed a conceptual model (Figure 2.8) identifying the internal "products" within an R\&D framework, effectively mapping OI activities within the PDP framework of a development funnel (in his case, dividing the funnel into three R\&D core activities: basic research, applied research and development). For those authors, the products obtained throughout PDP are intellectual assets, and as such, may also be exchanged within other companies. It is within this conceptual framework that this study is structured. 
Figure 2.8 - Open product development process framework

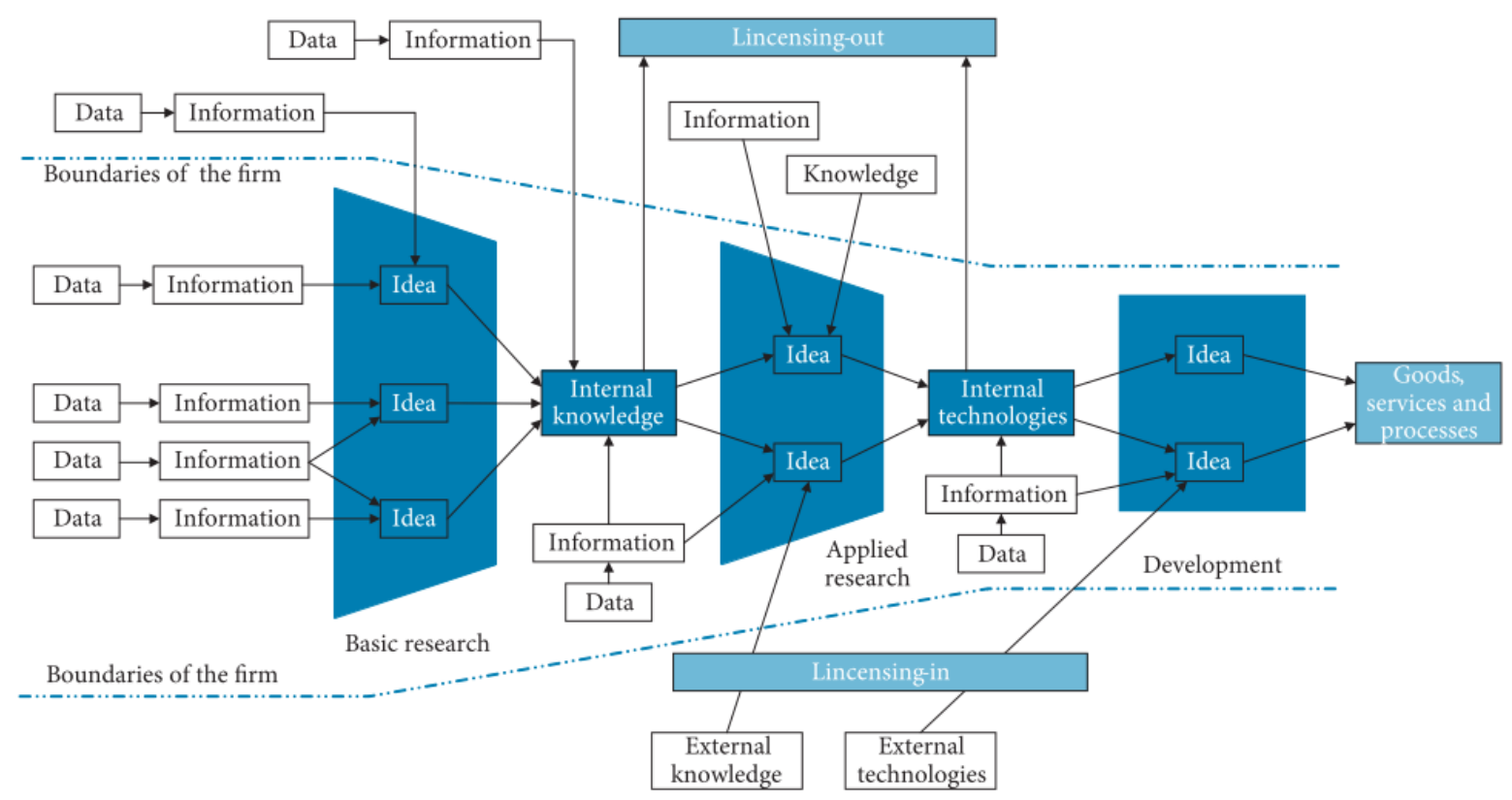

Source: (Armellini et al., 2014)

A few key points can be stated about the framework. Firstly, the product development process is divided into three different steps: basic research, applied research and development itself. This division comes from the Frascatti Manual (OECD, 2002) and the development stage is a combination of both experimental development and pre-production development. These terms somewhat correlate to the development funnel stages provided in Section 2.1 (investigations, development and shipping products). The geometric shape of the funnel also carries the meaning that a selection, combination and filtering process should happen for the intellectual assets (hereby also names artifacts) that exist within the PDP.

The framework then considers that three types of artifacts can be exchanged across the boundaries of the firm: information, knowledge, and technologies. A fourth artifact, data, does not exchange between the boundaries of the organization, but rather is the basic input for information.

The process can be summarized by the inputs and outputs of each stage of development. Basic research consists of taking data and information and processing it into knowledge, that can then be used in applied research to produce technologies. Technologies are then the basic input for the development processes, which have as the final artifact the product or service developed 
and ready for the market. Data and information are in every stage of the framework, but the main exchangeable assets are knowledge and technologies.

A discussion could also be made on the fact that the framework does not consider the exchange of raw, unprocessed data from external sources and to use that data in the development process, a phenomenon that is growing in popularity in association with the terms Big Data. 


\section{RESEARCH METHOD}

\subsection{RESEARCH CLASSIFICATION AND METHOD CHOICE}

Following the goal outlined in the first chapter of this text - to analyze how OI occurs within the Brazilian automotive industry automaker and auto parts companies, a fitting classification for this research is that of a descriptive research, that is, its goal is to describe characteristics of a population or phenomenon by way of comparing defined variables and parameters.

As to the method chosen, the research method adopted is that of a questionnaire-based survey, with the objective of inquiring pre-selected individual that were, at the time of the research, working for automaker and auto parts companies in positions related to product development and its management. A survey-based approach allows the researcher to structure interviews ahead of time, standardizing the inquiries, and permits the application of the survey through non-physical means, such as online surveys. By allowing pre-selected online respondents that fit all the criteria mentioned above, one can increase the breadth of answers while maintaining the depth of face-to-face interviews.

\subsection{HYPOTHESES AND CONSTRUCTS}

In order to determine what is to be inquired in the survey, the questions proposed in Section 1.4 are then translated into three constructs (Figure 3.1):

- OI Organizational Culture: The main actors or partners involved in the practice of OI of each company, the state of maturity and importance of their partnership for the development process, and the main OI activities done through that partnership;

- PDP Aspects: the main characteristics of the PDP of each company.

- OI Barriers and Risks: the barriers and risks associated with the implementation of open innovation projects, and how much each of those perceived risks affect OI;

Those constructs are then used to formulate the questions that should be asked in the questionnaire. 


\section{Figure 3.1 - Research Constructs}

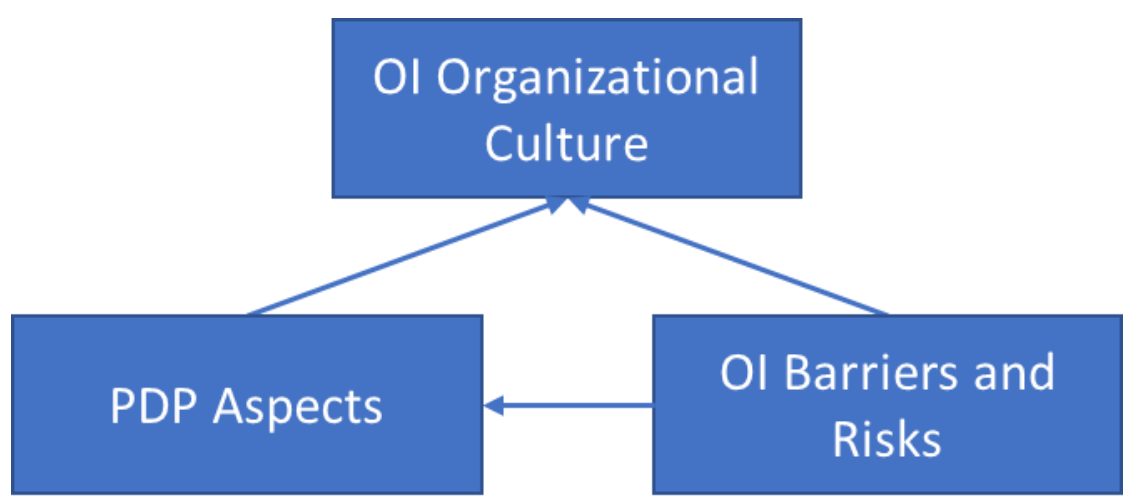

Source: from the author.

Regarding the constructs mentioned in Figure 3.1, the following variables are assigned to each construct (Table 3.1):

Table 3.1 - List of variables related to each construct

\begin{tabular}{ll}
\hline Construct & Variables Studied \\
\hline OI Organizational & Most important partnerships \\
\cline { 2 - 2 } Culture & Reason for partnership (activities performed) \\
\cline { 2 - 2 } & Cultural aspects of the organization regarding OI \\
\hline PDP Aspects & Degree of innovation (incremental/radical) \\
\cline { 2 - 2 } & Adoption to newer PDP development methods and models \\
\hline OI Barriers and Risks & Perceived barriers and risks for the implementation of OI projects \\
\hline
\end{tabular}

\section{Source: from the author.}

Following the variables presented, the set of hypotheses that relate the constructs according to Figure 3.1 is as follows:

H1: companies that perform more open innovation, perceive more value in OI and engage in partnerships that are considered important to the company are more likely to engage in more radical innovation, as well as to adopt newer PDP models and development methods.

H2: companies that engage in more radical innovation, as well as adopt newer PDP models and development methods are more likely to encounter fewer barriers and value less the risks of the implementation of OI engagements. 
H3: companies that have perform more OI and perceive more value in OI are more likely to encounter fewer barriers and value less the risks of the implementation of OI engagements.

In summary, this study provides a theoretical model as shown in Figure 3.2. In that figure, arrows come from the independent variable towards the dependent variable. According to these hypotheses, Open Innovation is impacted positively by both the adoption of newer PDP models and methods and the degree of product innovation performed in a company. Having a more structured OI environment and formalized OI organizational culture should also be negatively impacted by the barriers and the value of risks found in the implementation of OI engagements. Finally, less barriers and risks in the implementation of OI projects should then result in a more updated PDP, more structured towards OI and incurring in more radical (as opposed to incremental) product innovation.

Figure 3.2 - Conceptual model for the constructs' hypotheses

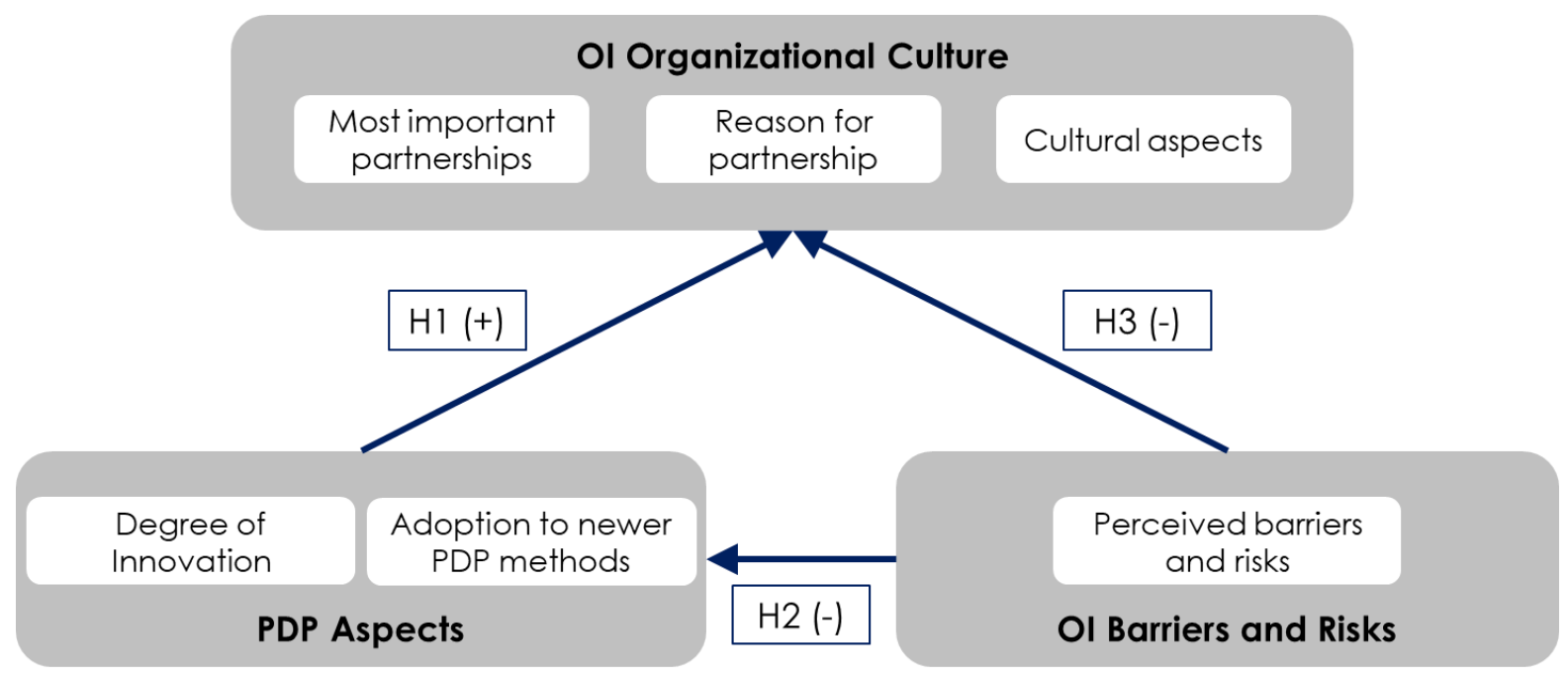

Source: from the author.

These hypotheses are then tested on a measure by measure basis in Section 4. The complete hypotheses are then shown in Table 3.2.

Table 3.2 - Hypotheses for the regression model

\begin{tabular}{ccc}
\hline Hypothesis & Dependent measure & Independent measure \\
\hline H1a & Most important partnerships & Degree of innovation \\
H1b & Most important partnerships & Adoption to newer PDP methods \\
H1c & Reasons for partnership & Degree of innovation \\
H1d & Reasons for partnership & Adoption to newer PDP methods \\
H1e & Cultural aspects & Degree of innovation \\
\hline
\end{tabular}




\begin{tabular}{ccc}
\hline H1f & Cultural aspects & Adoption to newer PDP methods \\
H2a & Degree of innovation & Perceived barriers and risks \\
H2b & Adoption to newer PDP methods & Perceived barriers and risks \\
H3a & Most important partnerships & Perceived barriers and risks \\
H3b & Reasons for partnership & Perceived barriers and risks \\
H3c & Cultural aspects & Perceived barriers and risks \\
\hline
\end{tabular}

\section{Source: from the author.}

In order to study each construct and test each hypothesis, the final questionnaire has the structure summarized by Table 3.3:

Table 3.3 - Survey questions divided by variable groups and constructs

\begin{tabular}{cccc}
\hline Construct & Variable & Questions & Scale \\
\hline OI & Most important partnerships & 4 & Likert (1 to 5) \\
\cline { 2 - 4 } Organizational \\
\cline { 2 - 4 } Culture & Reasons for partnership & 3 & Likert (1 to 5) \\
\cline { 2 - 4 } PDP Aspects & Cultural Aspects & 3 & Likert (1 to 5) \\
\cline { 2 - 4 } & Degree of innovation & 1 & Likert (1 to 5) \\
\hline OI Barriers & Adoption to newer PDP methods/models & 1 & Likert (1 to 5) \\
and Risks & Perceived barriers and risks & 1 & Likert (1 to 5) \\
\hline
\end{tabular}

\section{Source: from the author.}

\subsection{SURVEY APPLICATION}

The prepared survey is then applied to engineers, managers and directors that were, at the time of the survey application, working for automaker and auto parts companies in departments related to product development - those usually go by the name of one or more of the following: (New) Product Development, R\&D, Systems Engineering, Product Engineering, Project Office, among a few others. Other criteria, such as having been enrolled in a post-graduate course before and/or publishing a paper in a scientific journal or event, have also been used to prospect possible respondents. Though the entire research is anonymous in nature, through an individualized token sent to each possible respondent, it is possible to assess exactly who is filling the survey, as well as the (automotive) company he works for. But, most importantly, this method allows the researchers to restrict access to the survey to only those who fit the criteria mentioned in the beginning of this paragraph. 
The questionnaire is directed at the individual, and questions are asked based on his perception towards his employer, specifically at the plant or unit level. Appendix A contains the complete questionnaire questions.

It should be noted that since this study is part of a bigger research project with the purpose of applying a similar survey in other countries and other industries. At the time of this writing, this survey has already been applied with respondents from Canada, France and Germany (as well as Brazil). Therefore, the survey in Appendix A contains unused questions in this study, which were used in these other studies. The relationship between the questionnaire questions and the constructs and variables (mentioned in Table 3.3) is presented in

Table 3.4, and not all questions found in Appendix A are listed in the table.

Table 3.4 - Survey questions grouped by variable

\begin{tabular}{|c|c|c|}
\hline Construct & Variable & Questions \\
\hline \multirow{3}{*}{$\begin{array}{l}\text { OI Organizational } \\
\text { Culture }\end{array}$} & Most important partnerships & F1-F4 \\
\hline & Reasons for partnership & B1, B2, B6 \\
\hline & Cultural Aspects & B4, B5, B7, D3 \\
\hline \multirow{2}{*}{ PDP Aspects } & Degree of innovation & $\mathrm{C} 1$ \\
\hline & Adoption to newer PDP methods/models & $\mathrm{C} 2$ \\
\hline OI Barriers and Risks & Perceived barriers and risks & D4 \\
\hline \multirow{5}{*}{ Control Variables } & Company size & A1 \\
\hline & Plant/unit size & A1 \\
\hline & Age of respondent & G3 \\
\hline & $\begin{array}{c}\text { Respondent expertise (measured in years of } \\
\text { experience) }\end{array}$ & $\mathrm{G} 2$ \\
\hline & Respondent job title & G1, G4 \\
\hline
\end{tabular}

Source: from the author.

Besides the variables listed, a few questions from the questionnaire pertain to control variables, listed in Table 3.5. 
Table 3.5 - Control variables

\begin{tabular}{cc}
\hline Control variable & Question \\
\hline Company size & A1 \\
Plant/unit size & A1 \\
Age of respondent & G3 \\
Respondent expertise (measured in years of experience) & G2 \\
Respondent job title & G1, G4
\end{tabular}

Source: from the author.

Data was collected throughout the year of 2018, and the final sample size of respondents that come from professionals working in areas related to product development and innovation in Brazilian automaker companies (hereafter automaker respondents) amounts to 65 valid responses. Respondents that come from auto parts manufacturer companies (hereafter auto parts respondents) amount to another 74 valid responses, on a total of 139 responses from both groups.

It should be noted that one of the objectives of this research was also to supply the Brazilian automotive industry with information and knowledge regarding Open Innovation and how it is affecting product development processes within their industry. Therefore, every respondent received a benchmarking report, detailing how their answers compared to all respondents'. 


\section{RESULTS AND ANALYSES: AUTOMAKER COMPANIES}

This chapter brings the results and analyses from the first subset: automaker respondents, presenting the methodology used in processing the data obtained through the survey.

Section 4.1 addresses the descriptive statistics of the collected answers, as well as presents some demographic data on the respondents. Section 4.2 brings the authors' interpretation of the descriptive data. Sections 4.3 and 4.4 present, for one of the measures structured in Section 3, the approach used in the PCF analysis and its results. For each other measure, the same approach was taken, and results are summarized in the Appendix B.

\subsection{DESCRIPTIVE STATISTICS}

As one of the measures of respondents' expertise, it was assessed how many years of experience they had in the automotive industry. Respondents' had an average of 17.4 years of experience in the sector, and the distribution is shown in Figure 4.1. Overall, this is considered a rather senior sample size, even for the industry standards.

Figure 4.1 - Histogram of respondents' year of experience in the automotive industry

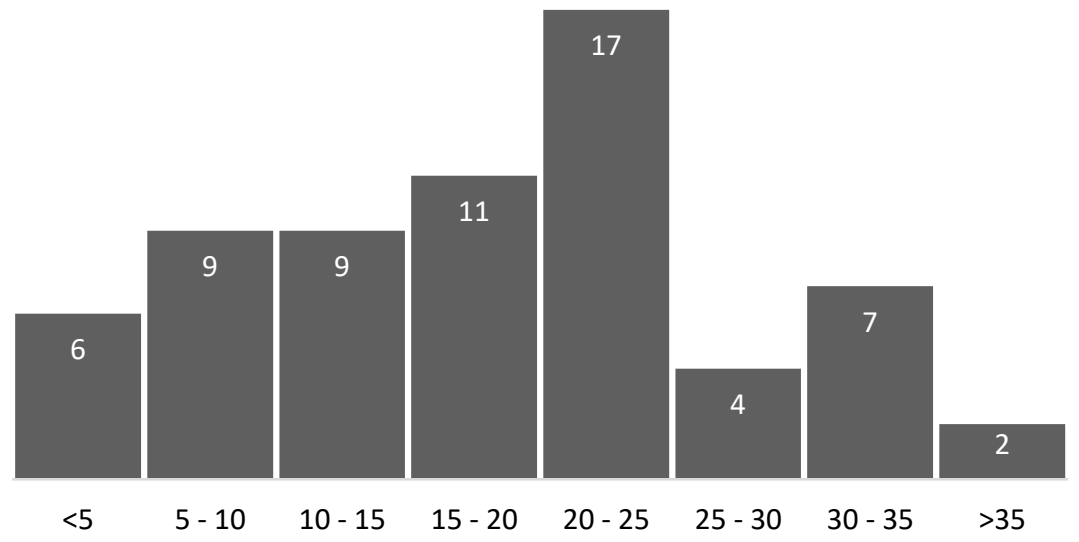

Respondents' also registered the company that they (at the time of the survey) worked for. Brazil has no local automaker company, that is, all the companies installed in the country are subsidiaries from multinational companies with headquarters overseas, and as such all the 65 respondents come from multinational companies.

Another useful classification for the Brazilian industry is to group automaker companies into two categories: the firstcomers, which were the automakers that began their operations in Brazil during the "first wave" of automakers, in the early 60's; and the new or late comers, which 
arrived at the country with Brazil's economic liberalization in the early 90's (Ibusuki et al., 2015). Those two groups have a very distinctive industrial and engineering structure (in Brazil) from each other, and as such it could be used as another control variable in the study. Out of the 65 respondents, 51 come from firstcomer companies, while the remaining 14 come from new or late comer companies. As expected, the firstcomer companies, that employ more professionals and have a stronger history in Brazil, also represent the majority of respondents.

With respect to open innovation and product development itself, the first aspect analyzed is which OI activities respondents claimed that their companies were employing, and how important they were. Based on a 5-point Likert scale, from Not important to Extremely important, respondents assessed the impact of a series of open innovation practices, grouped into inbound and outbound activities (as outlined in Section 3.2). Figure 4.2 and Figure 4.3 presents the global mean values for each inbound and outbound activity, respectively. 
Figure 4.2 - Open innovation inbound activities (global mean values)

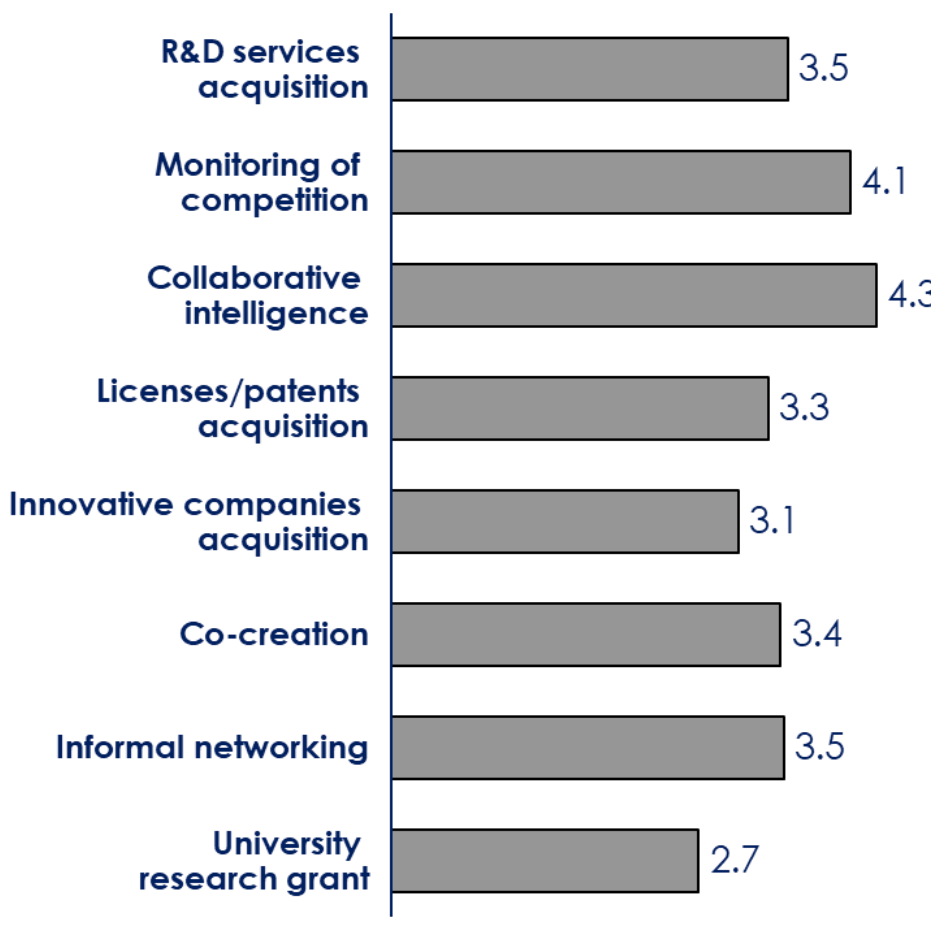

Figure 4.3 - Open innovation outbound activities (global mean values)

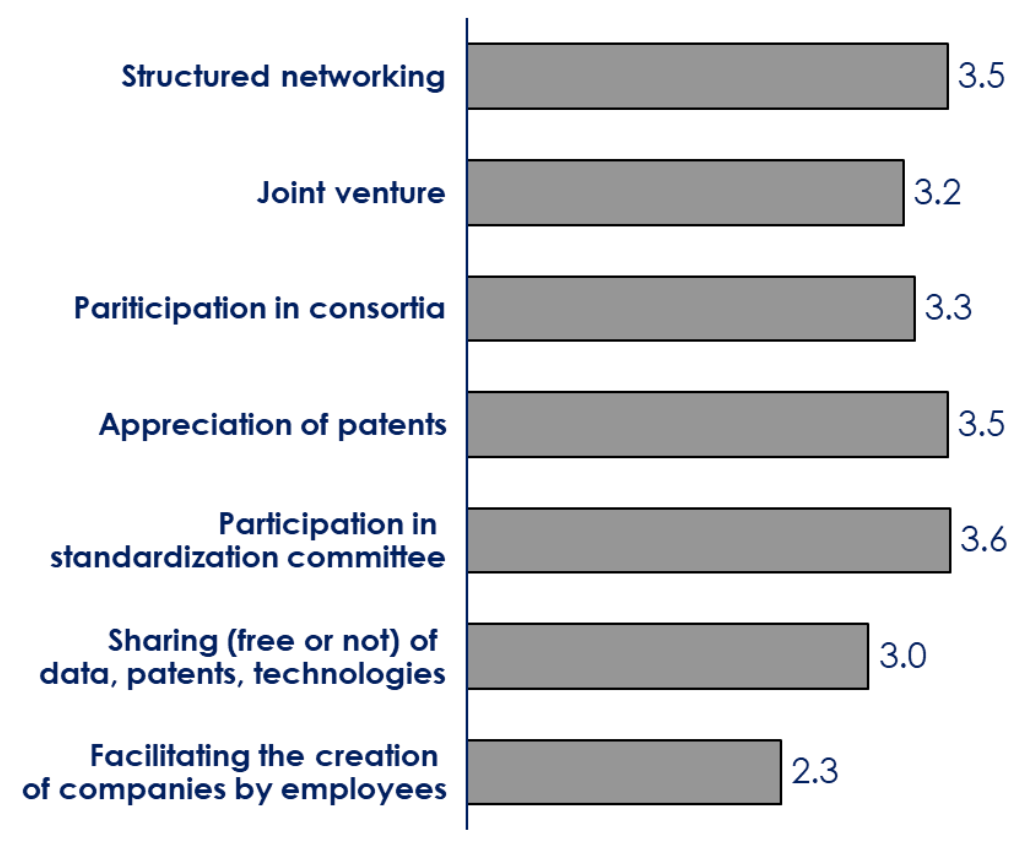

The following question asked respondents to assess how important each item from a list of potential benefits is to the implementation of open innovation projects. In other words, what is the potential value that could be obtained through open innovation. Figure 4.4 displays the global mean values for this question. 
Figure 4.4 - Perceived value of open innovation

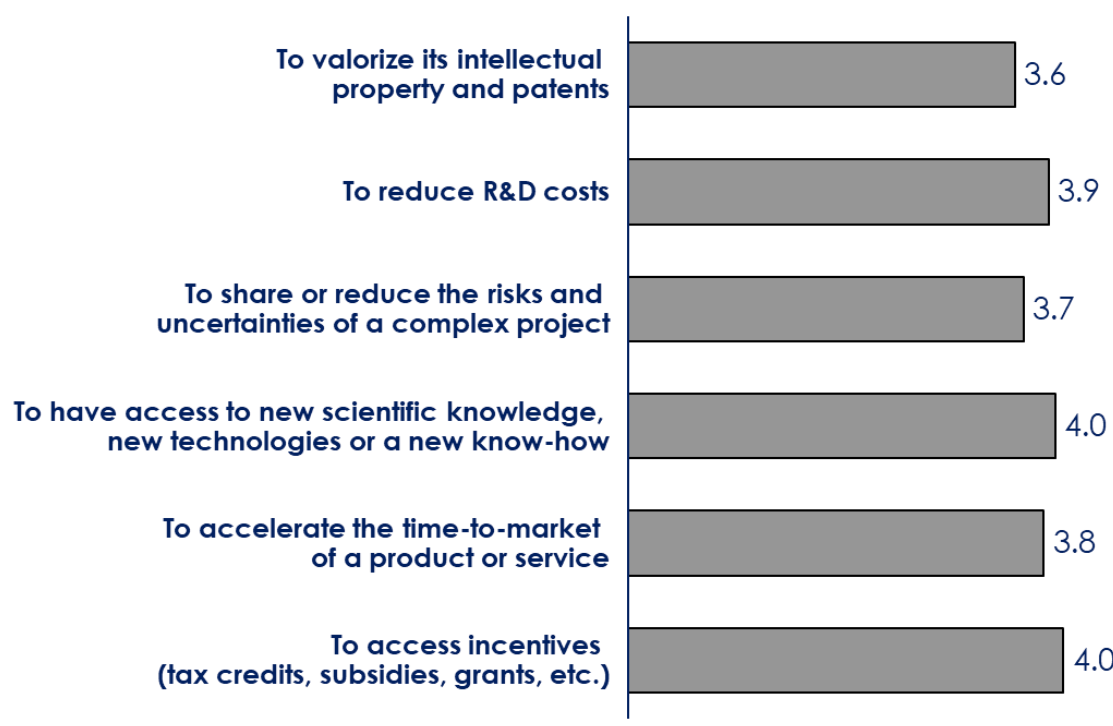

Next, respondents were asked to rank their three most important partnerships in open innovation, from a list of ten possible answers. Figure 4.5 presents the results, as a percentage of the total from the three partners listed from each candidate (so, if a candidate chose the same option for the three most important partners, it counts the answer three times).

\section{Figure 4.5 - Most important partnerships in open innovation (as a \% of total)}

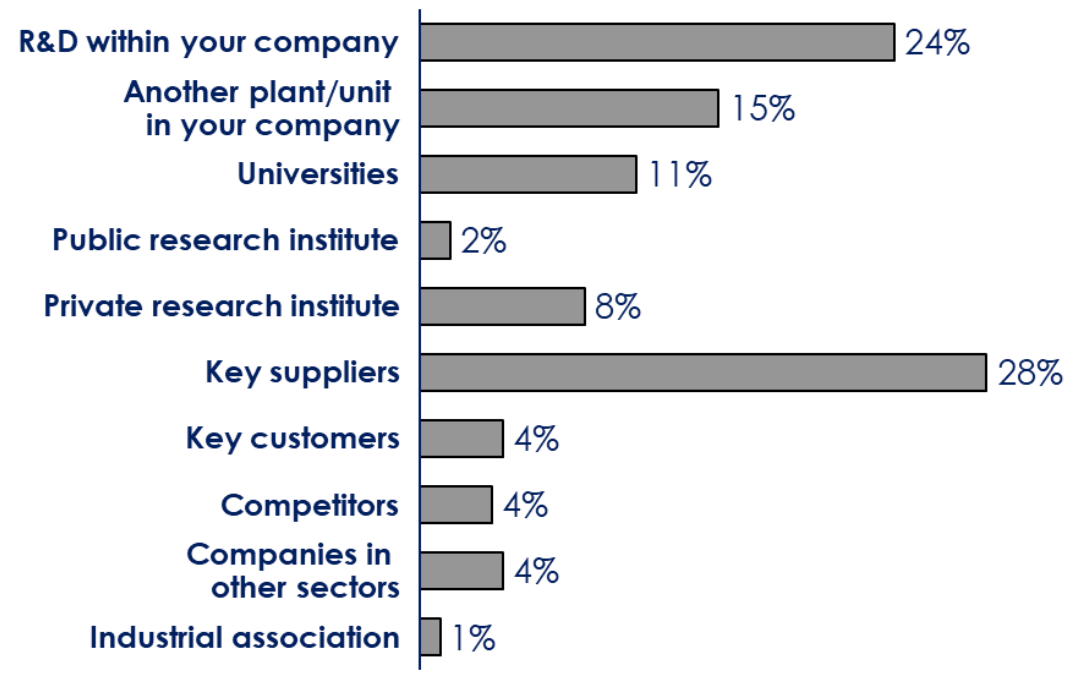

Finally, on the main risks and barriers that can hinder or impede the implementation of OI projects or engagements, respondents were asked to, again on a 5-point Likert scale, the importance given (and perceived) to each of the following barriers or risks in the implementation of OI engagements. Figure 4.6 shows the results for the averages calculated for each item. 
Figure 4.6 - Barriers and risks in OI engagements

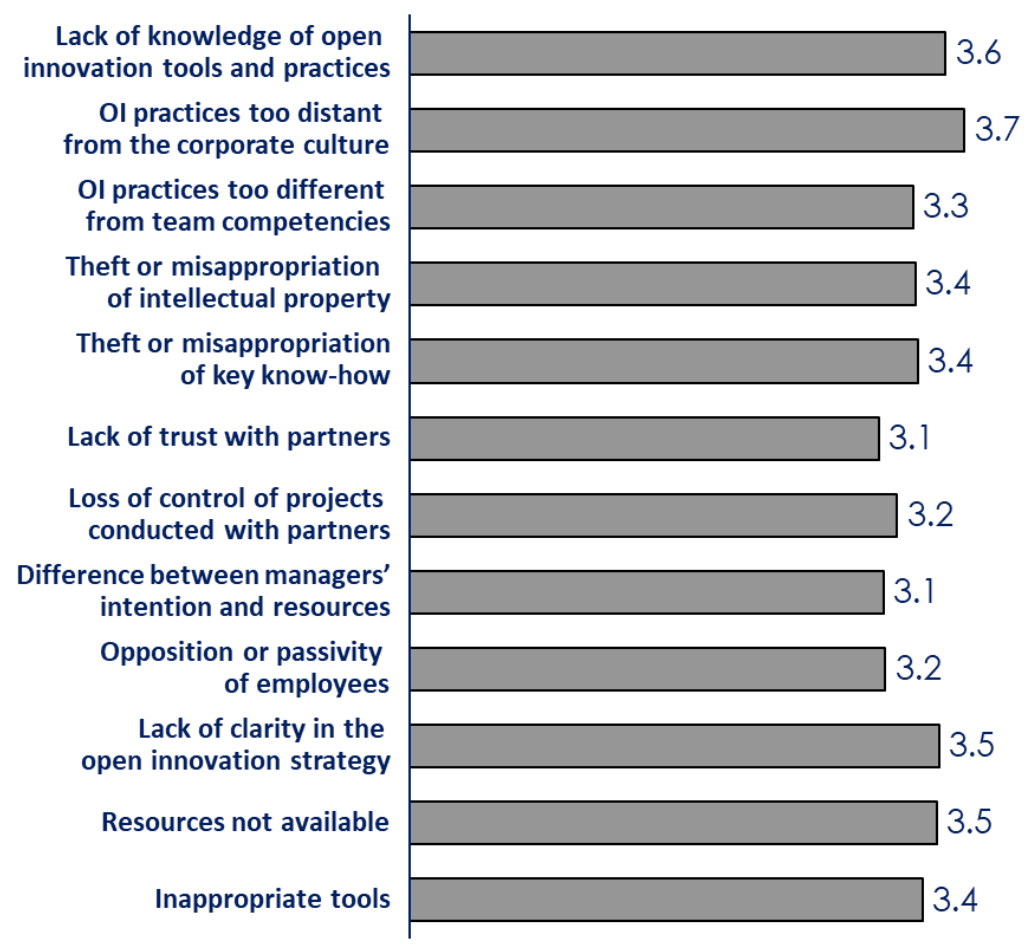

\subsection{INTERPRETATION OF DESCRIPTIVE STATISTICS}

\subsubsection{OI practices in the automotive industry}

Though section 4.3 goes into detail on the statistical analysis of the data obtained through the survey, some observation of the descriptive statistics provided in Section 4.1 could assist in providing some insight on open innovation in the automotive industry.

The first array of questions in the survey relate to open innovation activities that respondents consider most important for their companies, both inbound and outbound. The main inbound activities were the acquisition of $R \& D$ services, corporate intelligence surveillance and "collective intelligence" (defined as benchmarking with other companies). Those are mostly management techniques and tools used with product development, but they do not change the essence of its process. On the other hand, more costly activities, both financial and risk-wise, such as the purchase of patents and licenses, as well as the acquisition of startup companies, were considered the least important for the respondents.

Outbound activities were rated less important than the inbound ones, in accordance with the current literature. Specifically, the activity of sharing data, technology and patents was considered the least important among all (inbound and outbound activities). 
$55 \%$ of the respondents answered that their companies have been doing open innovation (defined as seen on section 2.2) for more than five years, while $21 \%$ of the respondents consider that their companies do not engage in OI yet.

When asked what reasons are the most important in performing open innovation, respondents consider that valorizing their patents and IP is the least important reason, while gaining access to tax incentives is the most important.

Though the focus of this study is not on the effect of public policies in open innovation, it is important to comment about the Brazilian case. On the subject of tax incentive policies, the Brazilian automotive industry has benefited from a few different programs that rewarded investments in research and development. Since 1995, and still active as of the time of this writing, Lei do bem ("Law of good") is a federal policy aimed to encourage companies in dedicating their resources to $\mathrm{R} \& \mathrm{D}$, maintaining tax reductions with such effort. Exclusive to the automotive industry, Inovar Auto was another federal policy, active from 2012 to 2017, structured to accelerate the development of more energy efficient vehicles, by means of incentivizing investment in $\mathrm{R} \& \mathrm{D}$, engineering and process improvements (Ibusuki et al., 2015). Since 2018, program Rota 2030 (“Route 2030”) aims to further improve and incentivize development in the automotive industry, with basically the same strategic direction as Inovar Auto, but with a greater focus on job creation and patent development (Government, 2018).

\subsubsection{The effects of OI in PDP}

On PDP, 91\% of the respondents considered the products developed in their companies more incremental than radical with respects to its innovation. It has already been stated that all the auto makers present in Brazil are subsidiaries with headquarters overseas, and most of the R\&D is performed outside (Ibusuki et al., 2015; Ibusuki, Kobayashi, \& Kaminski, 2012). However, $68 \%$ of the respondents agree that the way product development is done has changed in the last two years, and $65 \%$ of them agree that open innovation was part of this change.

\subsubsection{Risks and hindrances of engaging in OI}

Implementing new OI projects seem to carry considerable risks. 64\% of the respondents consider that newer OI projects could be hindered by setting themselves too far apart from current corporate culture. 
On the subject of organizational culture and its influence on open innovation, $71 \%$ of the respondents agree that external sources are one of the main ways of introducing new technologies and techniques to their business. However, only $38 \%$ of them believe that their company encourages them to find and use outside technology, and $45 \%$ of them think that developing the technology themselves is preferable to sourcing it from an outsider.

Respondents seem to set their own business unit/plant apart from the corporate headquarters. $62 \%$ of the respondents believe that there is a lack of clarity in their company's open innovation strategy, and over half of the respondents believe that there is both a lack of resources, tools and knowledge hindering the implementation of new OI projects. The fear of theft or misappropriation of intellectual property also concerns $66 \%$ of the respondents.

\subsubsection{Partners in OI}

The most important partners in open innovation are, according to the respondents, mainly $R \& D$ units within the same parent company and key suppliers. Those partners are considered most important when sharing privileged information on the industry ( $82 \%$ of respondents consider this important), reducing development lead time and costs (78\% of respondents agree) and on granting access to key R\&D capabilities (77\% of respondents). These points do make sense with the idea that the subsidiaries installed in Brazil are heavily dependent on the headquarters and with their key suppliers in order to develop new products faster and cheaper. Key suppliers should give access to niche technologies and work together with the local development teams to develop new solutions specific to the local industry and market.

\subsection{MEASURES FOR THE REGRESSION MODEL}

Measures presented in Section 3.2were subjected to rotated principal-component factor (PCF) analyses in order to reduce and identify relevant factors for each measure. Orthogonal rotations (varimax) were performed using Stata/IC13 software. The criteria chosen for adopting or discarding factors was based on a minimum eigenvalue of 1.0, with a minimum Cronbach's alpha of 0.6. Variables with a factor loading of less than 0.5 were purged and the analysis was iteratively rerun. A Kaiser-Meyer-Olkin (KMO) test was also used to assess the sampling adequacy for each measure in the model, with a minimum threshold of 0.5 . The next sections describe, for each measure, the approach used in the PCF analysis and its results. 


\subsubsection{OI Organizational Culture: Most important partnerships in open innovation}

For the measure of most important partnerships in open innovation and the activities performed in those relationships, participants had to first list the three most important partners for their company. Then, for each one, a five-point Likert scale (from not important to extremely important) was used to assess how important certain activities were in establishing that partnership.

For the PCF analysis of this measure, there is an assumption that the three most important partners are equal and, therefore, the results for the three can be averaged to a single variable. Then, the rotated PCF analysis can proceed as usual. Two factors with eigenvalue greater than 1.0 were found, Partners_F1 $(\lambda=4.7)$ and Partners_F2 $(\lambda=4.43)$, explaining $70 \%$ of the variance found. Both presented a sufficient value of Cronbach-alpha (0.91, for both). The KMO for the measure was also greater than $0.5(0.84)$ and, therefore, both factors were kept in the analysis.

Table 4.1 - Importance of partnerships in OI factor analysis

\begin{tabular}{lcc}
\hline Importance of partnerships in OI & $\begin{array}{c}\text { Factor 1 } \\
\text { (Partners_F1) }\end{array}$ & $\begin{array}{c}\text { Factor 2 } \\
\text { (Partners_F2) }\end{array}$ \\
\hline Access to new markets & 0.86 & - \\
Sharing privileged information on the market/industry & 0.84 & - \\
Scaling up production processes & 0.85 & - \\
Access to new distribution networks & 0.88 & - \\
Sharing information for production and procurement & 0.83 & 0.92 \\
Access to critical R\&D competencies & - & 0.91 \\
Access to R\&D infrastructure (e.g. laboratory equipment) & - & 0.83 \\
Long-term research on prospective technologies (exploratory & - & 0.67 \\
research) & - & 0.59 \\
Development of prototypes & - & 0.80 \\
Reduction of costs or lead time for product development & - & - \\
Sharing technical information for R\&D and/or product & 0.62 & 0.60 \\
development & - & 0.34 \\
Access to incentives or government funds & 0.36 \\
Facilitate the networking and/or intermediation in the business & 0.36 & 0.70 \\
ecosystem & 4.70 & 4.43 \\
\hline \% prop. & 0.91 & 0.91 \\
\% cumul. & 0.84 & \\
Eigenvalue & & \\
Cronbach-alpha & & - \\
\hline KMO (global) & & - \\
\hline
\end{tabular}




\subsubsection{OI Organizational Culture: Open innovation perceived value and practices (reasons for partnership)}

Open innovation practices were measured separately in relation to inbound and outbound practices. Both were assessed by asking respondents to indicate the level of importance (in a Likert scale, from Not important to Extremely important) for each practice in their company. The perceived value found in open innovation was assessed by the same parameters, but instead listing benefits that could be obtained through the practice of open innovation.

For the inbound practices, all variables resulted in a factor loading greater than 0.5 and were, therefore, kept in the factor analysis (see Table 4.2). The first factor was the only one with an eigenvalue greater than $1(\lambda=4.1)$, and explained $51 \%$ of the variance. With a Cronbach's alpha of 0.87 and KMO also equal to 0.87 (greater than 0.6 and 0.5 , respectively), the variables can be reduced to the single factor OI_inbound.

Table 4.2 - Open innovation inbound practices factor analysis

\begin{tabular}{lc}
\hline Open innovation inbound activities & $\begin{array}{l}\text { Factor 1 } \\
\text { (OI_inbound) }\end{array}$ \\
\hline Purchase of R\&D services & 0.58 \\
"Active" monitoring/surveillance of technologies with advanced tools & 0.61 \\
Collective intelligence tools to gather or test ideas, products, concepts, etc. & 0.70 \\
Purchase of licenses/patents & 0.81 \\
Acquisition of innovative companies & 0.75 \\
Co-creation projects with third parties & 0.79 \\
Informal networking & 0.70 \\
University research grant & 0.74 \\
\hline$\%$ prop. & $51 \%$ \\
\% cumul. & $51 \%$ \\
Eigenvalue & 4.10 \\
Cronbach-alpha & 0.87 \\
\hline KMO & 0.87
\end{tabular}

For the outbound practices, the results are similar (see Table 4.3). All variables obtained a factor loading greater than 0.5 for the first factor, which was also the only one with an eigenvalue greater than $1(\lambda=4.23)$. The factor OI_outbound explains $60 \%$ of the variance. With satisfactory values of Cronbach-alpha (0.88) and KMO (0.84), it is therefore sufficient to reduce the variables to a single factor. 
Table 4.3 - Open innovation outbound practices factor analysis

\section{Open innovation outbound activities}

Structured networking (publication, social media, congresses, conferences, associations, etc.)

Joint Venture

Participation in a consortium

Appreciation of your patents

Participation in standardization committees

Sharing (free or not) data, patents, technologies, etc.

Facilitating the creation of companies by collaborators

$\%$ prop.

$\%$ cumul.

Eigenvalue

Cronbach-alpha
Factor 1

(OI_outbound)

0.59

0.79

0.89

0.78

0.72

0.88

0.76

$60 \%$

$60 \%$

4.23

0.88

0.84

Finally, for the perceived importance of OI engagements, results are also similar to the other two measures (Table 4.4). Only one factor presented eigenvalue greater than 1.0, OI_reasons, and its metrics are satisfactory (alpha of 0.89 and $\mathrm{KMO}$ of 0.81 ). The factor explains $64 \%$ of the variance of all variables, since none had a factor loading of less than 0.5.

Table 4.4 - Perceived importance of OI engagements factor analysis

\section{Perceived importance of OI engagements}

To valorize its intellectual property and patents

To reduce $R \& D$ costs

To share or reduce the risks and uncertainties of a complex project

To have access to new scientific knowledge, new technologies or a new know-how

To accelerate the time-to-market of a product or service

To access incentives (tax credits, subsidies, grants, etc.)

$\%$ prop.

$\%$ cumul.

Eigenvalue

Cronbach-alpha

\section{Factor 1}

(OI_reasons)

0.71

0.83

0.85

0.88

0.85

0.64

0.64

0.64

3.82

0.89

0.81 


\subsubsection{OI Organizational Culture: Organizational culture of open innovation (cultural aspects)}

Organizational culture was assessed by asking respondents, on the same scale, to assess characteristics of management and employees that can improve the adoption of open innovation engagements (i.e. the company has an environment that favors open innovation practices).

For this group of questions (Table 4.5), two factors with eigenvalue greater than 1 were found. The first factor, Cult_Aspects_F1 $(\lambda=3.55)$, explains $39 \%$ of the variance with a Cronbachalpha of 0.87 . The second factor, Cult_Aspects_F2 $(\lambda=2.58)$ explains $29 \%$ of the variance with an alpha of 0.80 . Both factors are kept in the analysis.

Table 4.5 - Organizational culture in OI factor analysis

\begin{tabular}{|c|c|c|}
\hline Organizational culture in OI & $\begin{array}{l}\text { Factor } 1 \\
\text { (Cult_Aspects_F1) }\end{array}$ & $\begin{array}{l}\text { Factor } 2 \\
\text { (Cult_Aspects_F2) }\end{array}$ \\
\hline Management encourages teamwork & 0.89 & - \\
\hline $\begin{array}{l}\text { Management encourages everyone's participation in the } \\
\text { search for solution }\end{array}$ & 0.87 & - \\
\hline $\begin{array}{l}\text { Leaders or managers in your plant/unit have the flexibility } \\
\text { required to implement changes }\end{array}$ & 0.57 & - \\
\hline Employees' suggestions for improvement are encouraged & 0.73 & - \\
\hline $\begin{array}{l}\text { Employees that propose improvements are recognized by } \\
\text { their solutions }\end{array}$ & 0.61 & - \\
\hline The company offers training to its employees & 0.68 & - \\
\hline $\begin{array}{l}\text { The company uses techniques to stimulate creativity } \\
\text { among its employees }\end{array}$ & - & 0.69 \\
\hline $\begin{array}{l}\text { A team (dedicated or not) is in charge of promoting a } \\
\text { culture of open innovation in the corporate culture }\end{array}$ & - & 0.81 \\
\hline Indicators specific to open innovation are used & - & 0.88 \\
\hline$\%$ prop. & 0.39 & 0.29 \\
\hline$\%$ cumul. & 0.39 & 0.68 \\
\hline Eigenvalue & 3.55 & 2.58 \\
\hline Cronbach-alpha & 0.87 & 0.80 \\
\hline KMO (global) & 0.81 & \\
\hline
\end{tabular}

Two additional variables, OI_Maturity and OI_Strategy, assessed the respondents' perception on how mature the company is in open innovation practices and how integrated to its strategy open innovation is, respectively. Since each of these variables correspond to a single question in the survey, they are kept as distinct variables. 


\subsubsection{PDP aspects: Degree of innovation}

The last two measures are more related to new product development. Both use a five-point Likert scale (from completely disagree to completely agree). The first asks of respondents to assess how incremental or radical the innovations performed by their company are, the second measure assess, and the second measure assess whether the processes related to product development have changed in the last few years (since 2014) and whether new methods and tools have been adopted.

For the degree of innovation measure (Table 4.6), two factors with eigenvalue greater than 1.0 were found. PDP_Degree_F1 $(\lambda=1.51)$ presented a Cronbach-alpha of 0.67 and remained in the analysis. Even though the other factor presented sufficient eigenvalue, its Cronbach-alpha was of 0.58 , and was discarded in the analysis.

Table 4.6 - Degree of innovation performed in their company factor analysis

\begin{tabular}{lcc}
\hline Degree of innovation performed in their company & $\begin{array}{l}\text { Factor 1 } \\
\text { (PDP_Degree_F1) }\end{array}$ & $\begin{array}{l}\text { Factor 2 } \\
\text { (discarded) }\end{array}$ \\
\hline $\begin{array}{l}\text { The products developed are more incremental than radical in } \\
\text { their innovations }\end{array}$ & 0.86 & - \\
$\quad \begin{array}{l}\text { The products are developed based on information from prior } \\
\text { projects/products }\end{array}$ & 0.87 & - \\
$\quad$ Products are being developed to new target markets & - & 0.84 \\
$\quad$ The products developed necessitated the development of a & - & 0.83 \\
new platform and/or new business models & 0.38 & 0.36 \\
\hline prop. & 0.38 & 0.73 \\
$\%$ cumul. & 1.51 & 1.42 \\
Eigenvalue & 0.67 & $\mathbf{0 . 5 8}$ \\
Cronbach-alpha & 0.50 & \\
\hline KMO (global) & & \\
\hline
\end{tabular}

\subsubsection{PDP Aspects: Adoption to newer PDP methods}

Finally, for the measure of adoption to newer PDP methods and tools (Table 4.7), only one factor remained, PDP_adoption $(\lambda=3.12)$, explaining $78 \%$ of the variance found. With a Cronbach-alpha of 0.9 and KMO of 0.8, was kept in the analysis.

Table 4.7 - Adoption to newer PDP methods and tools factor analysis

Adoption to newer PDP methods and tools

The way PDP is done has changed since 2014

Open innovation has influenced the way PDP is done
Factor 1

(PDP_adoption)

0.70

0.94 
Open innovation is responsible for the improvement of existing and implemented PDP methods or tools in your plant/unit

Open innovation is responsible for the adoption of new PDP methods or tools (scrum, agile, etc.) in your plant/unit

$\%$ prop.

0.78

$\%$ cumul.

0.78

Eigenvalue

3.12

Cronbach-alpha

0.90

KMO

0.80

\subsubsection{Perceived barriers and risks in OI engagements}

The measure of perceived barriers and risks in OI engagements were assessed by means of a five-point Likert scale (from not important to extremely important) on how much each risk (from a list of 13) hindered the implementation of new OI projects or engagements in the respondents' company.

Results from the PCF (Table 4.8) reduced the thirteen variables to three factors, Barriers_F1 $(\lambda=3.28)$, Barriers_F2 $(\lambda=2.27)$ and Barriers_F3 $(\lambda=2.59)$. All presented a greater than 0.6 Cronbach-alpha, and the KMO found for the variables were greater than 0.5 . Therefore, the three factors were kept in the analysis.

Table 4.8 - Perceived barriers and risks in OI engagements

\begin{tabular}{|c|c|c|c|}
\hline $\begin{array}{l}\text { Perceived barriers and risks in OI } \\
\text { engagements }\end{array}$ & $\begin{array}{l}\text { Factor } 1 \\
\text { (Barriers_F1) }\end{array}$ & $\begin{array}{l}\text { Factor } 2 \\
\text { (Barriers_F2) }\end{array}$ & $\begin{array}{l}\text { Factor } 3 \\
\text { (Barriers_F3) }\end{array}$ \\
\hline $\begin{array}{l}\text { Lack of knowledge of the open innovation } \\
\text { tools and practices }\end{array}$ & - & 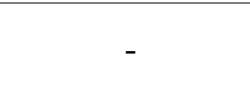 & 0.75 \\
\hline $\begin{array}{l}\text { Practices too distant from the corporate } \\
\text { culture }\end{array}$ & - & - & 0.89 \\
\hline $\begin{array}{l}\text { Practices too different from team } \\
\text { competencies }\end{array}$ & - & - & 0.84 \\
\hline $\begin{array}{l}\text { Theft or misappropriation of intellectual } \\
\text { property }\end{array}$ & - & 0.94 & - \\
\hline Theft or misappropriation of key know-how & - & 0.92 & - \\
\hline Lack of trust with partners & - & 0.79 & - \\
\hline $\begin{array}{l}\text { Loss of control of projects conducted with } \\
\text { partners }\end{array}$ & - & 0.84 & - \\
\hline $\begin{array}{l}\text { Difference between the intentions displayed } \\
\text { by the managers and the resources allocated to } \\
\text { the approach }\end{array}$ & 0.67 & - & - \\
\hline Opposition or passivity of employees & 0.65 & - & - \\
\hline $\begin{array}{l}\text { Lack of clarity in the open innovation } \\
\text { strategy }\end{array}$ & 0.78 & - & - \\
\hline Resources not available & 0.85 & - & - \\
\hline Inappropriate tools & 0.90 & - & - \\
\hline$\%$ prop. & 0.27 & 0.27 & 0.22 \\
\hline
\end{tabular}




\begin{tabular}{llll} 
\% cumul. & 0.27 & 0.55 & 0.76 \\
Eigenvalue & 3.28 & 2.27 & 2.59 \\
Cronbach-alpha & 0.88 & 0.92 & 0.84 \\
\hline KMO (global) & 0.78 & & \\
\hline
\end{tabular}

\subsubsection{Summary of variables}

For each of the factors presented in the past sections, new variables were defined. The PCF analyses resulted in the creation of thirteen variables, to be used in the regression models. Table 4.9 presents a summary of all the variables used in the models.

Finally, two control variables are used in the regression model. The first, Type_Maker, which categorizes the respondents' companies binarily as First or Newcomers (as defined by Ibusuki et al., 2015), an important characterization of the Brazilian industry that could have influence on the results. The second variable is Total_Exp, and corresponds to the amount, in years, that each respondent has of experience working in the automotive industry.

Table 4.9 - Summary of variables

\begin{tabular}{lccc}
\hline \multicolumn{1}{c}{ Description of variable } & Section & Method & Variable \\
\hline Partnerships in OI & 4.3 .1 & PCF & Partners_F1 \\
Partnerships in OI & 4.3 .1 & PCF & Partners_F2 \\
\hline Open innovation inbound practices & 4.3 .2 & PCF & OI_Inbound \\
Open innovation outbound practices & 4.3 .2 & PCF & OI_Outbound \\
Perceived importance of OI & 4.3 .2 & PCF & OI_Reasons \\
\hline Organizational culture & 4.3 .3 & PCF & Cult_Aspects_F1 \\
Perceived importance of OI & 4.3 .3 & PCF & Cult_Aspects_F2 \\
Maturity of company in OI & 4.3 .3 & Single var & OI_Maturity \\
How important OI is to the company's strategy & 4.3 .3 & Single var & OI_Strategy \\
Evolution of OI culture in company & 4.3 .3 & PCF & Cult_Change \\
\hline Degree of innovation & 4.3 .4 & PCF & PDP_Degree_F1 \\
Adoption to newer PDP methods & 4.3 .5 & PCF & PDP_Adoption \\
\hline Barriers and risks & 4.3 .6 & PCF & Barriers_F1 \\
Barriers and risks & 4.3 .6 & PCF & Barriers_F2 \\
Barriers and risks & 4.3 .6 & PCF & Barriers_F3 \\
\hline First or late comer in Brazil & - & Category & Type_Maker \\
Respondent's years of experience in auto industry & - & Single var & Exp_Total
\end{tabular}

\subsection{REGRESSION MODEL AND INTERPRETATION OF RESULTS}

First, a correlation matrix is performed on the variables to assess whether a regression analysis is suited for the data. As can be observed in Table 4.10, the majority of correlations are low, 
and there are no significant correlations among the same group of measures (highlighted in bold). This allows the analysis to move on to the regressions.

Table 4.10 - Correlation matrix for variables used in regression model

\begin{tabular}{lccccccccccccccc}
\hline Description of variable & $\mathbf{( 1 )}$ & $\mathbf{( 2 )}$ & $\mathbf{( 3 )}$ & $\mathbf{( 4 )}$ & $\mathbf{( 5 )}$ & $\mathbf{( 6 )}$ & $\mathbf{( 7 )}$ & $\mathbf{( 8 )}$ & $\mathbf{( 9 )}$ & $\mathbf{( 1 0 )}$ & $\mathbf{( 1 1 )}$ & $\mathbf{( 1 2 )}$ & $\mathbf{( 1 3 )}$ & $\mathbf{( 1 4 )}$ & $\mathbf{( 1 5 )}$ \\
\hline OI_Inbound (1) & 1.00 & - & - & - & - & - & - & - & - & - & - & - & - & - & - \\
OI_Outbound (2) & .83 & 1.00 & - & - & - & - & - & - & - & - & - & - & - & - & - \\
OI_Reasons (3) & .61 & .60 & 1.00 & - & - & - & - & - & - & - & - & - & - & - & - \\
\hline OI_Maturity (4) & .47 & .50 & .33 & 1.00 & - & - & - & - & - & - & - & - & - & - & - \\
OI_Strategy (5) & .53 & .59 & .62 & .60 & 1.00 & - & - & - & - & - & - & - & - & - & - \\
Cult_Change (6) & .50 & .58 & .32 & .50 & .48 & 1.00 & - & - & - & - & - & - & - & - & - \\
Cult_Aspects_F1 (7) & .57 & .62 & .45 & .49 & .51 & .72 & 1.00 & - & - & - & - & - & - & - & - \\
Cult_Aspects_F2 (8) & .26 & .29 & .04 & .09 & -.06 & .36 &. $\mathbf{1 5}$ & 1.00 & - & - & - & - & - & - & - \\
\hline Barriers_F1 (9) & .35 & .27 & .28 & .04 & .17 & .14 & -.02 & .10 & 1.00 & - & - & - & - & - & - \\
Barriers_F2 (10) & -.19 & -.31 & -.14 & -.42 & -.34 & -.22 & -.05 & -.10 & $\mathbf{. 0 6}$ & 1.00 & - & - & - & - & - \\
Barriers_F3 (11) & -.09 & -.14 & .03 & -.18 & -.06 & -.04 & -.21 & .07 & $\mathbf{- . 0 2}$ &. $\mathbf{3 1}$ & 1.00 & - & - & - & - \\
\hline PDP_Degree (12) & -.08 & .09 & .06 & .09 & .22 & .08 & -.17 & -.15 & .24 & -.33 & .11 & 1.00 & - & - & - \\
PDP_Adoption (13) & .74 & .75 & .49 & .53 & .61 & .67 & .64 & .29 & .10 & -.22 & -.25 & .01 & 1.00 & - & - \\
\hline Partners_F1 (14) & .62 & .60 & .28 & .29 & .34 & .53 & .45 & .15 & .39 & -.33 & -.32 & .19 & .58 & 1.00 & - \\
Partners_F2 (15) & -.24 & -.33 & -.22 & -.21 & -.20 & -.18 & -.18 & -.26 & -.13 & .34 & .22 & -.05 & -.33 & -.23 & 1.00 \\
\hline
\end{tabular}

Ordinary Least Squares (OLS) regressions were performed using Stata/IC13 software. For each analysis, three regressions were performed: one without control variables (Model 1), one controlling for years of experience (Model 2). The final model, (Model 3), besides controlling for years of experience, also restricts the sample size to only the sample for First comers, which comprises most of the sample size (51 of 65 respondents). This is important because first comer companies might have a very different stance on innovation in Brazil than the late comers.

The tables in this chapter present results of Model 3. However, full results for all three models are in Appendix B. Variables which the regression resulted in a significant p-value, which is taken to be less than 0.1 in this exploratory analysis, are highlighted in bold. Table 4.11, Table 4.12, and Table 4.13 present summaries of the regressions, grouped by the constructs outlined in Section 3.2, directly translating the three hypotheses enunciated (also in Section 3.2).

Table 4.11 - OLS regressions correlations summary for hypothesis 1: OI Organizational Culture versus PDP Aspects (model 3)

\begin{tabular}{cccc}
\hline & \multicolumn{2}{c}{ Independent Variable } \\
\hline Measure & Dependent Variable & PDP_Degree & PDP_Adoption \\
\hline Partners_F1 & 0.17 & $\mathbf{0 . 3 6}{ }^{* *}$
\end{tabular}




\begin{tabular}{cccc}
$\begin{array}{c}\text { Most } \\
\text { important } \\
\text { partnerships }\end{array}$ & Partners_F2 & -0.23 & -0.10 \\
\hline \multirow{2}{*}{$\begin{array}{c}\text { Reasons for } \\
\text { partnership }\end{array}$} & OI_Inbound & -0.08 & $\mathbf{0 . 6 7} * * *$ \\
& OI_Outbound & 0.04 & $\mathbf{0 . 6 5} * * *$ \\
& OI_Reasons & 0.11 & $\mathbf{0 . 6 4} * * *$ \\
\hline Cultural & Cult_Aspects_F1 & -0.08 & $\mathbf{0 . 3 7} * *$ \\
aspects & Cult_Aspects_F2 & 0.01 & $\mathbf{0 . 2 7 +}$ \\
& OI_Strategy & 0.16 & $\mathbf{0 . 8 4} * * *$ \\
& OI_Maturity & $\mathbf{0 . 1 9 +}$ & $\mathbf{0 . 3 3} * *$ \\
\hline
\end{tabular}

p- values: $+\mathrm{p}<.1 * \mathrm{p}<.05 * * \mathrm{p}<.01 * * * \mathrm{p}<.001$ (highlighted in bold)

Table 4.12 - OLS regressions correlations summary for hypothesis 2: PDP Aspects versus Barriers and Risks (model 3)

\begin{tabular}{ccccc}
\hline \multicolumn{5}{c}{ Independent Variable } \\
\hline Measure & Dependent Variable & Barriers_F1 & Barriers_F2 & Barriers_F3 \\
\hline \multirow{2}{*}{ PDP Aspects } & PDP_Adoption & 0.17 & -0.10 & -0.18 \\
& PDP_Degree_F1 & 0.00 & $\mathbf{- 0 . 3 6 * *}$ & 0.12 \\
\hline
\end{tabular}

p- values: $+\mathrm{p}<.1 * \mathrm{p}<.05 * * \mathrm{p}<.01 * * * \mathrm{p}<.001$ (highlighted in bold)

Table 4.13 - OLS regressions correlations summary for hypothesis 3: OI Organizational Culture versus Barriers and Risks (model 3)

\begin{tabular}{ccccc}
\hline & \multicolumn{5}{c}{ Independent Variable } \\
\hline Measure & Dependent Variable & Barriers_F1 & Barriers_F2 & Barriers_F3 \\
\hline $\begin{array}{c}\text { Most } \\
\text { important }\end{array}$ & Partners_F1 & $\mathbf{0 . 3 6 * *}$ & -0.08 & $\mathbf{- 0 . 2 5}^{*}$ \\
partnerships & Partners_F2 & -0.19 & $\mathbf{0 . 3 7 *}$ & 0.07 \\
\hline \multirow{2}{*}{ Reasons for } & OI_Inbound & $\mathbf{0 . 2 6 +}$ & 0.12 & $\mathbf{- 0 . 3 4 *}$ \\
partnership & OI_Outbound & 0.13 & -0.09 & $\mathbf{- 0 . 3 6 * *}$ \\
& OI_Reasons & 0.21 & 0.08 & -0.17 \\
\hline \multirow{3}{*}{ Cultural } & Cult_Aspects_F1 & -0.01 & 0.01 & -0.16 \\
aspects & Cult_Aspects_F2 & $\mathbf{0 . 3 0 *}$ & -0.16 & 0.10 \\
& OI_Strategy & 0.24 & -0.00 & -0.16 \\
& OI_Maturity & 0.12 & $\mathbf{- 0 . 4 2 * *}$ & 0.15 \\
\hline
\end{tabular}

p- values: $+\mathrm{p}<.1 * \mathrm{p}<.05 * * \mathrm{p}<.01 * * * \mathrm{p}<.001$ (highlighted in bold)

From the regressions summaries, only a few hypotheses can be accepted through the regressions, since most of them presented a p-value that do not reject the null hypothesis. The test of hypotheses is presented in Table 4.14. 
Table 4.14 - Test of hypotheses

\begin{tabular}{|c|c|c|}
\hline Hypothesis & Decision & Observation \\
\hline H1a & Rejected & No statistically significant correlations were found \\
\hline H1b & $\begin{array}{l}\text { Partially } \\
\text { accepted }\end{array}$ & $\begin{array}{l}\text { A significant positive correlation was found between } \\
\text { Partners_F1 and PDP_Adoption, but not with Partners_F2 }\end{array}$ \\
\hline H1c & Rejected & No statistically significant correlations were found \\
\hline H1d & Accepted & $\begin{array}{l}\text { A significant positive correlation was found between all the } \\
\text { three variables in the measure and PDP_Adoption }\end{array}$ \\
\hline H1e & $\begin{array}{l}\text { Partially } \\
\text { accepted }\end{array}$ & $\begin{array}{l}\text { There is a positive correlation between the variables } \\
\text { OI_Maturity and PDP_Degree, which is one out of five } \\
\text { variables from this measure }\end{array}$ \\
\hline H1f & Accepted & $\begin{array}{l}\text { A significant positive correlation was found between all the } \\
\text { five variables in the measure and PDP_Adoption }\end{array}$ \\
\hline H2a & $\begin{array}{l}\text { Partially } \\
\text { accepted }\end{array}$ & $\begin{array}{l}\text { A significant negative correlation was found between } \\
\text { PDP_Degree and Barriers_F2, but not in Barriers_F1, F3 }\end{array}$ \\
\hline $\mathbf{H} 2 \mathbf{b}$ & Rejected & No statistically significant correlations were found \\
\hline H3a & $\begin{array}{l}\text { Contradictory } \\
\text { regressions }\end{array}$ & $\begin{array}{l}\text { Partners_F1 showed a positive correlation with } \\
\text { Barriers_F1, but a negative correlation with Barriers_F3 }\end{array}$ \\
\hline H3b & $\begin{array}{l}\text { Contradictory } \\
\text { regressions }\end{array}$ & $\begin{array}{l}\text { OI_Inbound showed a positive correlation with } \\
\text { Barriers_F1, but a negative correlation with Barriers_F3 }\end{array}$ \\
\hline H3c & $\begin{array}{l}\text { Contradictory } \\
\text { regressions }\end{array}$ & $\begin{array}{l}\text { Cult_Aspects_F2 showed a positive correlation with } \\
\text { Barriers_F1, while OI_Maturity showed a negative correlation } \\
\text { with Barriers_F2 }\end{array}$ \\
\hline
\end{tabular}

Both hypotheses relating the Cultural Aspects and PDP Aspects measures (H1e and H1f) were accepted in the model, which do suggest a positive relationship between having a corporate culture that favors open innovation practices and evolving their PDP to adopt newer methodologies, as well as having a bigger focus on radical innovation.

All of the measures from the construct OI Organizational Culture presented a positive correlation with the measure PDP Adoption (hypothesis H1b, H1c and H1f). This could be evidence that adoption to newer product development methodologies and technologies could lead to a more "open" design process, which also includes a stronger innovation network and to perceive more value in open innovation itself.

Though the hypotheses relating Cultural Aspects and the Perceived Barriers and Risks constructs ( $\mathrm{H} 3 \mathrm{a}, \mathrm{H} 3 \mathrm{~b}$ and $\mathrm{H} 3 \mathrm{c})$ were not accepted, because their results are contradictory (that is, not statistically significant for all variables between constructs), one observation is important: the variables Barriers_F1 and Cult_Aspects_F2 show a positive and significant correlation. This interaction does make sense considering that formalized open innovation practices are expected to happen in an environment with reduced barriers and internal resistance to newer paradigms (note that this does not imply there is a causation clause). 
The remaining contradicted hypotheses, that is, those that presented results with both a positive and negative correlation, could be further studied to be broken up into more measures. 


\section{RESULTS AND ANALYSES: AUTO PARTS MANUFACTURERS}

This chapter brings the results and analyses from the auto parts manufacturers respondents, applying the same methodology used in Chapter 4 for the subset of respondents from automakers, in Section 5.1. It also performs the same regressions using the respondent origin (automaker or auto parts) as a control variable, in Section 5.2. For both sections, the full results are displayed in the Appendices, $\mathrm{C}$ and D, respectively. Discussion on the results found is left to Section 5.3.

Respondents that come from auto parts manufacturer companies (hereafter auto parts respondents) amount to another 74 valid responses, on a total of 139 responses from both groups.

\subsection{AUTO PARTS MANUFACTURERS}

Replicating the methodology used in Section 4.4, a correlation matrix is performed on the variables to assess whether a regression analysis is suited for the data. Correlations between variables among the same group of measures (highlighted in bold) are considered low $(<0.3$ in all cases). This allows the analysis to move on to the regressions.

For each analysis, two regressions were performed: one without control variables (Model 1), and one controlling for the respondent's years of experience (Model 2). It should be noted that the variables used are the same as those obtained in Section 4, which only used the Automaker Companies dataset.

Variables which the regression resulted in a significant p-value, which is taken to be less than 0.1 in this exploratory analysis, are highlighted in bold. Table 5.2, Table 5.3, and Table 5.4 present summaries of the regressions, grouped by the constructs outlined in Section 3.1, directly translating the three hypotheses enunciated (also in Section 3.1).

Table 5.1 - Correlation matrix for variables used in regression model for auto parts respondents

\begin{tabular}{|c|c|c|c|c|c|c|c|c|c|c|c|c|c|c|c|}
\hline Description of variable & (1) & (2) & (3) & (4) & (5) & (6) & (7) & (8) & (9) & (10) & (11) & (12) & (13) & (14) & (15) \\
\hline OI_Inbound (1) & 1.00 & - & - & - & - & - & - & - & - & - & - & - & - & - & - \\
\hline OI_Outbound (2) & .81 & 1.00 & - & - & - & - & - & - & - & - & - & - & - & - & - \\
\hline OI_Reasons (3) & .64 & .66 & 1.00 & - & - & - & - & - & - & - & - & - & - & - & - \\
\hline OI_Maturity (4) & .25 & .18 & .38 & 1.00 & - & - & - & - & - & - & - & - & - & - & - \\
\hline OI_Strategy (5) & .02 & -.06 & .27 & .44 & 1.00 & - & - & - & - & - & - & - & - & - & - \\
\hline Cult_Change (6) & .05 & -.10 & .07 & .54 & .44 & 1.00 & - & - & - & - & - & - & - & - & - \\
\hline Cult_Aspects_F1 (7) & .19 & .01 & .16 & .39 & .44 & .52 & 1.00 & - & - & - & - & - & - & - & - \\
\hline
\end{tabular}




\begin{tabular}{lccccccccccccccc} 
Cult_Aspects_F2 (8) & -.10 & -.06 & -.04 & -.04 & -.11 & -.24 & $\mathbf{- . 0 7}$ & 1.00 & - & - & - & - & - & - & - \\
\hline Barriers_F1 (9) & .34 & .37 & .27 & -.13 & .02 & -.26 & -.13 & .10 & 1.00 & - & - & - & - & - & - \\
Barriers_F2 (10) & -.07 & -.11 & -.19 & -.20 & -.17 & .12 & -.07 & .00 & $\mathbf{- . 0 5}$ & 1.00 & - & - & - & - & - \\
Barriers_F3 (11) & -.07 & .06 & .09 & -.10 & -.14 & -.03 & -.24 & .13 & $\mathbf{. 1 0}$ & $\mathbf{- . 1 3}$ & 1.00 & - & - & - & - \\
\hline PDP_Degree (12) & .28 & .36 & .27 & .47 & .40 & .38 & .29 & .01 & -.04 & -.04 & .03 & 1.00 & - & - & - \\
PDP_Adoption (13) & .17 & .04 & .23 & .33 & .54 & .64 & .49 & -.29 & .00 & .26 & -.25 & .38 & 1.00 & - & - \\
\hline Partners_F1 (14) & .42 & .46 & .40 & .09 & -.04 & -.06 & .19 & .15 & .47 & -.06 & -.08 & .15 & .16 & 1.00 & - \\
Partners_F2 (15) & .11 & .15 & .25 & .27 & .22 & .02 & .08 & .16 & .12 & -.11 & .06 & .26 & .19 & .05 & 1.00 \\
\hline
\end{tabular}

Table 5.2 - OLS regressions correlations summary for hypothesis 1: OI Organizational Culture versus PDP Aspects (model 2) for auto parts respondents

\begin{tabular}{cccc}
\hline & & \multicolumn{2}{c}{ Independent Variable } \\
\hline \multirow{2}{*}{ Measure } & Dependent Variable & PDP_Degree & PDP_Adoption \\
\hline \multirow{2}{*}{ Most important partnerships } & Partners_F1 & 0.14 & -0.12 \\
& Partners_F2 & -0.07 & 0.02 \\
\hline \multirow{3}{*}{ Reasons for partnership } & OI_Inbound & -0.02 & $\mathbf{0 . 2 6}^{*}$ \\
& OI_Outbound & 0.01 & 0.10 \\
& OI_Reasons & -0.01 & $\mathbf{0 . 2 8}^{*}$ \\
\hline \multirow{3}{*}{ Cultural aspects } & & & \\
& Cult_Aspects_F1 & 0.12 & $\mathbf{0 . 3 5}^{* *}$ \\
& Cult_Aspects_F2 & 0.05 & $\mathbf{- 0 . 3 8}^{* *}$ \\
& OI_Strategy & 0.11 & $\mathbf{0 . 4 7 * *}$ \\
& OI_Maturity & $\mathbf{0 . 3 6} * *$ & 0.11 \\
\hline
\end{tabular}

p- values: $+\mathrm{p}<.1 * \mathrm{p}<.05 * * \mathrm{p}<.01 * * * \mathrm{p}<.001$ (highlighted in bold)

Table 5.3 - OLS regressions correlations summary for hypothesis 2: PDP Aspects versus Barriers and Risks (model 2) for auto parts respondents

\begin{tabular}{ccccc}
\hline & & \multicolumn{3}{c}{ Independent Variable } \\
\hline Measure & $\begin{array}{c}\text { Dependent } \\
\text { Variable }\end{array}$ & Barriers_F1 & Barriers_F2 & Barriers_F3 \\
\hline PDP & PDP_Adoption & -0.01 & 0.08 & -0.10 \\
Aspects & PDP_Degree_F1 & -0.08 & 0.08 & 0.15 \\
\hline
\end{tabular}

p- values: $+\mathrm{p}<.1 * \mathrm{p}<.05 * * \mathrm{p}<.01 * * * \mathrm{p}<.001$ (highlighted in bold)

Table 5.4 - OLS regressions correlations summary for hypothesis 3: OI Organizational Culture versus Barriers and Risks (model 2) for auto parts respondents 


\begin{tabular}{ccccc} 
Measure & $\begin{array}{c}\text { Dependent } \\
\text { Variable }\end{array}$ & Barriers_F1 & Barriers_F2 & Barriers_F3 \\
\hline $\begin{array}{c}\text { Most } \\
\text { important } \\
\text { partnerships }\end{array}$ & Partners_F1 & $\mathbf{0 . 5 1 * * *}$ & -0.03 & $\mathbf{- 0 . 0 1}$ \\
& & & & \\
& Partners_F2 & -0.13 & -0.07 & -0.13 \\
Reasons for & OI_Inbound & $\mathbf{0 . 2 0 +}$ & -0.09 & -0.11 \\
partnership & OI_Outbound & 0.13 & -0.15 & -0.18 \\
& OI_Reasons & 0.04 & -0.02 & -0.02 \\
\hline \multirow{4}{*}{ Cultural } & Cult_Aspects_F1 & -0.11 & 0.06 & $\mathbf{- 0 . 1 9 +}$ \\
aspects & Cult_Aspects_F2 & $\mathbf{- 0 . 2 1 +}$ & 0.13 & 0.08 \\
& OI_Strategy & $\mathbf{0 . 3 5 *}$ & -0.19 & -0.12 \\
& OI_Maturity & $\mathbf{- 0 . 2 4 *}$ & -0.13 & -0.03 \\
\hline
\end{tabular}

p- values: $+\mathrm{p}<.1 * \mathrm{p}<.05 * * \mathrm{p}<.01 * * * \mathrm{p}<.001$ (highlighted in bold)

From the regressions summaries, only a few hypotheses can be accepted through the regressions, since most of them presented a p-value that do not reject the null hypothesis. The test of hypotheses is presented in Table 5.5.

Table 5.5 - Test of hypotheses for auto parts respondents

\begin{tabular}{lll}
\hline Hypothesis & Decision & Observation \\
\hline H1a & Rejected & No statistically significant correlations were found \\
\hline H1b & Rejected & No statistically significant correlations were found \\
\hline H1c & Rejected & No statistically significant correlations were found \\
\hline H1d & $\begin{array}{l}\text { Partially } \\
\text { accepted }\end{array}$ & A significant positive correlation was found between OI_Inbound, \\
\hline H1e & $\begin{array}{l}\text { Partially } \\
\text { accepted }\end{array}$ & There is a positive correlation between the variables OI_Maturity and \\
\hline H1f & $\begin{array}{l}\text { Partially } \\
\text { accepted }\end{array}$ & There is a positive correlation between the variables OI_Strategy, \\
\hline H2a & Rejected & No statistically significant correlations were found \\
\hline H2b & Rejected & No statistically significant correlations were found \\
\hline H3a & Rejected & No statistically significant correlations were found \\
\hline H3b & Rejected & No statistically significant correlations were found \\
\hline H3c & Partially & Barriers_F1 showed significant correlations with three out of four variables \\
in Cultural Aspects (positive with OI_Strategy and negative with \\
\hline
\end{tabular}

\subsection{ANALYSIS USING DATA FROM BOTH AUTOMAKERS AND AUTO PARTS MANUFACTURERS}

This section follows the same method as in sections 4.4 and 5.1. First, a correlation matrix is performed on the variables to assess whether a regression analysis is suited for the data. Correlations between variables among the same group of measures (highlighted in bold) are 
considered low ( $<0.3$ in all cases). This allows the analysis to move on to the regressions. In this iteration, all variables are being considered in the analysis, and the respondent's origin (as in, from automaker or auto parts companies) is used as a control variable. It should be noted that the variables used are the same as those obtained in Section 4, which only used the Automaker Companies dataset.

Variables in which the regression resulted in a significant p-value, which is taken to be less than 0.1 in this exploratory analysis, are highlighted in bold. Table 5.6Table 5.7, Table 5.8, and Table 5.9 present summaries of the regressions, grouped by the constructs outlined in Section 3.1, directly translating the three hypotheses enunciated (also in Section 3.1). The test of hypotheses is presented in Table 5.10.

Table 5.6 - Correlation matrix for variables used in regression model, with the complete dataset

\begin{tabular}{lccccccccccccccc}
\hline Description of variable & $\mathbf{( 1 )}$ & $\mathbf{( 2 )}$ & $\mathbf{( 3 )}$ & $\mathbf{( 4 )}$ & $\mathbf{( 5 )}$ & $\mathbf{( 6 )}$ & $\mathbf{( 7 )}$ & $\mathbf{( 8 )}$ & $\mathbf{( 9 )}$ & $\mathbf{( 1 0})$ & $\mathbf{( 1 1 )}$ & $\mathbf{( 1 2})$ & $\mathbf{( 1 3 )}$ & $\mathbf{( 1 4 )}$ & $\mathbf{( 1 5 )}$ \\
\hline OI_inbound (1) & 1 & - & - & - & - & - & - & - & - & - & - & - & - & - & - \\
OI_outbound (2) & .81 & 1 & - & - & - & - & - & - & - & - & - & - & - & - & - \\
OI_reasons (3) & .62 & .62 & 1 & - & - & - & - & - & - & - & - & - & - & - & - \\
\hline OI_maturity (4) & .31 & .26 & .36 & 1 & - & - & - & - & - & - & - & - & - & - & - \\
OI_strategy (5) & .18 & .16 & .40 & .51 & 1 & - & - & - & - & - & - & - & - & - & - \\
Cult_Change (6) & .18 & .12 & .16 & .53 & .46 & 1 & - & - & - & - & - & - & - & - & - \\
Cult_Aspects1 (7) & .27 & .17 & .26 & .44 & .48 & .60 & 1 & - & - & - & - & - & - & - & - \\
Cult_Aspects2 (8) & .17 & .18 & .04 & .07 & .04 & .28 & .10 & 1 & - & - & - & - & - & - & - \\
\hline Barriers_F1 (9) & .36 & .36 & .27 & -.09 & .05 & -.12 & -.12 & .03 & 1 & - & - & - & - & - & - \\
Barriers_F2 (10) & -.15 & -.25 & -.14 & -.26 & -.19 & -.03 & -.01 & -.08 & $\mathbf{- . 0 6}$ & 1 & - & - & - & - & - \\
Barriers_F3 (11) & -.08 & -.03 & .08 & -.05 & -.05 & .10 & -.18 & -.04 & $\mathbf{- . 0 2}$ & .07 & 1 & - & - & - & - \\
\hline PDP_Degree (12) & .26 & .34 & .23 & .37 & .42 & .36 & .26 & -.04 & .04 & -.15 & .04 & 1 & - & - & - \\
PDP_Adoption (13) & .33 & .25 & .31 & .40 & .56 & .65 & .54 & .29 & .01 & .08 & -.14 & .37 & 1 & - & - \\
\hline Partners_F1 (14) & .49 & .52 & .35 & .15 & .08 & .13 & .25 & -.02 & .45 & -.21 & -.18 & .16 & .28 & 1 & - \\
Partners_F2 (15) & .17 & .33 & .22 & .21 & .15 & .07 & .03 & .15 & .20 & -.31 & -.06 & .16 & .19 & $\mathbf{. 1 1}$ & $\mathbf{1}$ \\
\hline
\end{tabular}

Table 5.7 - OLS regressions correlations summary for hypothesis 1: OI Organizational Culture versus PDP Aspects (model 2) for the complete dataset

\begin{tabular}{cccc}
\hline & \multicolumn{2}{c}{ Independent Variable } \\
\hline Measure & $\begin{array}{c}\text { Dependent } \\
\text { Variable }\end{array}$ & PDP_Degree & PDP_Adoption \\
\hline $\begin{array}{c}\text { Most } \\
\text { important } \\
\text { partnerships }\end{array}$ & Partners_F1 & $\mathbf{0 . 1 5 +}$ & 0.08 \\
$\begin{array}{c}\text { Peasons for } \\
\text { partnership }\end{array}$ & OI_Inbound & 0.01 & 0.07 \\
\hline
\end{tabular}




$$
\text { OI_Reasons } \quad 0.00 \quad \mathbf{0 . 4 0}^{* * * *}
$$

\begin{tabular}{cccc}
\hline & Cult_Aspects_F1 & 0.11 & $\mathbf{0 . 3 5} * * *$ \\
Cultural & & & \\
aspects & Cult_Aspects_F2 & -0.06 & $\mathbf{0 . 3 5} * * *$ \\
& OI_Strategy & 0.13 & $\mathbf{0 . 6 0} * * *$ \\
& OI_Maturity & $\mathbf{0 . 2 1} *$ & $0.19^{*}$ \\
\hline
\end{tabular}

p- values: $+\mathrm{p}<.1 * \mathrm{p}<.05 * * \mathrm{p}<.01 * * * \mathrm{p}<.001$ (highlighted in bold)

Table 5.8 - OLS regressions correlations summary for hypothesis 2: PDP Aspects versus Barriers and risks (model 2) for the complete dataset

\begin{tabular}{ccccc}
\hline & \multicolumn{3}{c}{ Independent Variable } \\
\hline Measure & $\begin{array}{c}\text { Dependent } \\
\text { Variable }\end{array}$ & Barriers_F1 & Barriers_F2 & Barriers_F3 \\
\hline PDP & PDP_Adoption & 0.06 & -0.01 & -0.11 \\
Aspects & PDP_Degree_F1 & 0.00 & -0.06 & 0.10 \\
\hline
\end{tabular}

p- values: $+\mathrm{p}<.1 * \mathrm{p}<.05 * * \mathrm{p}<.01 * * * \mathrm{p}<.001$ (highlighted in bold)

Table 5.9 - OLS regressions correlations summary for hypothesis 3: OI Organizational Culture versus Barriers and risks (model 2) for the complete dataset

\begin{tabular}{|c|c|c|c|c|}
\hline \multirow[b]{2}{*}{ Measure } & \multirow[b]{2}{*}{$\begin{array}{c}\text { Dependent } \\
\text { Variable }\end{array}$} & \multicolumn{3}{|c|}{ Independent Variable } \\
\hline & & Barriers_F1 & Barriers_F2 & Barriers_F3 \\
\hline \multirow{2}{*}{$\begin{array}{c}\text { Most } \\
\text { important } \\
\text { partnerships }\end{array}$} & Partners_F1 & $0.45 * * *$ & -0.06 & $-0.18+$ \\
\hline & Partners_F2 & 0.06 & $-0.26 * *$ & -0.03 \\
\hline \multirow{3}{*}{$\begin{array}{l}\text { Reasons for } \\
\text { partnership }\end{array}$} & OI_Inbound & 0.20 & -0.03 & $-0.19 *$ \\
\hline & OI_Outbound & 0.11 & -0.11 & $-0.22 *$ \\
\hline & OI_Reasons & 0.11 & 0.01 & -0.09 \\
\hline \multirow{4}{*}{$\begin{array}{l}\text { Cultural } \\
\text { aspects }\end{array}$} & Cult_Aspects_F1 & -0.03 & -0.03 & $-0.18 *$ \\
\hline & Cult_Aspects_F2 & 0.19* & $-0.16+$ & 0.05 \\
\hline & OI_Strategy & $0.29 * *$ & -0.12 & $-' 0.10$ \\
\hline & OI_Maturity & -0.08 & $-0.21 * *$ & 0 \\
\hline
\end{tabular}

p- values: $+\mathrm{p}<.1 * \mathrm{p}<.05 * * \mathrm{p}<.01 * * * \mathrm{p}<.001$ (highlighted in bold)

Table 5.10 - Test of hypotheses for the complete dataset

\begin{tabular}{lll}
\hline Hypothesis & Decision & \multicolumn{1}{c}{ Observation } \\
\hline H1a & Rejected & No statistically significant correlations were found \\
\hline H1b & Rejected & No statistically significant correlations were found \\
\cline { 2 - 3 }
\end{tabular}




\begin{tabular}{lll}
\hline H1c & Rejected & No statistically significant correlations were found \\
\hline H1d & Accepted & Significant positive correlation found between all concerning variables \\
\hline H1e & $\begin{array}{l}\text { Partially } \\
\text { accepted }\end{array}$ & $\begin{array}{l}\text { There is a positive correlation between the variables OI_Maturity and } \\
\text { PDP_Degree, which is one out of five variables from this measure }\end{array}$ \\
\hline H1f & Accepted & Significant positive correlation found between all concerning variables \\
\hline H2a & Rejected & No statistically significant correlations were found \\
\hline H2b & Rejected & No statistically significant correlations were found \\
\hline H3a & Rejected & $\begin{array}{l}\text { Positive correlation found between variables Barriers_F1 and } \\
\text { Partners_F1, but negative correlation found in other variables }\end{array}$ \\
\hline H3b & Rejected & No statistically significant correlations were found \\
\hline H3c & Rejected & $\begin{array}{l}\text { Statistically significant correlations found among a few measures, but not } \\
\text { consistently among all variables }\end{array}$ \\
\hline
\end{tabular}

\subsection{DISCUSSION ON THE RESULTS OF THE REGRESSIONS}

So far, this study has conducted three different sets of analysis: one using only data from automaker respondents, one using data from auto parts respondents, and one combining both and using that information as a control variable. For each set, the hypotheses presented in Chapter 3 were tested, and the results among the three sets were somewhat consistent. For convenience purposes, Table 5.11 groups the results of Table 4.14, Table 5.5, and Table 5.10.

Table 5.11 - Comparison between the hypothesis test between each set of data

\begin{tabular}{lccc}
\hline Hypothesis & Automakers & Auto parts & $\begin{array}{c}\text { Complete } \\
\text { dataset }\end{array}$ \\
\hline H1a & Rejected & Rejected & Rejected \\
\hline H1b & Partially accepted & Rejected & Rejected \\
\hline H1c & Rejected & Rejected & Rejected \\
\hline H1d & Accepted & $\begin{array}{l}\text { Partially } \\
\text { accepted }\end{array}$ & Accepted \\
\hline H1e & Partially accepted & $\begin{array}{l}\text { Partially } \\
\text { accepted }\end{array}$ & $\begin{array}{c}\text { Partially } \\
\text { accepted }\end{array}$ \\
\hline H1f & Accepted & $\begin{array}{l}\text { Partially } \\
\text { accepted }\end{array}$ & Accepted \\
\hline H2a & Partially accepted & Rejected & Rejected \\
\hline H2b & Rejected & Rejected & Rejected \\
\hline H3a & $\begin{array}{c}\text { Contradictory } \\
\text { regressions }\end{array}$ & Rejected & Rejected \\
\hline H3b & $\begin{array}{c}\text { Contradictory } \\
\text { regressions }\end{array}$ & Rejected & Rejected \\
\hline H3c & $\begin{array}{c}\text { Contradictory } \\
\text { regressions }\end{array}$ & $\begin{array}{l}\text { Partially } \\
\text { accepted }\end{array}$ & Rejected \\
\hline
\end{tabular}

Most hypothesis could not be properly validated, since the regressions performed did not reject the null hypothesis. Regarding the rejected hypotheses, not much else can be said - at least not using such a quantitative analysis and without running into the risk of severe overfitting by 
manipulating the variables again. Interpretative analyses of the results, as performed in Section 4.1 and 4.2, provide some insight, at least to the extent of the researcher's knowledge, on each of the measures presented. For future works regarding this subject, one perhaps should focus on a more intensive case study approach.

However, for all three data sets, hypotheses H1d, H1e and H1f were partially or completely accepted through the chosen criteria.

Hypothesis H1d relates the measure Reasons for partnership with Adoption to newer PDP methods. Recalling that the measure Reasons for partnerships considered questions B1, B2 and B5 from the survey (from Section 3.2), this measure mostly asks the respondent to rank how important his company considers each of the open innovation practices, both inbound and outbound, as well as ranking the importance of practicing open innovation (as in, what could be gained for his company). This, in turn, has a positive relationship with Adoption to newer PDP methods, in which the survey question asks from the respondents how much of the product development process of his company has changed/evolved in the past few years, especially considering new tools or techniques. It also asks the respondent how much of that change they believe to have been caused by or influenced by open innovation.

Hypotheses H1e and H1f relates the measure of Cultural Aspects to the Degree of Innovation and Adoption of newer PDP methods measures, respectively. The cultural aspects measure asks respondents to assess changes in open innovation culture that their company might have experienced in the past few years, as well as asking respondents to assess characteristics of management and employees that can improve the adoption of open innovation engagements (i.e. the company has an environment that favors open innovation practices). The results found in the analyses performed in this study do suggest a positive relationship between having a corporate culture that favors open innovation practices and evolving their PDP to adopt newer methodologies, as well as having a bigger focus on radical innovation. 


\section{CONCLUSIONS}

This research proposed to analyze and compare how open innovations happen in the product development processes. With a survey, data was gathered from 139 professionals working in the Brazilian automotive industry, 65 to Brazilian automakers and 74 to Brazilian auto parts manufacturers. Three different constructs were analyzed: the organizational culture surrounding open innovation, barriers and risks to implementation of open innovation, and the characteristics of PDP.

Analysis was divided in two main sections: qualitative and descriptive analysis, as well as quantitative analysis using principal components factors and regressions.

Descriptive data suggests that inbound practices were more present than outbound practices, with a strong presence of the supplier in the design process (and not so much of a client presence). This suggestion corroborates the open innovation "journey", mentioned in the literature review. The most important practices mentioned were, besides the acquisition of R\&D services, mostly management techniques and tools used with product development, that do not change the product development process in a substantial way. More costly activities, such as the purchase of patents and licenses, as well as the acquisition of startup companies, were considered the least important for the respondents. In other words, most of the observed open innovation activities in the automotive industry consist of a close supplier-automaker relationship, and not of the more novel activities that cemented the definition of 'open innovation' as a concept separate from the closed model of innovation.

Partners in open innovation partners seem to be considered most important when enabling key capabilities or knowledge to the local subsidiaries, giving the impression of their dependency on the headquarters and with their key suppliers in order to develop new products faster and cheaper.

Respondents also seem to believe there is a disconnection in corporate culture and the local culture in respect to open innovation, with a lack of clarity in their company's open innovation strategy, culminating in a lack of resources, tools and knowledge hindering the implementation of new OI projects.

Quantitative analysis using principal components factors and statistical regressions abled the test of hypotheses. These analyses were done on three sets of data: one using only data from 
automaker respondents, one using data from auto parts respondents, and one combining both and using that information as a control variable. Due to the exploratory nature of the research, most of the hypotheses could not be fully verified. However, three hypotheses were consistently validated in all three datasets. The first accepted hypothesis relates the measures of Reasons for partnership with Adoption to newer PDP methods. The second and third accepted hypotheses relate measure Cultural Aspects to Degree of Innovation and Adoption of newer PDP methods measures, respectively.

Accepted hypotheses could be evidence that adoption of newer product development methodologies and technologies could lead to a more "open" design process, which also includes a stronger innovation network and to perceive more value in open innovation itself.

The methods chosen in this study carry with themselves plenty of limitations. For one, there is the limitation of, even though each interviewee was picked based on his position on the company, assuming that the interviewee does in fact represent his company. Still, the sample size presented a significant experience in the industry (over 17 years on average). Not only that, but the way that the survey has been applied, with an individualized token for each possible respondent, assure the researchers that only people that fit the proposed criteria (engineers and managers in product development within automotive companies) answered the survey, and each answer can be traced back to its token, providing a much more reliable (than an otherwise generally applied online survey) dataset.

Another limitation was the sample size chosen. Even with considerable effort to track and get 65 valid answers from automakers and another 74 from auto parts manufacturers, a quantitative study like the one performed could definitely benefit from more answers. Not only that, but the survey was initially only applied to the Brazilian automotive industry. Future work could be done comparing results between countries or between industries.

On the subject of future work related to this research, in the interest of offering a full panorama of the Brazilian automotive industry, perhaps a more appropriate research method should consist of more granular data (instead of a few dozen responses from professionals from the industry). For that, an approach based on machine learning through data available through transparency organizations could be a useful approach.

Considering the results found, especially concerning the qualitative data, the researchers of this study believe that the direction that the Brazilian automotive industry is currently heading might 
be too slow to catch up with the rapid advancements that the global industry has seen in the last few years. Open innovation might be a tool to aid in this catching up. Partnership with local startups might provide capabilities not found within the multinational enterprises, boosting the Brazilian industry in ways not possible without considering external sources of innovation. As has been mentioned in this study, Brazil has employed public policies that tried to favor innovation throughout the past three decades. Perhaps it might be in the interest of both the Brazilian government and its automotive industry to use open innovation as a tool in new public policies. 


\section{REFERENCES}

ANFAVEA. (2019). Brazilian Automotive Industry Yearbook 2019 (Vol. 129). São Paulo: ANFAVEA - Brazilian Automotive Industry Association.

Armellini, F. (2013). Patterns of open innovation within product development: a comparative study between Brazilian and Canadian aerospace industries. Escola Politécnica, Universidade de São Paulo, São Paulo. https://doi.org/10.11606/T.3.2013.tde-10072013112917

Armellini, F., Beaudry, C., \& Kaminski, P. C. (2016). Open within a box : an analysis of open innovation patterns within Canadian aerospace companies. Sinergie, 34(101), 15-36. https://doi.org/10.7433/s101.2016.02

Armellini, F., Kaminski, P. C., \& Beaudry, C. (2014). The open innovation journey in emerging economies: An analysis of the Brazilian aerospace industry. Journal of Aerospace Technology and Management, 6(4), 462-474. https://doi.org/10.5028/jatm.v6i4.390

Asimow, M. (1962). Introduction to Design. Upper Saddle River, NJ, United States: PrenticeHall.

Balcet, G., \& Consoni, F. L. (2007). Global technology and Knowledge Management: Product development in Brazilian car industry. International Journal of Automotive Technology and Management, 7(2-3), 135-152. https://doi.org/10.1504/IJATM.2007.014971

Baraldi, E. C., \& Kaminski, P. C. (2018). Reference model for the implementation of new assembly processes in the automotive sector. Cogent Engineering, 5(1), 1-27. https://doi.org/10.1080/23311916.2018.1482984

Blankesteijn, M., De Jong, F., \& Bossink, B. (2019). Closed-open innovation strategy for autonomous vehicle development. International Journal of Automotive Technology and Management, 19(1-2), 74-103. https://doi.org/10.1504/IJATM.2019.098507

Bogers, M., Chesbrough, H., \& Moedas, C. (2018). Open innovation: Research, practices, and policies. California Management Review, 60(2), 5-16. https://doi.org/10.1177/0008125617745086

Brown, S. L., \& Eisenhardt, K. M. (1995). Product development: Past research, present 
findings, future directions. The Academy of Management Review, 20, 343-378.

Canuto da Silva, G., \& Kaminski, P. C. (2016). Selection of virtual and physical prototypes in the product development process. The International Journal of Advanced Manufacturing Technology, 84(5-8), 1513-1530. https://doi.org/10.1007/s00170-015-7762-2

Canuto da Silva, G., \& Kaminski, P. C. (2017). Proposal of framework to managing the automotive product development process. Cogent Engineering, 4(1), 1-25. https://doi.org/10.1080/23311916.2017.1317318

Chesbrough, H., \& Bogers, M. (2014). Explicating Open Innovation: Clarifying an Emerging Paradigm for Understanding Innovation Keywords. New Frontiers in Open Innovation, 137. https://doi.org/10.1093/acprof

Chesbrough, H. W. (2003). Open Innovation: The New Imperative for Creating and Profiting from Technology. Boston, Massachusetts: Harvard Business School Press.

Chesbrough, H. W., \& Appleyard, M. M. (2007). Open Innovation and Strategy. California Management Review, 50(1), 57-76. https://doi.org/10.1016/j.jbiosc.2010.11.012

Chesbrough, Vanhaverbeke, W., \& West, J. (2006). Open Innovation: Researching a New Paradigm. Oxford: Oxford University Press.

Chiaroni, D., Chiesa, V., \& Frattini, F. (2011). The Open Innovation Journey: How firms dynamically implement the emerging innovation management paradigm. Technovation, 31(1), 34-43. https://doi.org/10.1016/j.technovation.2009.08.007

Clark, K. B., \& Fujimoto, T. (1991). Product development performance: strategy, organization and management in the world auto industry. Harvard Business School Press.

Clark, K. B., \& Wheelwright, S. C. (1993). Managing New Product and Process Development. New York: Free Press.

Cooper, R. G. (1990). Stage-gate systems: A new tool for managing new products. Business Horizons, 33(3), 44-54. https://doi.org/10.1016/0007-6813(90)90040-I

Cooper, R. G., Edgett, S. J., \& Kleinschmidt, E. J. (2001). Portfolio Management for New Products (2nd editio). Basic Books. 
Dahlander, L., \& Gann, D. M. (2010). How open is innovation? Research Policy, 39(6), 699709. https://doi.org/10.1016/j.respol.2010.01.013

Dias, A. V. C., Galina, S. V. R., \& Silva, F. D. A. (1999). Análise Contemporânea da Cadeia Produtiva do Setor Automobilístico: Aspectos relativos à Capacitação Tecnológica. In XIX Encontro Nacional de Engenharia de Produção (p. 17). Rio de Janeiro.

Dieter, G. E., \& Schmidt, L. C. (2009). Engineering Design (4th ed.). New York: McGrawHill.

Evans, J. H. (1959). Basic Design Concepts. Journal of the American Society for Naval Engineers, 71(4), 671-678. https://doi.org/10.1111/j.1559-3584.1959.tb01836.x

Gassmann, O., Enkel, E., \& Chesbrough, H. W. (2010). The Future of Open Innovation. R\&D Management. R\&D Management, 1-9. https://doi.org/10.1016/j.lrp.2009.07.010

Gondim, I. J. C., Borini, F. M., \& Carneiro-Da-Cunha, J. A. (2017). Tax burden on open innovation: The case of the automotive industry in Brazil. International Journal of Automotive Technology and Management, 17(3), 248-269. https://doi.org/10.1504/IJATM.2017.086409

Government, F. Law no. 13755, December 10th 2018 (2018). Brasília.

Ibusuki, U., Bernardes, R. C., \& Consoni, F. L. (2015). New Brazilian automotive industrial policy: analysis of the consequences for local R\&D based on new comer's strategies. International Journal of Automotive Technology and Management, 15(1), 63-79. https://doi.org/10.1504/IJATM.2015.067092

Ibusuki, U., Kobayashi, H., \& Kaminski, P. C. (2012). Localisation of product development based on competitive advantage of location and government policies: A case study of car makers in Brazil. International Journal of Automotive Technology and Management, 12(2), 172-196. https://doi.org/10.1504/IJATM.2012.046861

Ili, S., Albers, A., \& Miller, S. (2010). Open innovation in the automotive industry. $R \& D$ Management, 40(3), 246-255. https://doi.org/10.1111/j.1467-9310.2010.00595.x

Jugend, D., Jabbour, C. J. C., Alves Scaliza, J. A., Rocha, R. S., Junior, J. A. G., Latan, H., \& Salgado, M. H. (2018). Relationships among open innovation, innovative performance, 
government support and firm size: Comparing Brazilian firms embracing different levels of radicalism in innovation. Technovation, 74-75(March), 54-65. https://doi.org/10.1016/j.technovation.2018.02.004

Kaminski, P. C. (2000). Desenvolvendo Produtos com Planejamento, Criatividade e Qualidade. São Paulo: Livros Técnicos e Científicos SA.

Karlsson, C., \& Sköld, M. (2013). Forms of innovation openness in global automotive groups. International Journal of Automotive Technology and Management, 13(1), 1-17. https://doi.org/10.1504/IJATM.2013.052776

Krishnan, V., \& Ulrich, K. T. (2001). Product Development Decisions: A Review of the Literature. Management Science, 47(1), 1-21. https://doi.org/10.1287/mnsc.47.1.1.10668

Liyanage, S., Greenfield, P. F., \& Don, R. (1999). Towards a fourth generation R\&D management model-research networks in knowledge management. International Journal of Technology Management, 18(3/4), 372. https://doi.org/10.1504/IJTM.1999.002770

MacNeill, S., \& Bailey, D. (2010). Changing policies for the automotive industry in an 'old' industrial region: an open innovation model for the UK West Midlands? International Journal of Automotive Technology and Management, 10(2-3), 128-144. https://doi.org/10.1504/IJATM.2010.03262

Marin, R. O., \& Kaminski, P. C. (2018). Analysing open innovation integration to product development processes within the Brazilian automotive industry. In DESIGN 2018 (pp. 1915-1924). Dubrovnik, Croatia. https://doi.org/10.21278/idc.2018.0462

Marin, R. O., Kaminski, P. C., \& Armellini, F. (2018). Open innovation practices in the automotive industry: an exploratory comparison between Brazil and France. In $S A E$ Technical Paper. SAE International. https://doi.org/10.4271/2018-36-0210

Martins, M. B., \& Kaminski, P. C. (2019). Differences in open innovation practices between headquarters and subsidiaries in the automotive industry: The French case. Cogent Engineering, 6(1), 1-21. https://doi.org/10.1080/23311916.2019.1684806

Massis, A. De, Lazzarotti, V., Pizzurno, E., \& Salzillo, E. (2012). Open Innovation in the Automotive Industry: A Multiple Case-Study. In Management of Technological 
Innovation in Developing and Developed Countries (Vol. 40, pp. 246-255). InTech. https://doi.org/10.5772/34092

Mello, A. M. de, Marx, R., \& Motta, F. G. (2016). A preliminary analysis of Inovar Auto impact on the Brazilian Automotive Industry R\&D activity. RAI Revista de Administração e Inovação, 13(1), 22-28. https://doi.org/10.1016/j.rai.2016.02.001

OECD. (2002). Frascati Manual: Proposed Standard Practice for Surveys on Research and Experimental Development. The Measurement of Scientific and Technological Activities (Vol. 6th). https://doi.org/10.1787/9789264199040-en

OECD. (2008). Open Innovation in Global Networks. OECD Publishing. OECD Publishing. https://doi.org/10.1787/9789264047693-en

Oliveira, A. C. de, \& Kaminski, P. C. (2012). A reference model to determine the degree of maturity in the product development process of industrial SMEs. Technovation, 32(12), 671-680. https://doi.org/10.1016/j.technovation.2012.08.001

Omar, M. A. (2011). The Automotive Body Manufacturing Systems and Processes. Chichester, UK: John Wiley \& Sons, Ltd. https://doi.org/10.1002/9781119990888

Parente, R. C., \& Geleilate, J. M. G. (2016). Developing new products in the automotive industry: Exploring the interplay between process clockspeed and supply chain integration. Industrial and Corporate Change, 25(3), 507-521. https://doi.org/10.1093/icc/dtv039

Rozenfeld, H., Forcellini, F. A., Amaral, D. C., Toledo, J. C. de, Silva, S. L. da, Alliprandini, D. H., \& Scalice, K. R. (2006). Gestão de Desenvolvimento de Produtos - uma referência para a melhoria do processo. São Paulo: Saraiva.

Suh, N. P. (2001). Axiomatic Design: advances and applications. Oxford: Oxford University Press.

Theoto, T. N., \& Kaminski, P. C. (2019). A country-specific evaluation on the feasibility of autonomous vehicles. Product Management \& Development, 17(2), 123-133. https://doi.org/10.4322/pmd.2019.013

Vrande, V. van de, Jong, J. P. J. de, Vanhaverbeke, W., \& de Rochemont, M. (2009). Open 
innovation in SMEs: Trends, motives and management challenges. Technovation, 29(67), 423-437. https://doi.org/10.1016/j.technovation.2008.10.001

Walsh, J. P., Lee, Y. N., \& Nagaoka, S. (2016). Openness and innovation in the US: Collaboration form, idea generation and implementation. Research Policy, 45(8), 16601671. https://doi.org/10.1016/j.respol.2016.04.013

Weber, J. (2009). Automotive Development Processes. Berlin, Heidelberg: Springer Berlin Heidelberg. https://doi.org/10.1007/978-3-642-01253-2

West, J., \& Bogers, M. (2014). Leveraging External Sources of Innovation: A Review of Research on Open Innovation. Journal of Product Innovation Management, 31(4), 814831. https://doi.org/10.1111/jpim.12125

Wittmann, J. (2017). Electrification and Digitalization as Disruptive Trends: New Perspectives for the Automotive Industry? In Phantom Ex Machina (pp. 137-159). Cham: Springer International Publishing. https://doi.org/10.1007/978-3-319-44468-0_9

Womack, J. P., Jones, D. T., \& Roos, D. (1990). The Machine that Changed the World. New York: Free Press.

Wynn, D. C., \& Clarkson, P. J. (2018). Process models in design and development. Research in Engineering Design, 29(2), 161-202. https://doi.org/10.1007/s00163-017-0262-7 
APPENDIX A: QUESTIONNAIRE 


\section{Section A: General Information}

In this survey:

- The plant/unit corresponds to your operations unit, the site where you work.

- The company corresponds to the company as a whole, i.e. all units, global.

A1. In 2016, what was the number of full-time employees:

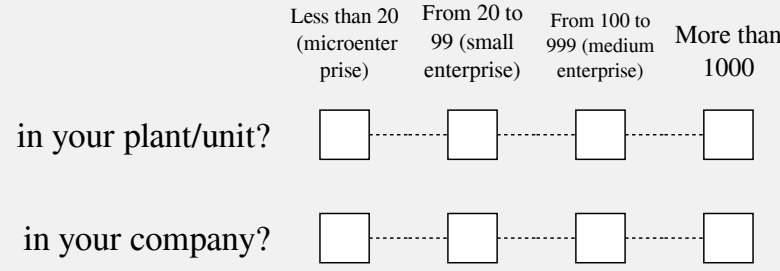

A2. Does your company:

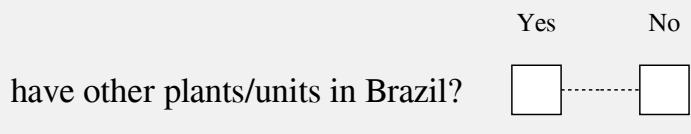

have other plants/units outside Brazil?

conduct research in Brazil?

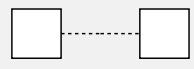

conduct development in Brazil?

conduct reseach outside Brazil?

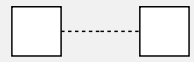

conduct development outside Brazil?

A3. Which of the following activities are currently performed by your plant/unit?

Administrative Services

Research

Development of Products, Services and Processes

Production

Marketing/Sales

Distribution

After-sales Service and Support 
Other

Other

A4. How would you categorize your company in regard to its business segment?

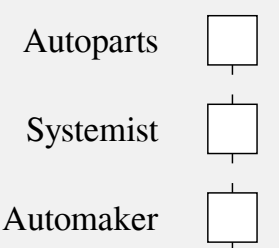

Services provider (technical consulting, product development, design, etc.)

A5. For your plant/unit, indicate the degree of change observed in 2015-2016, compared to 2013-2014, in the following:

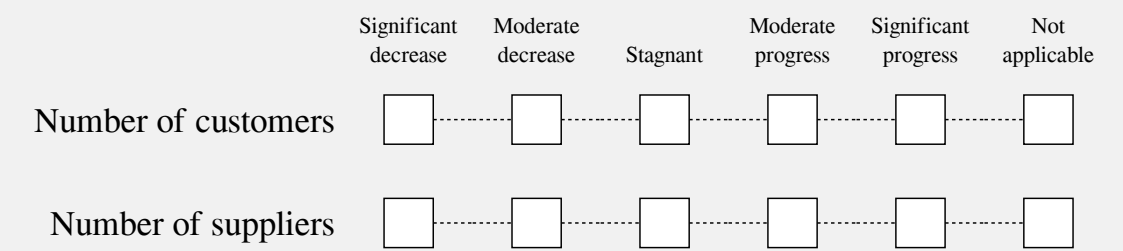

Number of full-time employees

Number of ongoing product/service development

projects
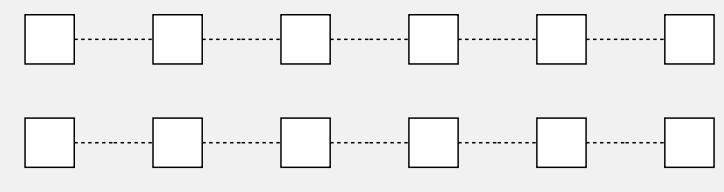

Number of partners in product/service development

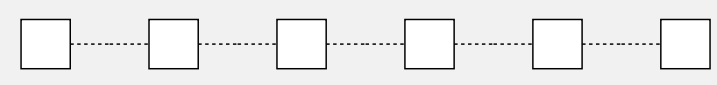

Revenue

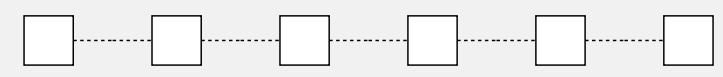

A6. For your plant/unit, indicate the frequency of change in the following external environmental factors:

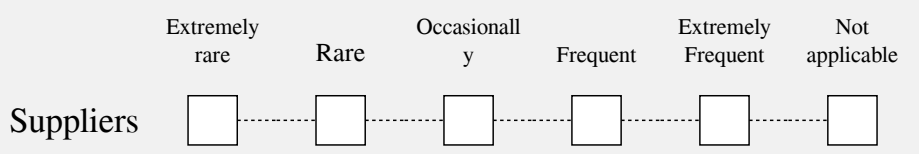

Distributors of your products or services

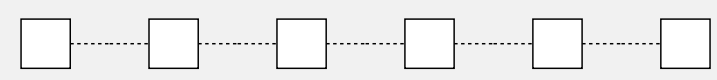

Users of your products or services

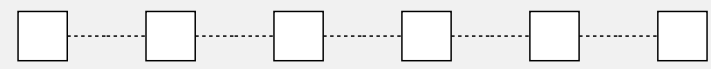

Your competitors

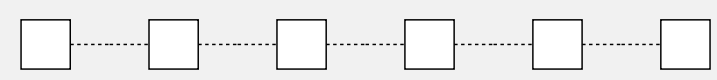

Government regulation in your industry

Development of new or improved production methods in

your industry (automotive)

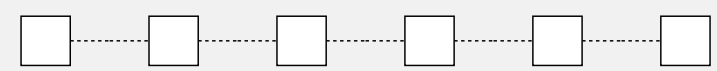


Development of new or improved products or services in your industry (automotive)

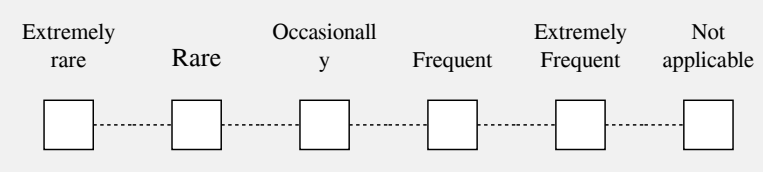

A7. What percentage of your plant's/unit's revenue is represented by activities related to the automotive industry?

\section{$0-20 \%$}

$20-40 \%$

$40-60 \%$

$60-80 \%$

$80-100 \%$

A8. Does your plant/unit have a department or division dedicated to the automotive industry?

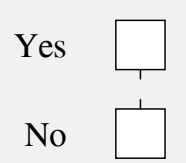

A9. How would you characterize the targeting of the products offered to your unit's/plant's clients?

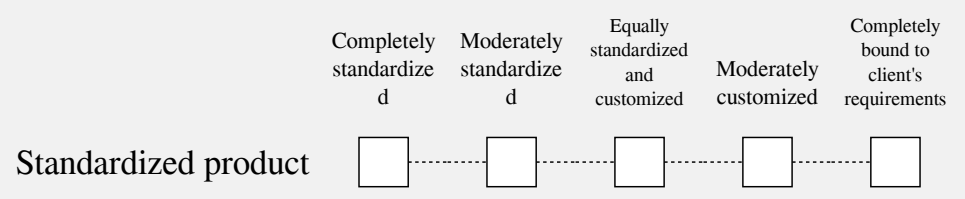

\section{Section B: Open Innovation Practices}

For this section, the term INNOVATION is defined as: "the development and implementation in the market of new or improved products, services or processes".

Open innovation is defined by Chesbrough et al. (2006) as "the purposive use of inflows and outflows of knowledge to accelerate innovation in one's own market, and expand the use of internal knowledge in external markets, respectively".

Open innovation, then, refers to modes of innovation based on sharing or collaboration. This can include sharing knowledge to find solutions for complex problems, or sharing the risks, uncertanties and investiments required for a project.

\section{B1. For your plant/unit, indicate the level of importance of each of the} following tool/activities among your inbound open innovation practices:

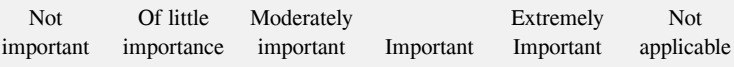

Purchase of R\&D services

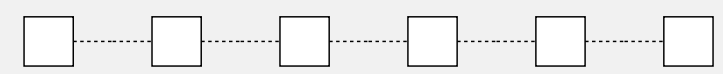

"Active" monitoring of technologies with advanced tools (surveillance of other companies/industries focusing on what is important and strategic to the company)

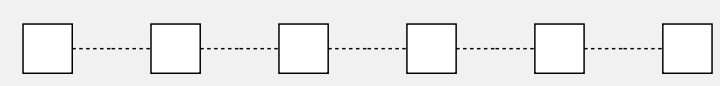


Collective intelligence (benchmarking, making different people think together) to gather or test ideas, products, concepts, etc.

Purchase of licenses/patents

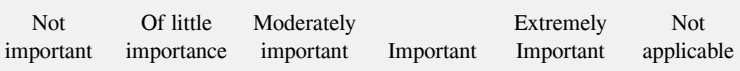
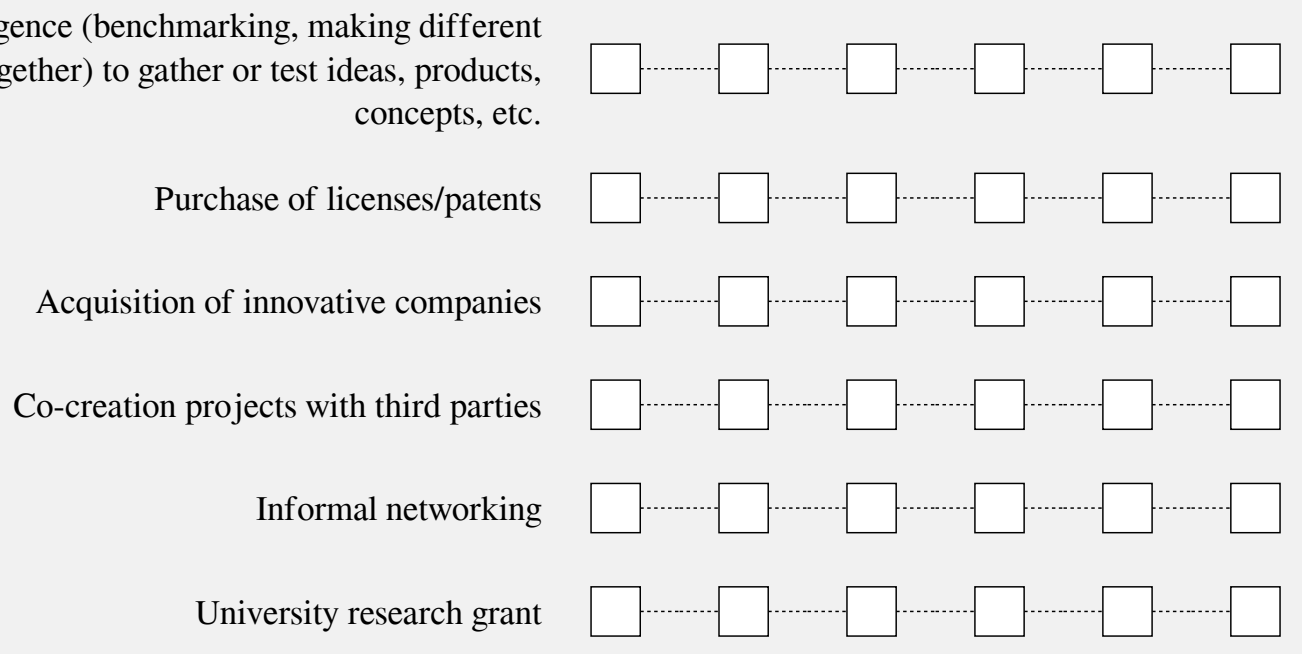

B2. For your plant/unit, indicate the level of importance of each of the following tool/activities among your outbound open innovation practices:

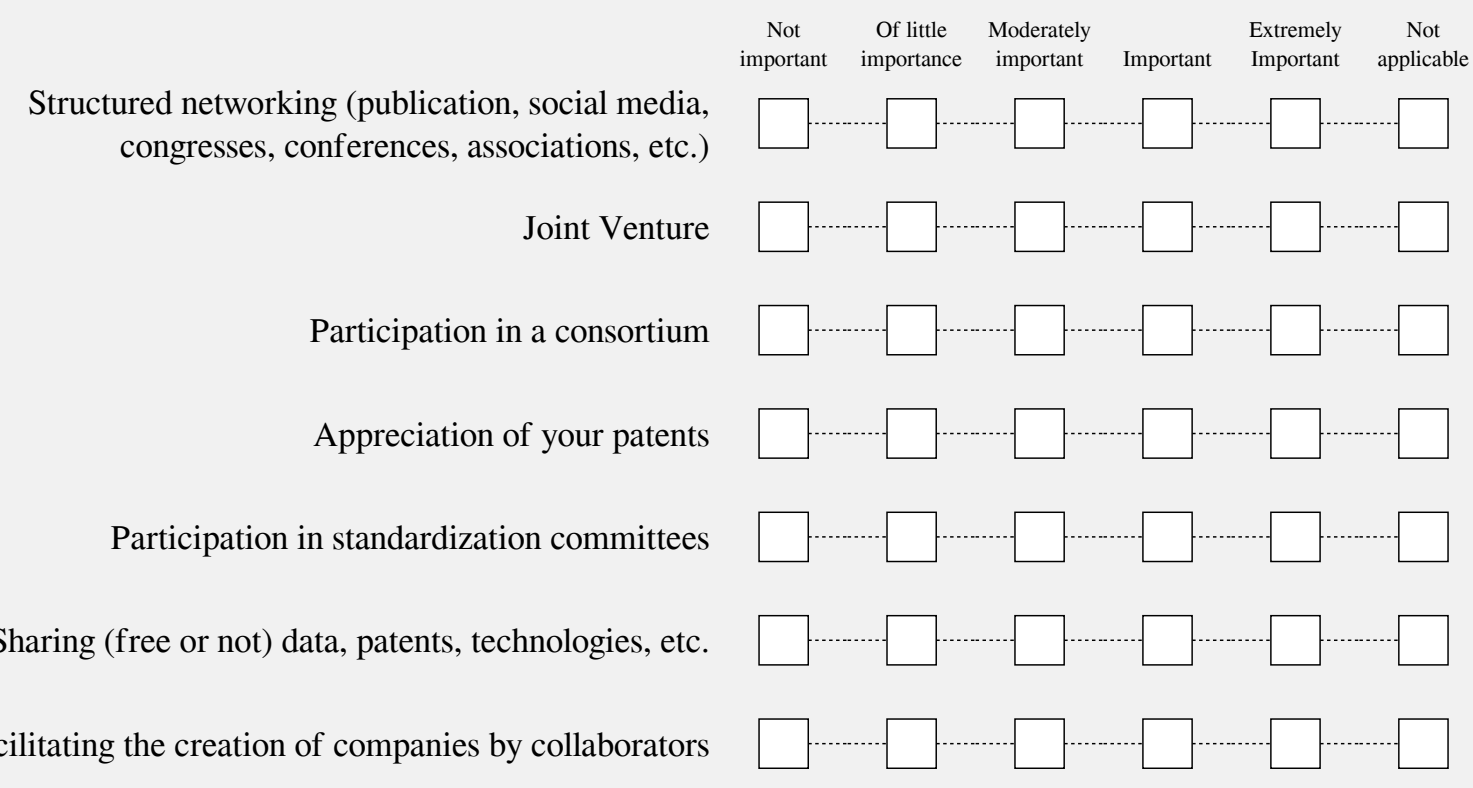

B3. Based on the definition described in the beginning of this section, how long has your plant/unit been engaging in open innovation practices?

Not yet

Less than 2 years

From 2 to 5 years

From 5 to 10 years

For more than 10 years

Participation in open innovation practices have stopped 
B4. What importance does open innovation have in your plant's/unit's innovation strategy?

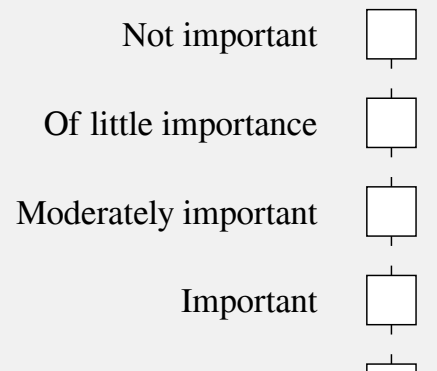

Extremely Important

B5. What degree of maturity in open innovation stages best corresponds to your plant's/unit's current practice?

Introduction (willingness shown but few facts, local experiments)

Development (large-scale internal learning and promotion, heterogeneous practices and convictions)

Essential (structured management method and tools, generalization in progress, open innovation at the heart of strategy and practices)

B6. Indicate the degree of importance of the following reasons for practicing open innovation:

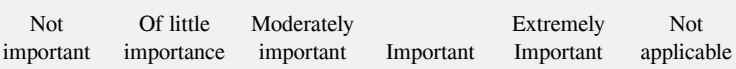

To valorize its intellectual property and patents

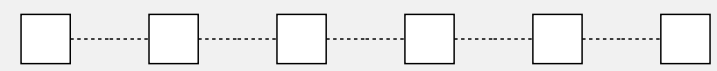

To reduce $R \& D$ costs

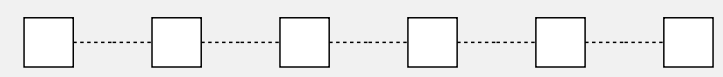

To share or reduce the risks and uncertainties of a complex project

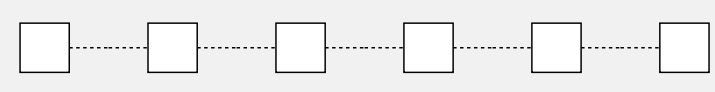

To have access to new scientific knowledge, new technologies or a new know-how

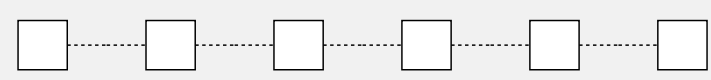

To accelerate the time-to-market of a product or service

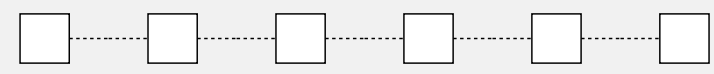

To access incentives (tax credits, subsidies, grants, etc.)

B7. Considering since 2014, indicate the extent to which you agree with each of the following statements regarding open innovation for your plant/unit:

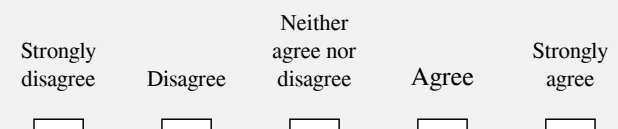

The open innovation culture has developed

The number of open innovation project has increased

Employees have progressed in their abilities to absorb external information, knowledge or technology

The open innovation strategy has become clearer, better understood and has been clarified

The open innovation processes have grown in maturity
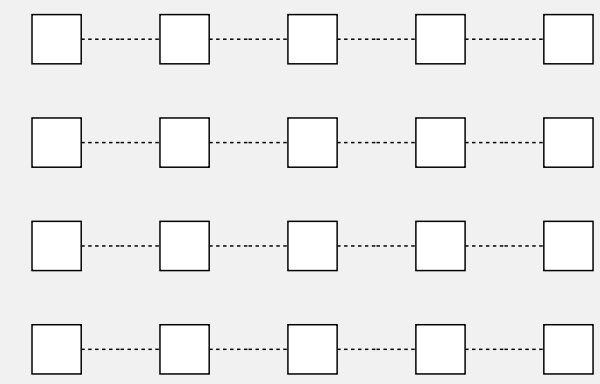
This plant/unit dedicates resources to open innovation

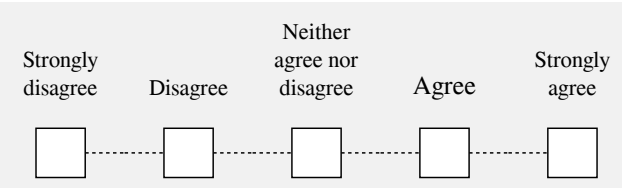

B8. What percentage of your plant's/unit's revenue is dedicated to:

innovation?

from this percentage in innovation, how much of it is in open innovation (100\% meaning that all innovation done in this plant/unit is open innovation)?

\section{Section C: Innovation and Product Development}

The Product Development Process (PDP) is defined by Kaminski (2000) as: "the group of activities, concerning almost all departments of a company, that have the purpose of transforming market necessities into economically viable products or services".

For this section, the term Product Development Process (PDP) refers to the organizational process of developing new products, services or processes.

\section{C1. With respect to product (and/or services and processes) development} in your plant/unit, especially since 2014, indicate the extent to which you agree with each of the following statements:

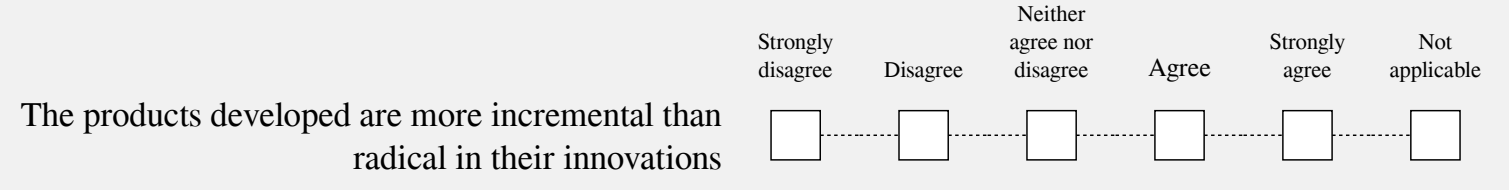

The products are developed based on informations from prior projects/products

Products are being developed to new target markets

The products developed necessitated the development of a new platform and/or new business models

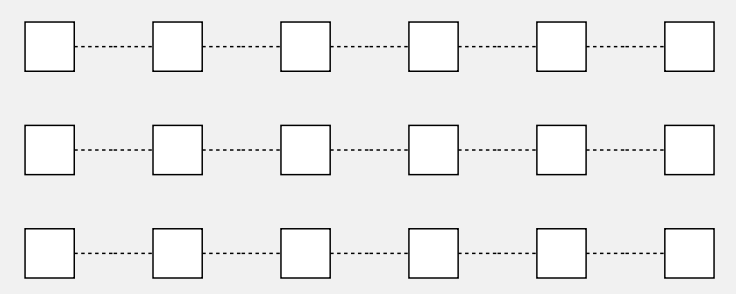

C2. With respect to Product Development Processes (PDP) in your plant/unit:

The way PDP is done has changed since 2014

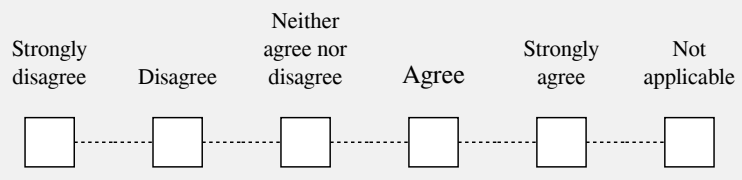

Open innovation has influenced the way PDP is done

Open innovation is responsible for the improvement of existing and implemented PDP methods or tools in your plant/unit

Open innovation is responsible for the adoption of new PDP methods or tools (scrum, agile) in your plant/unit
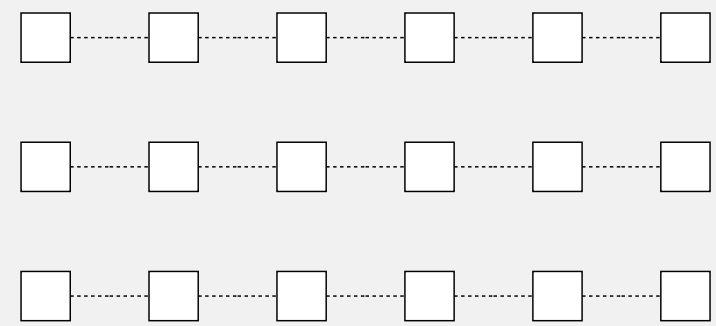


\section{Section D: Your Plant's/Unit's Organizational Culture}

\section{D1. Indicate the extent to which you agree with each of the following statements regarding your plant/unit:}

We would rather develop a new technology ourselves than purchase it or rely on the cooperation of our vendor

Even without using external technologies, we can reach our market with success

The use of external technologies is less attractive to our plant/unit, as we could reveal our technical knowledge to our partner

The use of external technologies is an important way of introducing new technologies to our plant/unit

In order to keep our competitive advantage, technologies that are important to our plant/unit must not me outsourced

Relevant technologies for our plant/unit cannot be developed efficiently and effectively by another company

Management seems to prefer technologies developed internally

Management urges us to find and use external technologies

Management encourages departments and employees to exchange information (both within your plant/unit and among other plants/units of the company)
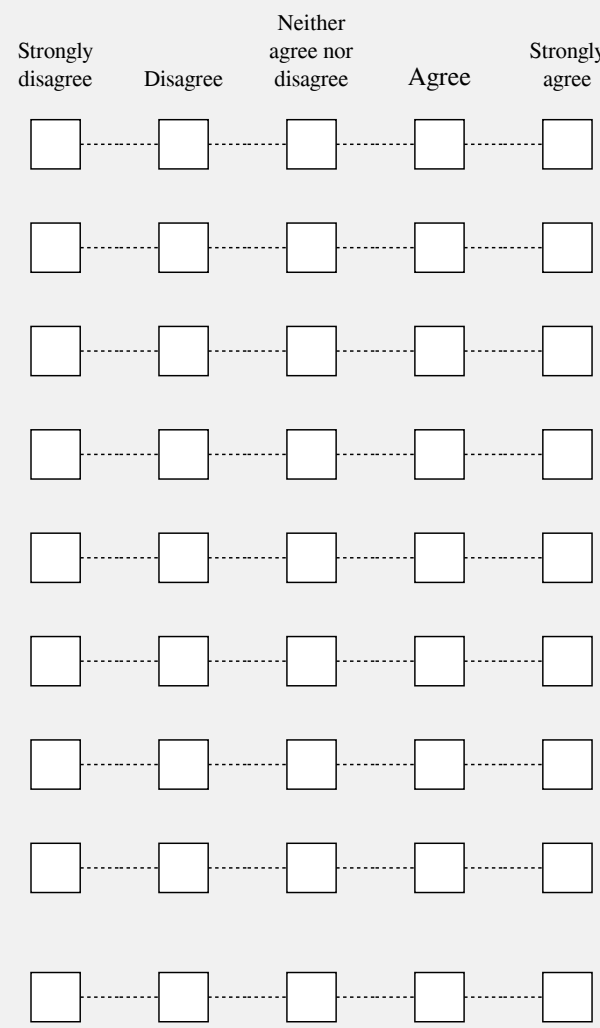

D2. Indicate the extent to which you agree with each of the following statements regarding your plant/unit:

We run the risk of losing control of our technology if we license it to third parties

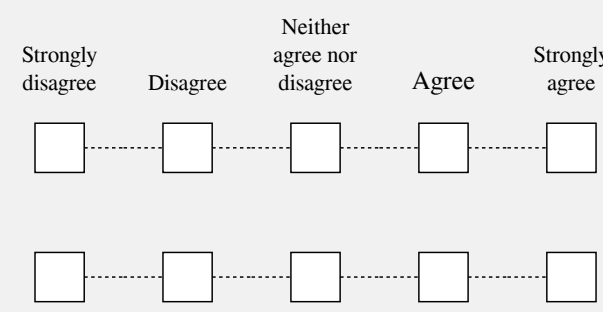

Our innovations should be brought onto the market by our unit/company instead of through alliances, licences, partnerships,

etc.

We should obtain the exclusive right to use a technology

Our technologies should be taken to the market only through our (existing) distribution network

The use of external access to the market is an important solution for taking out plant's/unit's technologies to the market

Management encourages and emphasizes the internal use of technologies

If we decide to not use a technology internally, management pushes us to find a marketing method outside our plant/unit

Specific practices are disseminated to steer projects with partners

Management is agile in finding compromises in terms of intellectual property management
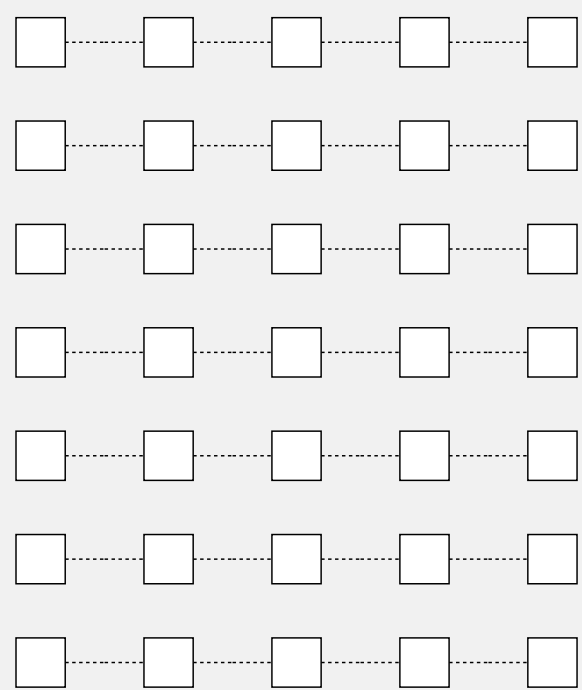
Management is agile in finding compromises in terms of value

sharing

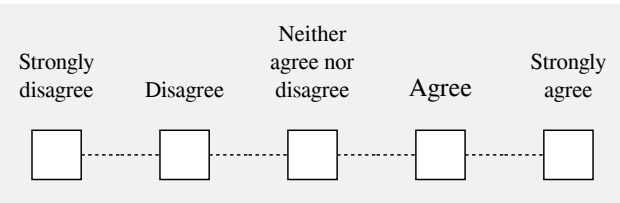

D3. Indicate the extent to which you agree with each of the following statements regarding your plant/unit:

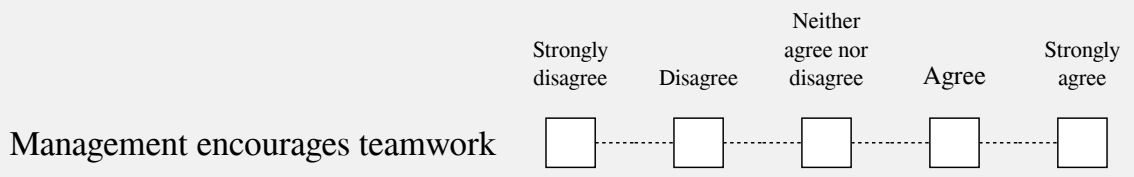

Management encourages everyone's participation in the search for solution

Leaders or managers in your plant/unit have the flexibility required to implement changes

Employees' suggestions for improvement are encouraged

Employees that propose improvements are recognized by their solutions

The company offers training to its employees

The company uses techniques to stimulate creativity among its employees
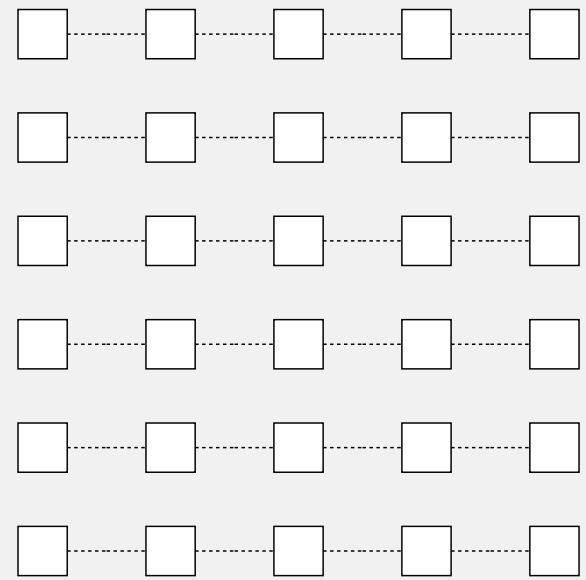

A team (dedicated or not) is in charge of promoting a culture of open innovation in the corporate culture

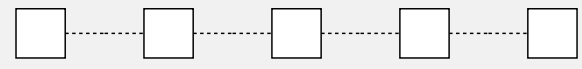
Indicators specific to open innovation are used

D4. For your company, indicate the degree of importance that the following risks exercise in hindering the implementation of open innovation projects:

Lack of knowledge of the open innovation tools and practices

Practices too distant from the corporate culture

Practices too different from team competencies

Theft or misappropriation of intellectual property

Theft or misappropriation of key know-how

Lack of trust with partners

Loss of control of projects conducted with partners

Difference between the intentions displayed by the managers and the resources allocated to the approach

Opposition or passivity of employees

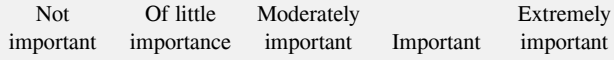
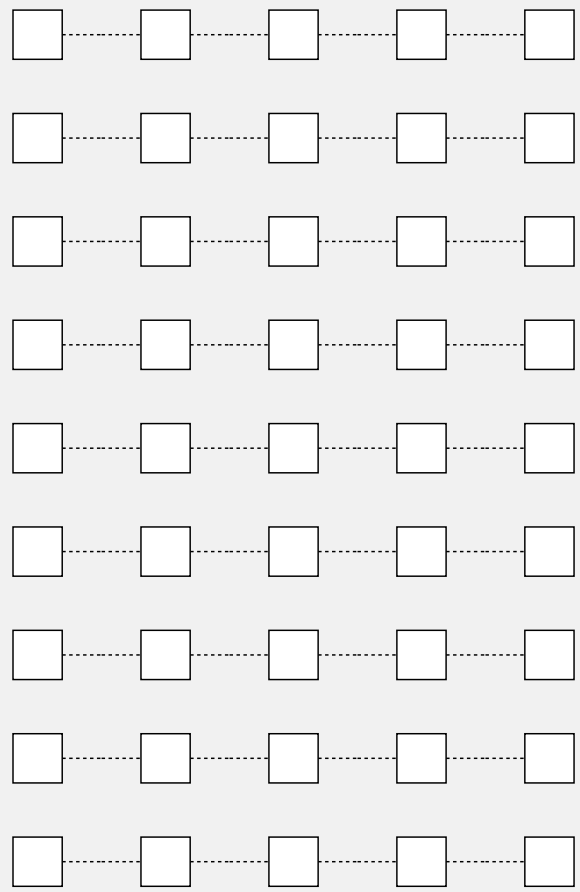
Lack of clarity in the open innovation strategy

$\begin{array}{ccccc}\text { Not } & \text { Of little } & \begin{array}{c}\text { Moderately } \\ \text { important }\end{array} & \text { Important } & \begin{array}{r}\text { Extremely } \\ \text { important }\end{array}\end{array}$

Resources not available
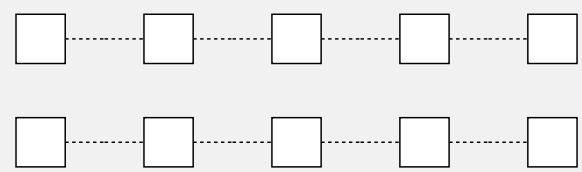

Inappropriate tools

\section{Section E: Satisfaction Regarding Open Innovation}

\section{E1. Indicate your level of satisfaction with the following proposals} regarding the results of your open innovation practice:

The central scale (corresponding to neutral) is omitted from this question.

Cost reduction

Improvement of the quality of products and services

Improvement of the quality/price ratio of your products and services

Improvement of the plant's/unit's revenue

Improvement of understanding of customer needs

Improvement of external communication

Improvement of project management effectiveness (effectiveness consists in the degree to which something is successful in producing a desired result; success)

Improvement of project management efficiency (efficiency consists in the degree to which something is done with maximum productivity and minimum wasted effort or expense)

Improvement of problem resolution speed Improvement of speed in seizing opportunities

Better diversification in products and services portfolio

Market share increase Implementation in new markets

$$
\begin{array}{ccccc}
\begin{array}{c}
\text { Very } \\
\text { dissatisfied }
\end{array} & \text { Disatisfied } & \text { Satisfied } & \begin{array}{c}
\text { Very } \\
\text { satisfied }
\end{array} & \begin{array}{c}
\text { Not } \\
\text { applicable }
\end{array}
\end{array}
$$
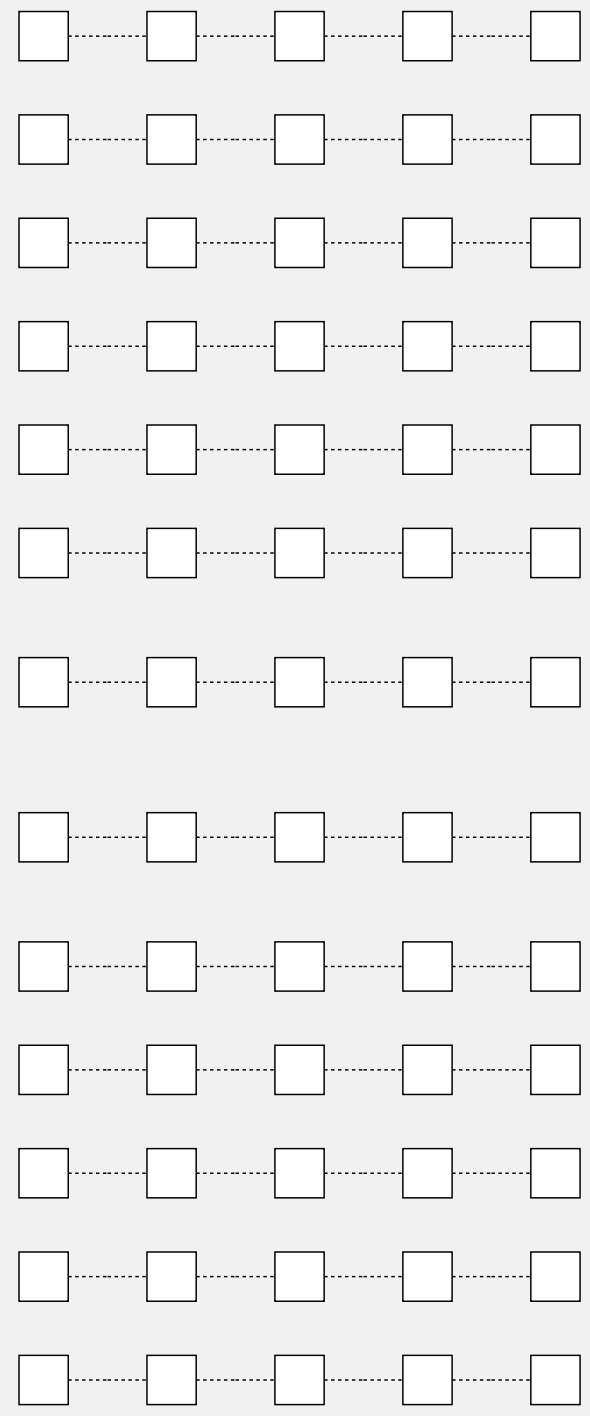


\section{Section F: Industrial Cluster Development}

F1. Indicate the three most important innovation partners for your plant/unit, in order of importance:

1: An R\&D plant/unit within your company

2: Another plant/unit (not R\&D) within your company

3: A university or higher education research center

4: A public research institute

5: A private research institute, an $R \& D$ company or a technical consulting firm

6: A key supplier

7: A key customer

8: A competitor or another company in your sector

9: A company from another sector

10: An industrial association or cluster

Type of partner

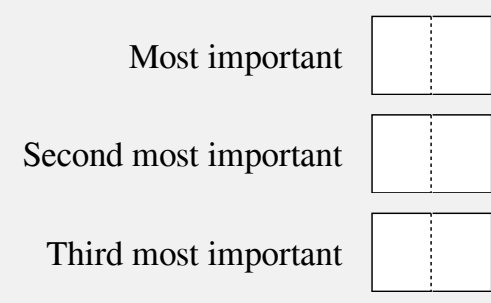

F2. Indicate the importance of each of the following factors in establishing a partnership with the most important partner mentioned in the previous question:

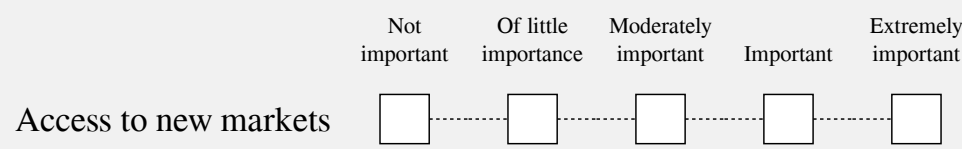

Sharing privileged information on the market/industry

Scaling up production processes
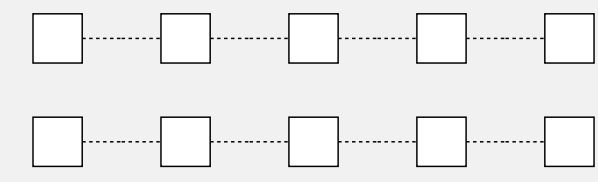

Access to new distribution networks

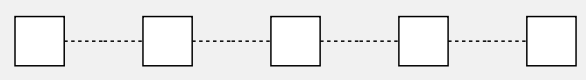

Sharing information for production and procurement

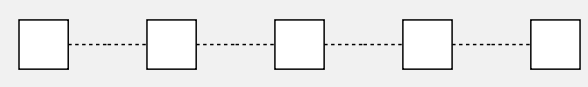

Access to critical R\&D competencies

Access to R\&D infrastructure (e.g. laboratory equipment)
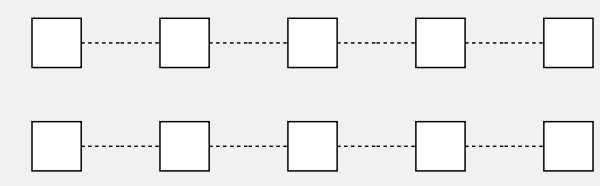

Long-term research on prospective technologies (exploratory research)

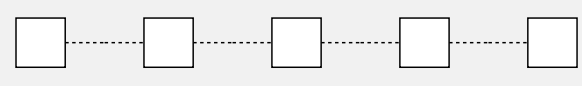

Development of prototypes

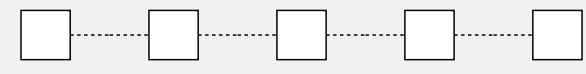

Reduction of costs or lead time for product development

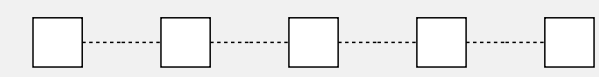


Sharing technical information for R\&D and/or product development $\begin{array}{ccccc}\text { Not } & \text { Of little } & \text { Moderately } & & \begin{array}{c}\text { Extremely } \\ \text { important }\end{array}\end{array}$

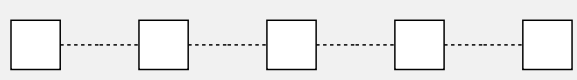

Access to incentives or government funds

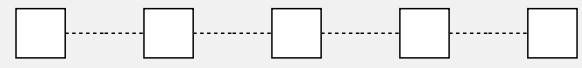

Facilitate the networking and/or intermediation in the business ecosystem

F3. Indicate the importance of each of the following factors in establishing a partnership with the second most important partner mentioned in Question 25:

\begin{tabular}{|c|c|c|}
\hline Not & Of little & Moderately \\
\hline
\end{tabular}

Access to new markets

Sharing privileged information on the market/industry

Scaling up production processes

Access to new distribution networks

Sharing information for production and procurement

Access to critical R\&D competencies

Access to R\&D infrastructure (e.g. laboratory equipment)

Long-term research on prospective technologies (exploratory research)

Development of prototypes

Reduction of costs or lead time for product development

Sharing technical information for R\&D and/or product development

Access to incentives or government funds

Facilitate the networking and/or intermediation in the business ecosystem
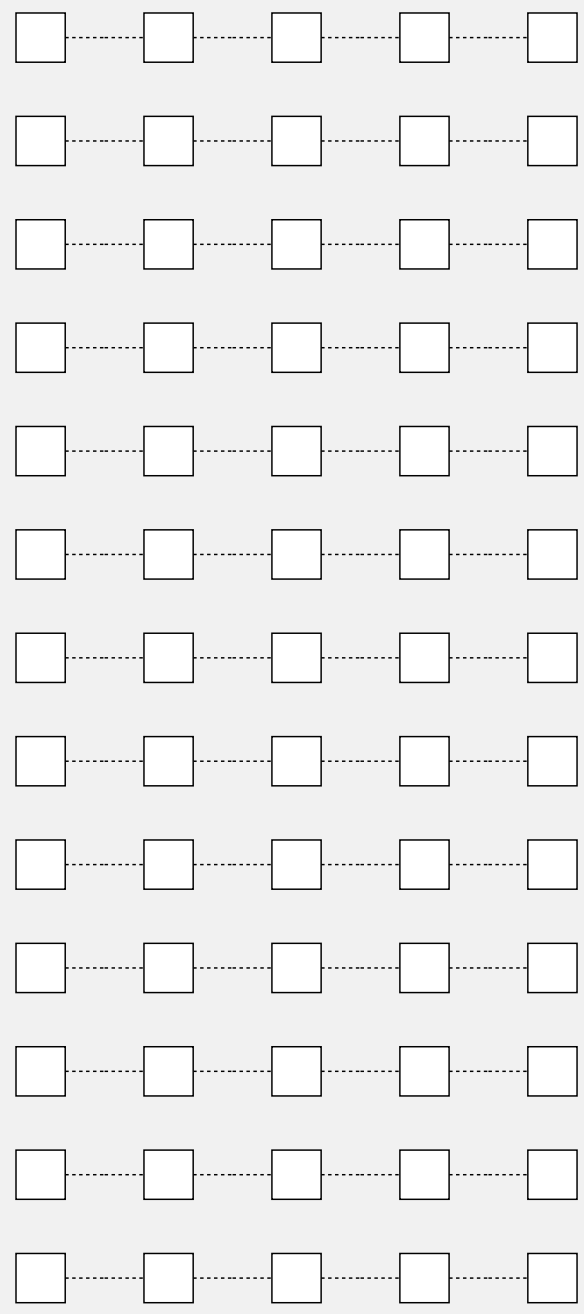

F4. Indicate the importance of each of the following factors in establishing a partnership with the third most important partner mentioned in Question 25:

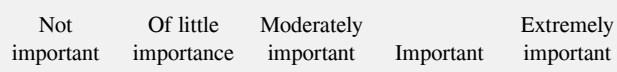

Access to new markets

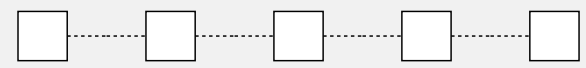

Sharing privileged information on the market/industry
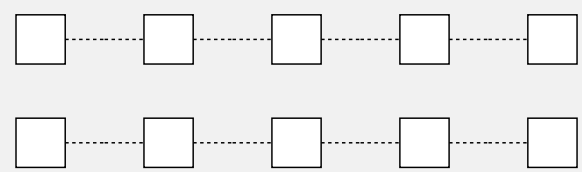
Sharing information for production and procurement

Access to critical R\&D competencies

Access to R\&D infrastructure (e.g. laboratory equipment)

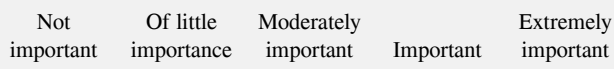

Access to new distribution networks
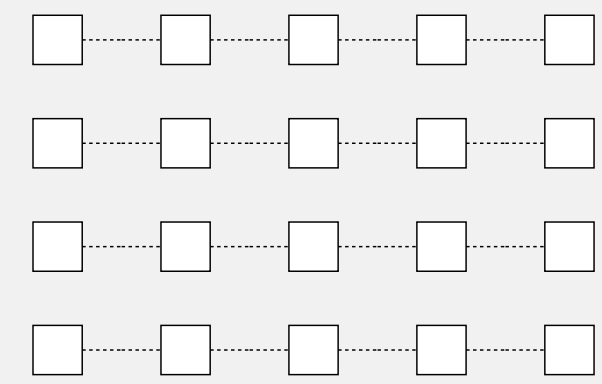

Long-term research on prospective technologies (exploratory research)

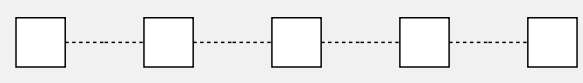

Development of prototypes

Reduction of costs or lead time for product development

Sharing technical information for R\&D and/or product development

Access to incentives or government funds

Facilitate the networking and/or intermediation in the business ecosystem
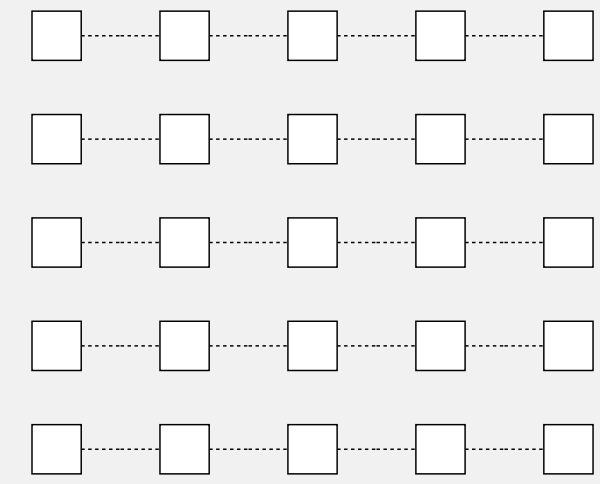

\section{Section G: Personal Information}

\section{G1. What position do you currently hold within your plant/unit?}

G2. How many years of experience do you have:

in your current position?

in the automotive industry?

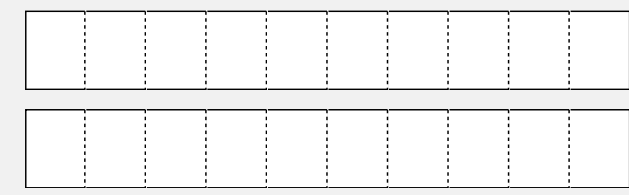

\section{G3. What is your age?}

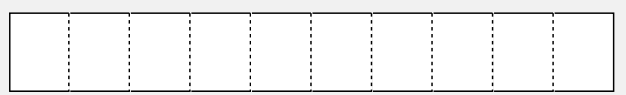

G4. Indicate your most relevant (academic) achievements: 
G5. If you are interested in the results of the study, please leave your email address so that we can inform you of the results at the end of the study: (your nominative data will be deleted from the database)

G6. What is the name of your company?

G7. What deparment within your plant/unit are you allocated?

\section{Section H: The Future of Urban Mobility}

H1. In your opinion, concerning Brazil in 2030, the following modes of eletrical vehicles will represent how much (in percentage) of the automotive companies' market share?

Completely electric vehicles (with no internal combustion engine)

Hybrid vehicles, and not completely electric

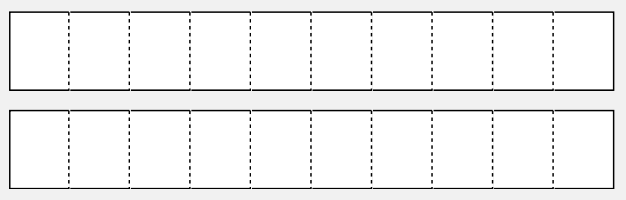




\section{APPENDIX B: OLS REGRESSION TABLES - AUTOMAKERS DATA}

Table B.1 - OLS regressions for Reasons for partnership measure versus PDP aspects measure (statistically significant $p$ values in bold)

\begin{tabular}{|c|c|c|c|c|c|c|c|c|c|}
\hline \multirow[b]{2}{*}{ Variable } & \multicolumn{3}{|c|}{ OI_Inbound } & \multicolumn{3}{|c|}{ OI_Outbound } & \multicolumn{3}{|c|}{ OI_Reasons } \\
\hline & $\begin{array}{c}\text { Model } \\
1\end{array}$ & $\begin{array}{c}\text { Model } \\
2 \\
\end{array}$ & $\begin{array}{c}\text { Model } \\
3 \\
\end{array}$ & $\begin{array}{c}\text { Model } \\
1 \\
\end{array}$ & $\begin{array}{c}\text { Model } \\
2 \\
\end{array}$ & $\begin{array}{c}\text { Model } \\
3 \\
\end{array}$ & $\begin{array}{c}\text { Model } \\
1 \\
\end{array}$ & $\begin{array}{c}\text { Model } \\
2 \\
\end{array}$ & $\begin{array}{c}\text { Model } \\
3 \\
\end{array}$ \\
\hline \multirow{2}{*}{ PDP_Degree_F1 } & -0.07 & -0.10 & -0.08 & 0.05 & 0.02 & 0.04 & 0.14 & 0.12 & 0.11 \\
\hline & $(0.10)$ & $(0.12)$ & $(0.12)$ & $(0.11)$ & $(0.12)$ & $(0.13)$ & $(0.11)$ & $(0.12)$ & (0.13) \\
\hline \multirow{2}{*}{ PDP_Adoption } & $0.72^{* * * *}$ & $0.74^{* * *}$ & $0.67^{* * * *}$ & $0.72^{* * * *}$ & $0.74^{* * * *}$ & $0.65^{* * *}$ & $0.62^{* * * *}$ & $0.63^{* * * *}$ & $0.64^{* * * *}$ \\
\hline & $(0.12)$ & $(0.13)$ & $(0.14)$ & $(0.13)$ & $(0.13)$ & $(0.15)$ & $(0.11)$ & $(0.11)$ & $(0.12)$ \\
\hline \multirow{2}{*}{ Exp_Total } & & -0.01 & -0.01 & & -0.01 & 0.00 & & -0.01 & -0.01 \\
\hline & & $(0.01)$ & $(0.01)$ & & $(0.01)$ & $(0.02)$ & & $(0.01)$ & $(0.02)$ \\
\hline$N$ & 49 & 49 & 41 & 47 & 47 & 38 & 53 & 53 & 46 \\
\hline adj. $R^{2}$ & 0.42 & 0.41 & 0.34 & 0.40 & 0.39 & 0.35 & 0.38 & 0.37 & 0.36 \\
\hline
\end{tabular}


Table B.2 - OLS regressions for Reasons for partnership measure versus Barriers and risks (statistically significant $p$ values in bold)

\begin{tabular}{|c|c|c|c|c|c|c|c|c|c|}
\hline \multirow{2}{*}{ Variable } & \multicolumn{3}{|c|}{ OI_inbound } & \multicolumn{3}{|c|}{ OI_outbound } & \multicolumn{3}{|c|}{ OI_Reasons } \\
\hline & $\begin{array}{c}\text { Model } \\
1 \\
\end{array}$ & $\begin{array}{c}\text { Model } \\
2 \\
\end{array}$ & $\begin{array}{c}\text { Model } \\
3 \\
\end{array}$ & $\begin{array}{c}\text { Model } \\
1 \\
\end{array}$ & $\begin{array}{c}\text { Model } \\
2 \\
\end{array}$ & $\begin{array}{c}\text { Model } \\
3 \\
\end{array}$ & $\begin{array}{c}\text { Model } \\
1 \\
\end{array}$ & $\begin{array}{c}\text { Model } \\
2 \\
\end{array}$ & $\begin{array}{c}\text { Model } \\
3 \\
\end{array}$ \\
\hline \multirow{2}{*}{ Barriers_F1 } & 0.19 & 0.22 & $0.26+$ & 0.09 & 0.11 & 0.13 & 0.20 & 0.20 & 0.21 \\
\hline & $(0.14)$ & $(0.13)$ & $(0.14)$ & $(0.14)$ & $(0.14)$ & $(0.14)$ & $(0.14)$ & $(0.14)$ & $(0.16)$ \\
\hline \multirow{2}{*}{ Barriers_F2 } & 0.07 & 0.07 & 0.12 & -0.11 & -0.10 & -0.09 & 0.07 & 0.07 & 0.08 \\
\hline & $(0.13)$ & $(0.13)$ & $(0.14)$ & $(0.14)$ & $(0.14)$ & $(0.15)$ & $(0.13)$ & $(0.13)$ & $(0.15)$ \\
\hline \multirow[t]{2}{*}{ Barriers_F3 } & $-0.22+$ & $-0.24+$ & $-0.34 *$ & $-0.25+$ & $-0.26+$ & $\overline{-}^{-}$ & -0.13 & -0.13 & -0.17 \\
\hline & $(0.13)$ & $(0.13)$ & $(0.13)$ & $(0.13)$ & $(0.13)$ & $(0.13)$ & $(0.13)$ & $(0.13)$ & $(0.14)$ \\
\hline \multirow{2}{*}{ Exp_Total } & & $0.03+$ & $0.03+$ & & 0.01 & 0.02 & & 0.00 & 0.01 \\
\hline & & $(0.01)$ & $(0.02)$ & & $(0.01)$ & $(0.02)$ & & $(0.01)$ & $(0.02)$ \\
\hline$N$ & 53 & 53 & 43 & 51 & 51 & 40 & 56 & 56 & 47 \\
\hline $\operatorname{adj} . R^{2}$ & 0.03 & 0.08 & 0.15 & 0.03 & 0.02 & 0.15 & 0.01 & -0.01 & -0.02 \\
\hline
\end{tabular}

Standard errors in parentheses, statistically significant $\mathrm{p}$ values in bold.

$+\mathrm{p}<.1, * \mathrm{p}<.05, * * \mathrm{p}<.01, * * * \mathrm{p}<.001$ 
Table B.3 - OLS regressions for PDP aspects measure versus Barriers and risks (statistically significant $p$ values in bold)

\begin{tabular}{|c|c|c|c|c|c|c|}
\hline \multirow{2}{*}{ Variable } & \multicolumn{3}{|c|}{ PDP_Adoption } & \multicolumn{3}{|c|}{ PDP_Degree_F1 } \\
\hline & Model 1 & Model 2 & Model 3 & Model 1 & Model 2 & Model 3 \\
\hline \multirow{2}{*}{ Barriers_F1 } & 0.15 & 0.17 & 0.17 & 0.03 & -0.00 & 0.00 \\
\hline & $(0.13)$ & $(0.12)$ & $(0.14)$ & $(0.12)$ & $(0.12)$ & $(0.12)$ \\
\hline \multirow{2}{*}{ Barriers_F2 } & -0.10 & -0.11 & -0.10 & $-0.23^{+}$ & $-0.22^{+}$ & $-0.36^{* *}$ \\
\hline & $(0.12)$ & $(0.12)$ & $(0.14)$ & $(0.12)$ & $(0.12)$ & $(0.13)$ \\
\hline \multirow{2}{*}{ Barriers_F3 } & -0.14 & -0.15 & -0.18 & 0.03 & 0.04 & 0.12 \\
\hline & $(0.13)$ & $(0.13)$ & $(0.14)$ & $(0.12)$ & $(0.12)$ & $(0.12)$ \\
\hline \multirow[t]{2}{*}{ Exp_Total } & & $0.03^{+}$ & 0.02 & & $-0.03^{*}$ & $-0.04^{* *}$ \\
\hline & & $(0.01)$ & $(0.02)$ & & $(0.01)$ & $(0.01)$ \\
\hline$N$ & 61 & 61 & 49 & 65 & 65 & 51 \\
\hline $\operatorname{adj} . R^{2}$ & 0.01 & 0.05 & 0.01 & 0.01 & 0.08 & 0.21 \\
\hline
\end{tabular}

Standard errors in parentheses, statistically significant $\mathrm{p}$ values in bold.

$+\mathrm{p}<.1, * \mathrm{p}<.05, * * \mathrm{p}<.01, * * * \mathrm{p}<.001$ 
Table B.4 - OLS regressions for Partners measure versus Barriers and risks (statistically significant $p$ values in bold)

\begin{tabular}{c|ccc|ccc}
\hline \multirow{2}{*}{ Variable } & \multicolumn{3}{|c|}{ Partners_F1 } & \multicolumn{3}{c}{ Partners_F2 } \\
& Model 1 & Model 2 & Model 3 & Model 1 & Model 2 & Model 3 \\
\hline \multirow{2}{*}{ Barriers_F1 } & $\mathbf{0 . 3 6}^{* *}$ & $\mathbf{0 . 3 7 ^ { * * }}$ & $\mathbf{0 . 3 6}$ & -0.16 & -0.16 & -0.19 \\
& $(0.12)$ & $(0.12)$ & $(0.13)$ & $(0.12)$ & $(0.12)$ & $(0.14)$ \\
& -0.04 & -0.05 & -0.08 & $\mathbf{0 . 4 0}^{* *}$ & $\mathbf{0 . 4 0}^{* *}$ & $\mathbf{0 . 3 7}^{*}$ \\
Barriers_F2 & $(0.12)$ & $(0.12)$ & $(0.13)$ & $(0.12)$ & $(0.12)$ & $(0.14)$ \\
& $\mathbf{- 0 . 2 3 *}$ & $-\mathbf{0 . 2 3}$ & $\mathbf{- 0 . 2 5 *}$ & 0.03 & 0.04 & 0.07 \\
Barriers_F3 & $(0.12)$ & $(0.12)$ & $(0.12)$ & $(0.12)$ & $(0.12)$ & $(0.13)$ \\
& & 0.01 & 0.01 & & -0.00 & -0.01 \\
Exp_Total & & $(0.01)$ & $(0.02)$ & & $(0.01)$ & $(0.02)$ \\
\hline \multirow{2}{*}{$N$} & 65 & 65 & 51 & 65 & 65 & 51 \\
adj. $R^{2}$ & 0.14 & 0.14 & 0.14 & 0.15 & 0.13 & 0.10 \\
\hline
\end{tabular}

Standard errors in parentheses, statistically significant $\mathrm{p}$ values in bold.

$+\mathrm{p}<.1, * \mathrm{p}<.05, * * \mathrm{p}<.01, * * * \mathrm{p}<.001$ 
Table B.5 - OLS regressions for Partners measure versus PDP Aspects (statistically significant p values in bold)

\begin{tabular}{c|ccc|ccc}
\hline \multirow{2}{*}{ Variable } & \multicolumn{3}{|c|}{ Partners_F1 } & \multicolumn{3}{c}{ Partners_F2 } \\
& Model 1 & Model 2 & Model 3 & Model 1 & Model 2 & Model 3 \\
\hline \multirow{2}{*}{ PDP_Degree_F1 } & 0.16 & 0.18 & 0.17 & -0.09 & -0.10 & -0.23 \\
& $(0.12)$ & $(0.13)$ & $(0.14)$ & $(0.14)$ & $(0.15)$ & $(0.16)$ \\
PDP_Adoption & $\mathbf{0 . 4 5}^{* * * *}$ & $\mathbf{0 . 4 4 ^ { * * * * }}$ & $\mathbf{0 . 3 6}{ }^{* *}$ & -0.13 & -0.12 & -0.10 \\
& $(0.12)$ & $(0.12)$ & $(0.13)$ & $(0.13)$ & $(0.14)$ & $(0.15)$ \\
Exp_Total & & 0.01 & -0.00 & & -0.00 & -0.01 \\
& & $(0.01)$ & $(0.02)$ & & $(0.02)$ & $(0.02)$ \\
\hline \multirow{2}{*}{$N$} & 61 & 61 & 49 & 61 & 61 & 49 \\
adj. $R^{2}$ & 0.20 & 0.18 & 0.12 & -0.01 & -0.03 & -0.01 \\
\hline
\end{tabular}

Standard errors in parentheses, statistically significant $\mathrm{p}$ values in bold.

$+\mathrm{p}<.1, * \mathrm{p}<.05, * * \mathrm{p}<.01, * * * \mathrm{p}<.001$ 
Table B.6 - OLS regressions for Cultural aspects measure versus Barriers and risks measure (statistically significant $p$ values in bold)

\begin{tabular}{|c|c|c|c|c|c|c|c|c|c|c|c|c|}
\hline \multirow{2}{*}{$\begin{array}{c}\text { Variabl } \\
\mathrm{e}\end{array}$} & \multicolumn{3}{|c|}{ Cult_Aspects_F1 } & \multicolumn{3}{|c|}{ Cult_Aspects_F2 } & \multicolumn{3}{|c|}{ OI_Strategy } & \multicolumn{3}{|c|}{ OI_Maturity } \\
\hline & $\begin{array}{c}\text { Mod } \\
\text { el } 1 \\
\end{array}$ & $\begin{array}{l}\text { Mod } \\
\text { el } 2\end{array}$ & $\begin{array}{c}\text { Mod } \\
\text { el } 3 \\
\end{array}$ & $\begin{array}{c}\text { Mod } \\
\text { el } 1\end{array}$ & $\begin{array}{c}\text { Mod } \\
\text { el } 2\end{array}$ & $\begin{array}{c}\text { Mod } \\
\text { el } 3\end{array}$ & $\begin{array}{c}\text { Mod } \\
\text { el } 1\end{array}$ & $\begin{array}{c}\text { Mod } \\
\text { el } 2\end{array}$ & $\begin{array}{c}\text { Mod } \\
\text { el } 3\end{array}$ & $\begin{array}{l}\text { Mod } \\
\text { el } 1\end{array}$ & $\begin{array}{l}\text { Mod } \\
\text { el } 2\end{array}$ & $\begin{array}{c}\text { Mod } \\
\text { el } 3\end{array}$ \\
\hline $\begin{array}{c}\text { Barriers } \\
\text { F1 }\end{array}$ & 0.06 & 0.09 & $\begin{array}{c}- \\
0.01\end{array}$ & $0.25^{*}$ & $0.26 *$ & $0.30^{*}$ & 0.22 & 0.25 & 0.24 & 0.01 & 0.10 & 0.12 \\
\hline & $\begin{array}{c}(0.1 \\
3)\end{array}$ & $\begin{array}{c}(0.1 \\
2)\end{array}$ & $\begin{array}{c}(0.1 \\
4)\end{array}$ & $\begin{array}{l}(0.1 \\
2)\end{array}$ & $\begin{array}{l}(0.1 \\
2)\end{array}$ & $\begin{array}{c}(0.1 \\
3)\end{array}$ & $\begin{array}{c}(0.1 \\
6)\end{array}$ & $\begin{array}{c}(0.1 \\
6)\end{array}$ & $\begin{array}{c}(0.1 \\
8)\end{array}$ & $\begin{array}{c}(0.1 \\
3)\end{array}$ & $\begin{array}{c}(0.10 \\
)\end{array}$ & $\begin{array}{c}(0.11 \\
)\end{array}$ \\
\hline $\begin{array}{c}\text { Barriers } \\
\text { F2 }\end{array}$ & 0.05 & 0.04 & 0.01 & $-\overline{20}$ & $\overline{0 .}$ & $\begin{array}{c}- \\
0.16\end{array}$ & $\begin{array}{c}- \\
0.03\end{array}$ & - & $\begin{array}{c}- \\
0.00\end{array}$ & $\overline{0.30}^{*}$ & $\overline{\mathbf{0 . 3 1}}^{*}$ & $\overline{0.42}^{*}$ \\
\hline & $\begin{array}{c}(0.1 \\
3)\end{array}$ & $\begin{array}{l}(0.1 \\
2)\end{array}$ & $\begin{array}{c}(0.1 \\
4)\end{array}$ & $\begin{array}{l}(0.1 \\
2)\end{array}$ & $\begin{array}{c}(0.1 \\
2)\end{array}$ & $\begin{array}{c}(0.1 \\
3)\end{array}$ & $\begin{array}{c}(0.1 \\
6)\end{array}$ & $\begin{array}{c}(0.1 \\
6)\end{array}$ & $\begin{array}{l}(0.1 \\
9)\end{array}$ & $\begin{array}{c}(0.1 \\
2)\end{array}$ & $\begin{array}{c}(0.10 \\
)\end{array}$ & $\begin{array}{c}(0.11 \\
)\end{array}$ \\
\hline $\begin{array}{c}\text { Barriers } \\
\text { F3 }\end{array}$ & $\begin{array}{c}- \\
0.18\end{array}$ & $\begin{array}{c}- \\
0.18\end{array}$ & $\begin{array}{c}- \\
0.16\end{array}$ & 0.11 & 0.10 & 0.10 & $\begin{array}{c}- \\
0.09\end{array}$ & $\begin{array}{c}- \\
0.09\end{array}$ & $\begin{array}{c}- \\
0.16\end{array}$ & 0.00 & 0.09 & 0.15 \\
\hline & $\begin{array}{c}(0.1 \\
3)\end{array}$ & $\begin{array}{c}(0.1 \\
2)\end{array}$ & $\begin{array}{c}(0.1 \\
3)\end{array}$ & $\begin{array}{c}(0.1 \\
2)\end{array}$ & $\begin{array}{c}(0.1 \\
2)\end{array}$ & $\begin{array}{c}(0.1 \\
2)\end{array}$ & $\begin{array}{c}(0.1 \\
6)\end{array}$ & $\begin{array}{c}(0.1 \\
6)\end{array}$ & $\begin{array}{c}(0.1 \\
8)\end{array}$ & $\begin{array}{c}(0.1 \\
3)\end{array}$ & $\begin{array}{c}(0.11 \\
)\end{array}$ & $\begin{array}{c}(0.12 \\
)\end{array}$ \\
\hline $\begin{array}{l}\text { Exp } \\
\text { Total }\end{array}$ & & $0.03^{*}$ & 0.02 & & 0.01 & 0.01 & & $0.04^{*}$ & 0.04 & & $0.05^{*}$ & $0.05^{*}$ \\
\hline & & $\begin{array}{c}(0.0 \\
1)\end{array}$ & $\begin{array}{c}(0.0 \\
2)\end{array}$ & & $\begin{array}{c}(0.0 \\
1)\end{array}$ & $\begin{array}{c}(0.0 \\
1)\end{array}$ & & $\begin{array}{c}(0.0 \\
2)\end{array}$ & $\begin{array}{c}(0.0 \\
2)\end{array}$ & & $\begin{array}{c}0.01 \\
)\end{array}$ & $\begin{array}{c}(0.01 \\
)\end{array}$ \\
\hline$N$ & 65 & 65 & 51 & 65 & 65 & 51 & 65 & 65 & 51 & 50 & 50 & 41 \\
\hline $\operatorname{adj} . R^{2}$ & $\begin{array}{c}- \\
0.01\end{array}$ & 0.07 & $\begin{array}{c}- \\
0.01\end{array}$ & 0.07 & 0.06 & 0.08 & $\begin{array}{c}- \\
0.02\end{array}$ & 0.05 & 0.01 & 0.06 & 0.40 & 0.47 \\
\hline
\end{tabular}

Standard errors in parentheses, statistically significant $\mathrm{p}$ values in bold. $+\mathrm{p}<.1, * \mathrm{p}<.05, * * \mathrm{p}<.01, * * * \mathrm{p}<.001$ 
Table B.7 - OLS regressions for Cultural aspects measure versus PDP Aspects

\begin{tabular}{|c|c|c|c|c|c|c|c|c|c|c|c|c|}
\hline \multirow[b]{2}{*}{ Variable } & \multicolumn{3}{|c|}{ Cult_Aspects_F1 } & \multicolumn{3}{|c|}{ Cult_Aspects_F2 } & \multicolumn{3}{|c|}{ OI_Strategy } & \multicolumn{3}{|c|}{ OI_Maturity } \\
\hline & $\begin{array}{l}\text { Mod } \\
\text { el } 1\end{array}$ & $\begin{array}{c}\text { Mod } \\
\text { el } 2\end{array}$ & $\begin{array}{l}\text { Mod } \\
\text { el } 3\end{array}$ & $\begin{array}{l}\text { Mod } \\
\text { el } 1\end{array}$ & $\begin{array}{l}\text { Mod } \\
\text { el } 2\end{array}$ & $\begin{array}{l}\text { Mod } \\
\text { el } 3\end{array}$ & $\begin{array}{l}\text { Mod } \\
\text { el } 1\end{array}$ & $\begin{array}{l}\text { Mod } \\
\text { el } 2\end{array}$ & $\begin{array}{l}\text { Mod } \\
\text { el } 3\end{array}$ & $\begin{array}{l}\text { Mod } \\
\text { el } 1\end{array}$ & $\begin{array}{l}\text { Mod } \\
\text { el } 2\end{array}$ & $\begin{array}{l}\text { Mod } \\
\text { el } 3\end{array}$ \\
\hline $\begin{array}{c}\text { PDP_Degre } \\
\text { e_F1 }\end{array}$ & $\begin{array}{c}- \\
0.16 \\
(0.1 \\
2)\end{array}$ & $\begin{array}{c}- \\
0.07 \\
(0.1 \\
3)\end{array}$ & $\begin{array}{c}- \\
0.08 \\
(0.1 \\
4)\end{array}$ & $\begin{array}{c}- \\
0.02 \\
(0.1 \\
3)\end{array}$ & $\begin{array}{c}- \\
0.01 \\
(0.1 \\
4)\end{array}$ & $\begin{array}{c}0.01 \\
(0.1 \\
5)\end{array}$ & $\begin{array}{c}0.08 \\
(0.1 \\
3)\end{array}$ & $\begin{array}{c}0.16 \\
(0.1 \\
4)\end{array}$ & $\begin{array}{c}0.16 \\
(0.1 \\
5)\end{array}$ & $\begin{array}{c}- \\
0.01 \\
(0.1 \\
2)\end{array}$ & $\begin{array}{c}\begin{array}{c}\mathbf{0 . 1 8} \\
+\end{array} \\
(0.1 \\
0)\end{array}$ & $\begin{array}{c}\mathbf{0 . 1 9} \\
+ \\
(0.1 \\
1)\end{array}$ \\
\hline $\begin{array}{c}\text { PDP_Adopt } \\
\text { ion }\end{array}$ & $\begin{array}{c}\mathbf{0 . 4 3} \\
*_{* * * *} \\
(0.1 \\
2)\end{array}$ & $\begin{array}{c}\mathbf{0 . 3 8} \\
* * \\
(0.1 \\
2)\end{array}$ & $\begin{array}{c}\mathbf{0 . 3 7} \\
*_{*} \\
(0.1 \\
3)\end{array}$ & $\begin{array}{c}\mathbf{0 . 3 0} \\
* \\
(0.1 \\
3)\end{array}$ & $\begin{array}{c}\mathbf{0 . 2 9} \\
* \\
(0.1 \\
3)\end{array}$ & $\begin{array}{c}\mathbf{0 . 2 7} \\
+ \\
(0.1 \\
4)\end{array}$ & $\begin{array}{c}\mathbf{0 . 8 9} \\
* * * \\
(0.1 \\
3)\end{array}$ & $\begin{array}{c}\mathbf{0 . 8 5} \\
* * * \\
(0.1 \\
3)\end{array}$ & $\begin{array}{c}\mathbf{0 . 8 4} \\
* * * * \\
(0.1 \\
4)\end{array}$ & $\begin{array}{c}\mathbf{0 . 4 6}_{* * * *} \\
(0.1 \\
1)\end{array}$ & $\begin{array}{c}\mathbf{0 . 3 2} \\
*_{* *} \\
(0.1 \\
0)\end{array}$ & $\begin{array}{c}\mathbf{0 . 3 3} \\
{ }_{* *} \\
(0.1 \\
1)\end{array}$ \\
\hline Exp_Total & & $\begin{array}{c}0.03 \\
+ \\
(0.0 \\
1)\end{array}$ & $\begin{array}{c}0.02 \\
(0.0 \\
2) \\
\end{array}$ & & $\begin{array}{c}0.00 \\
(0.0 \\
2) \\
\end{array}$ & $\begin{array}{c}0.00 \\
(0.0 \\
2)\end{array}$ & & $\begin{array}{c}0.02 \\
(0.0 \\
1)\end{array}$ & $\begin{array}{c}0.02 \\
(0.0 \\
2)\end{array}$ & & $\begin{array}{c}0.05 \\
* * * \\
(0.0 \\
1)\end{array}$ & $\begin{array}{c}0.05 \\
* * * \\
(0.0 \\
1)\end{array}$ \\
\hline$N$ & 61 & 61 & 49 & 61 & 61 & 49 & 61 & 61 & 49 & 49 & 49 & 40 \\
\hline adj. $R^{2}$ & 0.19 & 0.22 & 0.15 & 0.06 & 0.04 & 0.02 & 0.44 & 0.46 & 0.45 & 0.23 & 0.49 & 0.50 \\
\hline
\end{tabular}




\section{APPENDIX C: OLS REGRESSION TABLES - AUTO PARTS MANUFACTURERS DATA}

Table C.1 - OLS regressions for Reasons for partnership measure versus PDP aspects measure (statistically significant $p$ values in bold)

\begin{tabular}{|c|c|c|c|c|c|c|}
\hline & \multicolumn{2}{|c|}{ OI inbound } & \multicolumn{2}{|c|}{ OI_outbound } & \multicolumn{2}{|c|}{ OI_Reasons } \\
\hline & Model 1 & Model 2 & Model 1 & Model 2 & Model 1 & Model 2 \\
\hline PDP_Degree_F1 & $\begin{array}{c}0.01 \\
(0.12)\end{array}$ & $\begin{array}{l}-0.02 \\
(0.12)\end{array}$ & $\begin{array}{c}0.02 \\
(0.13)\end{array}$ & $\begin{array}{c}0.01 \\
(0.13)\end{array}$ & $\begin{array}{l}-0.01 \\
(0.12)\end{array}$ & $\begin{array}{l}-0.01 \\
(0.12)\end{array}$ \\
\hline PDP_Adoption & $\begin{array}{c}\mathbf{0 . 3 1}^{*} \\
(0.12)\end{array}$ & $\begin{array}{c}\mathbf{0 . 2 6}^{*} \\
(0.12)\end{array}$ & $\begin{array}{c}0.13 \\
(0.13)\end{array}$ & $\begin{array}{c}0.10 \\
(0.13)\end{array}$ & $\begin{array}{c}\mathbf{0 . 3 0}^{*} \\
(0.12)\end{array}$ & $\begin{array}{c}\mathbf{0 . 2 8}^{*} \\
(0.13)\end{array}$ \\
\hline Exp_Total & & $\begin{array}{c}0.02^{+} \\
(0.01)\end{array}$ & & $\begin{array}{c}0.01 \\
(0.01)\end{array}$ & & $\begin{array}{c}0.00 \\
(0.01)\end{array}$ \\
\hline $\begin{array}{l}N \\
\text { adj. } R^{2}\end{array}$ & $\begin{array}{c}74 \\
0.07\end{array}$ & $\begin{array}{c}74 \\
0.10\end{array}$ & $\begin{array}{c}74 \\
-0.01\end{array}$ & $\begin{array}{c}74 \\
-0.01\end{array}$ & $\begin{array}{c}74 \\
0.06\end{array}$ & $\begin{array}{c}74 \\
0.05\end{array}$ \\
\hline
\end{tabular}

Standard errors in parentheses

${ }^{+} p<.1,{ }^{*} p<.05,{ }^{* *} p<.01,{ }^{* * *} p<.001$

Table C.2 - OLS regressions for Reasons for partnership measure versus Barriers and risks (statistically significant $p$ values in bold)

\begin{tabular}{l|cc|cc|cc} 
& \multicolumn{2}{|c|}{ OI_inbound } & \multicolumn{2}{c|}{ OI_outbound } & \multicolumn{2}{c}{ OI_Reasons } \\
& Model 1 & Model 2 & Model 1 & Model 2 & Model 1 & Model 2 \\
\hline Barriers_F1 & $\mathbf{0 . 2 6}^{*}$ & $\mathbf{0 . 2 0}^{+}$ & 0.15 & 0.13 & 0.07 & 0.04 \\
& $(0.11)$ & $(0.12)$ & $(0.11)$ & $(0.12)$ & $(0.12)$ & $(0.12)$ \\
& & & & & & \\
Barriers_F2 & -0.09 & -0.09 & -0.15 & -0.15 & -0.02 & -0.02 \\
& $(0.11)$ & $(0.11)$ & $(0.11)$ & $(0.12)$ & $(0.12)$ & $(0.12)$ \\
Barriers_F3 & -0.12 & -0.11 & -0.18 & -0.18 & -0.03 & -0.02 \\
& $(0.11)$ & $(0.11)$ & $(0.11)$ & $(0.12)$ & $(0.12)$ & $(0.12)$ \\
Exp_Total & & $0.02^{+}$ & & & & \\
& & $(0.01)$ & & $(0.01)$ & & 0.01 \\
& & & & & & \\
\hline$N$ & 74 & 74 & 74 & 74 & 74 & 74 \\
adj. $R^{2}$ & 0.05 & 0.08 & 0.04 & 0.03 & -0.04 & -0.04 \\
\hline
\end{tabular}

Standard errors in parentheses

${ }^{+} p<.1,{ }^{*} p<.05,{ }^{* *} p<.01,{ }^{* * *} p<.001$ 
Table C.3 - OLS regressions for PDP aspects measure versus Barriers and risks (statistically significant $p$ values in bold)

\begin{tabular}{l|cc|cc}
\hline & \multicolumn{2}{|c|}{ PDP_Adoption } & \multicolumn{2}{c}{ PDP_Degree_F1 } \\
& Model 1 & Model 2 & Model 1 & Model 2 \\
\hline Barriers_F1 & 0.07 & -0.01 & -0.01 & -0.08 \\
& $(0.12)$ & $(0.12)$ & $(0.12)$ & $(0.12)$ \\
Barriers_F2 & 0.08 & 0.08 & 0.08 & 0.08 \\
& $(0.12)$ & $(0.11)$ & $(0.12)$ & $(0.12)$ \\
& & & & \\
Barriers_F3 & -0.12 & -0.10 & 0.13 & 0.15 \\
& $(0.12)$ & $(0.11)$ & $(0.12)$ & $(0.12)$ \\
Exp_Total & & $0.03^{*}$ & & $0.02^{*}$ \\
& & $(0.01)$ & & $(0.01)$ \\
\hline$N$ & & & & \\
\hline & 74 & 74 & 74 & 74 \\
adj. $R^{2}$ & -0.02 & 0.05 & -0.02 & 0.03 \\
\hline
\end{tabular}

Standard errors in parentheses

${ }^{+} p<.1,{ }^{*} p<.05,{ }^{* *} p<.01,{ }^{* * *} p<.001$

Table C.4 - OLS regressions for Partners measure versus Barriers and risks (statistically significant $p$ values in bold)

\begin{tabular}{l|cc|cc}
\hline & \multicolumn{2}{|c|}{ Partners_F1 } & \multicolumn{2}{c}{ Partners_F2 } \\
& Model 1 & Model 2 & Model 1 & Model 2 \\
\hline Barriers_F1 & $\mathbf{0 . 5 5}^{* * *}$ & $\mathbf{0 . 5 1} 1^{* * *}$ & -0.08 & -0.13 \\
& $(0.10)$ & $(0.10)$ & $(0.12)$ & $(0.12)$ \\
& & & & \\
Barriers_F2 & -0.03 & -0.03 & -0.07 & -0.07 \\
& $(0.10)$ & $(0.10)$ & $(0.12)$ & $(0.12)$ \\
& & & & \\
Barriers_F3 & -0.12 & -0.11 & -0.14 & -0.13 \\
& $(0.10)$ & $(0.10)$ & $(0.12)$ & $(0.12)$ \\
Exp_Total & & 0.01 & & $0.02^{+}$ \\
& & $(0.01)$ & & $(0.01)$ \\
& & & & \\
\hline$N$ & 74 & 74 & 74 & 74 \\
adj. $R^{2}$ & 0.29 & 0.30 & -0.01 & 0.02 \\
\hline
\end{tabular}

Standard errors in parentheses

${ }^{+} p<.1,{ }^{*} p<.05,{ }^{* *} p<.01,{ }^{* * *} p<.001$ 
Table C.5 - OLS regressions for Partners measure versus PDP Aspects (statistically significant p values in bold)

\begin{tabular}{l|cc|cc}
\hline & \multicolumn{2}{|c|}{ Partners_F1 } & \multicolumn{2}{c}{ Partners_F2 } \\
& Model 1 & Model 2 & Model 1 & Model 2 \\
\hline PDP_Degree_F1 & 0.18 & 0.14 & -0.05 & -0.07 \\
& $(0.12)$ & $(0.12)$ & $(0.13)$ & $(0.13)$ \\
PDP_Adoption & -0.05 & -0.12 & 0.07 & 0.02 \\
& $(0.12)$ & $(0.12)$ & $(0.13)$ & $(0.13)$ \\
Exp_Total & & & & \\
& & $0.03^{*}$ & & 0.02 \\
& & $(0.01)$ & & $(0.01)$ \\
\hline$N$ & 74 & 74 & 74 & 74 \\
adj. $R^{2}$ & 0.00 & 0.07 & -0.02 & -0.00 \\
\hline
\end{tabular}

Standard errors in parentheses

${ }^{+} p<.1,{ }^{*} p<.05,{ }^{* *} p<.01,{ }^{* * *} p<.001$

Table C.6 - OLS regressions for Cultural aspects measure versus Barriers and risks measure (statistically significant $p$ values in bold)

\begin{tabular}{|c|c|c|c|c|c|c|c|c|}
\hline & \multicolumn{2}{|c|}{ Cult Aspects F1 } & \multicolumn{2}{|c|}{ Cult Aspects F2 } & \multicolumn{2}{|c|}{ OI Strategy } & \multicolumn{2}{|c|}{ OI Maturity } \\
\hline & $\begin{array}{c}\text { Model } \\
1\end{array}$ & Model 2 & $\begin{array}{c}\text { Model } \\
1\end{array}$ & Model 2 & Model 1 & Model 2 & $\begin{array}{c}\text { Model } \\
1\end{array}$ & Model 2 \\
\hline \multirow{2}{*}{$\begin{array}{l}\text { Barriers } \\
\text { F1 }\end{array}$} & -0.02 & -0.11 & -0.18 & $-0.21^{+}$ & $\mathbf{0 . 4 3}^{* *}$ & $0.35^{*}$ & -0.13 & $-0.24^{+}$ \\
\hline & $(0.12)$ & $(0.12)$ & $(0.12)$ & $(0.12)$ & $(0.14)$ & $(0.14)$ & $(0.14)$ & $(0.13)$ \\
\hline \multirow{2}{*}{$\begin{array}{l}\text { Barriers } \\
\text { F2 }\end{array}$} & -0.06 & -0.06 & 0.13 & 0.13 & -0.20 & -0.19 & -0.19 & -0.13 \\
\hline & $(0.12)$ & $(0.11)$ & $(0.12)$ & $(0.12)$ & $(0.14)$ & $(0.14)$ & $(0.12)$ & $(0.11)$ \\
\hline \multirow{2}{*}{$\begin{array}{l}\text { Barriers } \\
\text { F3 }\end{array}$} & $-0.21^{+}$ & $-0.19^{+}$ & 0.07 & 0.08 & -0.14 & -0.12 & -0.10 & -0.03 \\
\hline & $(0.12)$ & $(0.11)$ & $(0.12)$ & $(0.12)$ & $(0.14)$ & $(0.14)$ & $(0.11)$ & $(0.11)$ \\
\hline Exp Total & & $\begin{array}{l}0.03^{* *} \\
(0.01)\end{array}$ & & $\begin{array}{c}0.01 \\
(0.01)\end{array}$ & & $\begin{array}{c}0.03^{*} \\
(0.01)\end{array}$ & & $\begin{array}{l}0.03^{* *} \\
(0.01)\end{array}$ \\
\hline $\begin{array}{l}N \\
\text { adj. } R^{2}\end{array}$ & $\begin{array}{c}74 \\
0.01\end{array}$ & $\begin{array}{c}74 \\
0.10\end{array}$ & $\begin{array}{c}74 \\
0.01\end{array}$ & $\begin{array}{c}74 \\
0.01\end{array}$ & $\begin{array}{c}74 \\
0.11\end{array}$ & $\begin{array}{c}74 \\
0.17\end{array}$ & $\begin{array}{c}52 \\
0.01\end{array}$ & $\begin{array}{c}52 \\
0.17\end{array}$ \\
\hline
\end{tabular}

Standard errors in parentheses

${ }^{+} p<.1,{ }^{*} p<.05,{ }^{* *} p<.01,{ }^{* * * *} p<.001$ 
Table C.7 - OLS regressions for Cultural aspects measure versus PDP Aspects

\begin{tabular}{l|cc|cc|cc|cc|}
\hline & \multicolumn{2}{|c|}{ Cult Aspects F1 } & \multicolumn{2}{c|}{ Cult Aspects F2 } & \multicolumn{2}{c|}{ OI Strategy } & \multicolumn{2}{c|}{ OI Maturity } \\
& Model 1 & Model & Model & Model & Model 1 & Model 2 & Model 1 & Model 2 \\
& & 2 & 1 & 2 & & & & \\
\hline PDP Degree & 0.14 & 0.12 & 0.07 & 0.05 & 0.15 & 0.11 & $\mathbf{0 . 4 0}^{* * *}$ & $\mathbf{0 . 3 6}^{* *}$ \\
& & & & & & & & \\
& $(0.11)$ & $(0.11)$ & $(0.12)$ & $(0.12)$ & $(0.14)$ & $(0.14)$ & $(0.13)$ & $(0.13)$ \\
PDP & $\mathbf{0 . 4 0}^{* * *}$ & $\mathbf{0 . 3 5}$ & $\mathbf{- 0 . 3 4 ^ { * * }}$ & $\mathbf{- 0 . 3 8 * *}$ & $\mathbf{0 . 5 4}^{* * *}$ & $\mathbf{0 . 4 7}^{* *}$ & 0.17 & 0.11 \\
Adoption & & & & & & & & \\
& $(0.11)$ & $(0.11)$ & $(0.12)$ & $(0.12)$ & $(0.14)$ & $(0.14)$ & $(0.13)$ & $(0.13)$ \\
Exp Total & & $0.02^{+}$ & & 0.01 & & $0.02^{+}$ & & $0.02^{*}$ \\
& & $(0.01)$ & & $(0.01)$ & & $(0.01)$ & & $(0.01)$ \\
\hline$N$ & & & & & & & & \\
adj. $R^{2}$ & 0.20 & 0.22 & 0.08 & 0.09 & 0.20 & 0.23 & 0.22 & 0.27 \\
\hline
\end{tabular}

Standard errors in parentheses

$+\mathrm{p}<.1, * \mathrm{p}<.05, * * \mathrm{p}<.01, * * * \mathrm{p}<.001$ 


\section{APPENDIX D: OLS REGRESSION TABLES - COMPLETE} DATASET

Table D.1 - OLS regressions for Reasons for partnership measure versus PDP aspects measure (statistically significant $p$ values in bold)

\begin{tabular}{lccc}
\hline & $(1)$ & $(2)$ & $(3)$ \\
& OI_inbound & OI_outbound & OI_Reasons \\
\hline PDP_Degree F1 & 0.01 & 0.05 & 0.00 \\
& $(0.08)$ & $(0.09)$ & $(0.08)$ \\
PDP_Adoption & $\mathbf{0 . 3 6}^{* * *}$ & $\mathbf{0 . 2 3}^{*}$ & $\mathbf{0 . 4 0}^{* * *}$ \\
& $(0.09)$ & $(0.10)$ & $(0.09)$ \\
Exp_Total & $0.01^{+}$ & 0.01 & -0.00 \\
& $(0.01)$ & $(0.01)$ & $(0.01)$ \\
Automaker & $-0.48^{* *}$ & $-0.66^{* * *}$ & $-0.48^{* *}$ \\
& $(0.17)$ & $(0.18)$ & $(0.17)$ \\
\hline$N$ & & & \\
adj. $R^{2}$ & 123 & 121 & 127 \\
\hline
\end{tabular}

Standard errors in parentheses

${ }^{+} p<.1,{ }^{*} p<.05,{ }^{* *} p<.01,{ }^{* * *} p<.001$

Table D.2 - OLS regressions for Reasons for partnership measure versus Barriers and risks (statistically significant $p$ values in bold)

\begin{tabular}{lccc}
\hline & $(1)$ & $(2)$ & $(3)$ \\
& OI_inbound & OI_outbound & OI_Reasons \\
\hline Barriers_F1 & $\mathbf{0 . 2 0}$ & 0.11 & 0.11 \\
& $(0.08)$ & $(0.08)$ & $(0.09)$ \\
Barriers_F2 & -0.03 & -0.11 & 0.01 \\
& $(0.08)$ & $(0.08)$ & $(0.08)$ \\
Barriers_F3 & & & \\
& $-\mathbf{0 . 1 9}^{*}$ & $\mathbf{- 0 . 2 2}^{*}$ & -0.09 \\
Exp_Total & $(0.08)$ & $(0.08)$ & $(0.09)$ \\
& & & \\
Automaker & $0.02^{* *}$ & 0.01 & 0.01 \\
& $(0.01)$ & $(0.01)$ & $(0.01)$ \\
& $-0.45^{*}$ & $-0.53^{* *}$ & $-0.49^{* *}$ \\
\hline$N$ & $(0.17)$ & $(0.18)$ & $(0.18)$ \\
adj. $R^{2}$ & 127 & & \\
\hline
\end{tabular}

Standard errors in parentheses

${ }^{+} p<.1,{ }^{*} p<.05,{ }^{* *} p<.01,{ }^{* * *} p<.001$ 
Table D.3 - OLS regressions for PDP aspects measure versus Barriers and risks (statistically significant $p$ values in bold)

\begin{tabular}{lcc}
\hline & $(1)$ & $(2)$ \\
& PDP_Adoption & PDP_Degree_F1 \\
\hline Barriers_F1 & 0.06 & 0.00 \\
& $(0.08)$ & $(0.09)$ \\
Barriers_F2 & -0.01 & -0.06 \\
& $(0.08)$ & $(0.09)$ \\
Barriers_F3 & -0.11 & 0.10 \\
& $(0.09)$ & $(0.09)$ \\
Exp_Total & $0.03^{* *}$ & 0.01 \\
& $(0.01)$ & $(0.01)$ \\
Automaker & -0.12 & 0.11 \\
& $(0.17)$ & $(0.18)$ \\
\hline$N$ & & 139 \\
adj. $R^{2}$ & 135 & -0.01 \\
\hline
\end{tabular}

Standard errors in parentheses

${ }^{+} p<.1,{ }^{*} p<.05,{ }^{* *} p<.01,{ }^{* * *} p<.001$

Table D.4 - OLS regressions for Partners measure versus Barriers and risks (statistically significant $p$ values in bold)

\begin{tabular}{lcc}
\hline & $(1)$ & $(2)$ \\
& Partners_F1 & Partners_F2 \\
\hline Barriers_F1 & $\mathbf{0 . 4 5}^{* * * *}$ & 0.06 \\
& $(0.07)$ & $(0.08)$ \\
Barriers_F2 & -0.06 & $\mathbf{- . 2 6}^{* *}$ \\
& $(0.07)$ & $(0.08)$ \\
Barriers_F3 & $\mathbf{- 0 . 1 8}^{*}$ & -0.03 \\
& $(0.07)$ & $(0.08)$ \\
Exp_Total & $0.01^{*}$ & 0.01 \\
& $(0.01)$ & $(0.01)$ \\
Automaker & -0.15 & $-0.38^{*}$ \\
& $(0.15)$ & $(0.17)$ \\
\hline$N$ & & \\
adj. $R^{2}$ & 139 & 139 \\
\hline
\end{tabular}

Standard errors in parentheses

${ }^{+} p<.1,{ }^{*} p<.05,{ }^{* *} p<.01,{ }^{* * *} p<.001$ 
Table D.5 - OLS regressions for Partners measure versus PDP Aspects (statistically significant $p$ values in bold)

\begin{tabular}{lcc}
\hline & $(1)$ & $(2)$ \\
& Partners_F1 & Partners_F2 \\
\hline PDP_Degree & $\mathbf{0 . 1 5}^{+}$ & 0.04 \\
& $(0.09)$ & $(0.09)$ \\
PDP_Adoption & 0.08 & 0.07 \\
& $(0.09)$ & $(0.09)$ \\
Exp_Total & $0.02^{*}$ & 0.00 \\
& $(0.01)$ & $(0.01)$ \\
Automaker & -0.25 & $-0.51^{* *}$ \\
& $(0.17)$ & $(0.17)$ \\
\hline$N$ & & \\
adj. $R^{2}$ & 135 & 135 \\
\hline
\end{tabular}

Standard errors in parentheses

${ }^{+} p<.1,{ }^{*} p<.05,{ }^{* *} p<.01,{ }^{* * *} p<.001$

Table D.6 - OLS regressions for Cultural aspects measure versus Barriers and risks measure (statistically significant $p$ values in bold)

\begin{tabular}{lcccc}
\hline & $(1)$ & $(2)$ & $(3)$ & $(4)$ \\
& Cult_Aspects_F1 & Cult_Aspects_F2 & OI_Strategy & OI_Maturity \\
\hline Barriers_F1 & -0.03 & $\mathbf{0 . 1 9}$ & $\mathbf{0 . 2 9}^{* * *}$ & -0.08 \\
& $(0.08)$ & $(0.08)$ & $(0.10)$ & $(0.08)$ \\
Barriers_F2 & -0.03 & $\mathbf{- 0 . 1 6}^{+}$ & -0.12 & $\mathbf{- 0 . 2 1}^{* *}$ \\
& $(0.08)$ & $(0.08)$ & $(0.10)$ & $(0.07)$ \\
Barriers_F3 & $\mathbf{- 0 . 1 8 ^ { * }}$ & 0.05 & -0.10 & 0.00 \\
& $(0.08)$ & $(0.08)$ & $(0.10)$ & $(0.08)$ \\
Exp_Total & $0.03^{* * *}$ & -0.00 & $0.03^{* * *}$ & $0.04^{* * *}$ \\
& $(0.01)$ & $(0.01)$ & $(0.01)$ & $(0.01)$ \\
Automaker & 0.19 & -0.10 & 0.02 & 0.08 \\
& $(0.17)$ & $(0.17)$ & $(0.21)$ & $(0.15)$ \\
& & & & 102 \\
\hline$N$ & 139 & 139 & 139 & 0.26 \\
adj. $R^{2}$ & 0.10 & 0.04 & 0.12 & \\
\hline
\end{tabular}

Standard errors in parentheses

${ }^{+} p<.1,{ }^{*} p<.05,{ }^{* *} p<.01,{ }^{* * *} p<.001$ 
Table D.7 - OLS regressions for Cultural aspects measure versus PDP Aspects

\begin{tabular}{lcccc}
\hline & $(1)$ & $(2)$ & $(3)$ & $(4)$ \\
& Cult_Aspects_F1 & Cult_Aspects_F2 & OI_Strategy & OI_Maturity \\
\hline PDP_Degree_F1 & 0.11 & -0.06 & 0.13 & $\mathbf{0 . 2 1}^{*}$ \\
& $(0.08)$ & $(0.09)$ & $(0.10)$ & $(0.08)$ \\
PDP_Adoption & $\mathbf{0 . 3 5}^{* * *}$ & $\mathbf{0 . 3 5}^{* * *}$ & $\mathbf{0 . 6 0}^{* * *}$ & $\mathbf{0 . 1 9}^{*}$ \\
& $(0.08)$ & $(0.09)$ & $(0.10)$ & $(0.09)$ \\
Exp_Total & $0.02^{* *}$ & -0.01 & $0.02^{*}$ & $0.03^{* * *}$ \\
& $(0.01)$ & $(0.01)$ & $(0.01)$ & $(0.01)$ \\
Automaker & & & & \\
& 0.16 & -0.11 & 0.04 & -0.01 \\
& $(0.15)$ & $(0.17)$ & $(0.19)$ & $(0.14)$ \\
\hline$N$ & & & & \\
adj. $R^{2}$ & 135 & 135 & 135 & 101 \\
& 0.24 & 0.08 & 0.31 & 0.34 \\
\hline rerrors in parentheses & & & &
\end{tabular}

Standard errors in parentheses

${ }^{+} p<.1,{ }^{*} p<.05,{ }^{* *} p<.01,{ }^{* * *} p<.001$ 